\title{
Integrating Microscale Enzyme And Lectin Reactions Using Nanogel Assisted Capillary Electrophoresis
}

\author{
Srikanth Gattu \\ srgattu@mix.wvu.edu
}

Follow this and additional works at: https://researchrepository.wvu.edu/etd

Part of the Analytical Chemistry Commons, and the Medicinal-Pharmaceutical Chemistry Commons

\section{Recommended Citation}

Gattu, Srikanth, "Integrating Microscale Enzyme And Lectin Reactions Using Nanogel Assisted Capillary Electrophoresis" (2018). Graduate Theses, Dissertations, and Problem Reports. 3693.

https://researchrepository.wvu.edu/etd/3693

This Dissertation is protected by copyright and/or related rights. It has been brought to you by the The Research Repository @ WVU with permission from the rights-holder(s). You are free to use this Dissertation in any way that is permitted by the copyright and related rights legislation that applies to your use. For other uses you must obtain permission from the rights-holder(s) directly, unless additional rights are indicated by a Creative Commons license in the record and/ or on the work itself. This Dissertation has been accepted for inclusion in WVU Graduate Theses, Dissertations, and Problem Reports collection by an authorized administrator of The Research Repository @ WVU.

For more information, please contact researchrepository@mail.wvu.edu. 


\title{
INTEGRATING MICROSCALE ENZYME AND LECTIN REACTIONS USING NANOGEL ASSISTED CAPILLARY ELECTROPHORESIS
}

\author{
Srikanth Gattu
}

\author{
Dissertation submitted to the Eberly College of Arts and Sciences \\ at West Virginia University \\ in partial fulfillment of the requirements for the degree of \\ Doctor of Philosophy \\ in \\ Chemistry
}

Lisa A. Holland, Ph.D., Committee Chair

Harry O. Finklea, Ph.D.

Justin A. Legleiter, Ph.D.

Stephen J. Valentine, Ph.D.

Slawomir Lukomski, Ph.D.

\author{
Chemistry Department \\ Morgantown, West Virginia \\ 2018
}

Keywords: Glycans, Enzymes, Lectins, Michaelis-Menten, Capillary Electrophoresis Copyright 2018 Srikanth Gattu 


\section{ABSTRACT \\ Integrating Microscale Enzyme and Lectin Reactions Using Nanogel Assisted Capillary Electrophoresis}

\section{Srikanth Gattu}

Protein glycosylation is one of the most prevalent post-translational modifications which plays an important role in determining the structure, stability, and function of proteins. Changes in glycosylation patterns are a hallmark of cancer and other diseases. Characterizing glycosylation is difficult because these structures vary in their linkage and monomer sequence, which gives rise to vast microheterogenity that could affect the function of the molecule. A novel method using capillary gel electrophoresis by integrating microscale enzymes and lectin reactions in the capillary was developed to verify glycan structure by analyzing monosaccharides. Capillary electrophoresis (CE) improves upon conventional methods of glycan structure characterization by reducing the amount of enzyme or lectins from milliliters to nanoliters and incubation times needed for enzyme reactions from hours to minutes. The significant advancement that was found is to use nanoliter volumes of enzymes costing about $\$ 0.01$ for a single analysis and shorter incubation times.

Characterizing glycosylation for complex glycans was demonstrated using enzymes alone or a combination of enzymes and lectins with aid of a nanogel to determine specific signatures in glycoproteins. Nanogels are used to increase enzyme stability, and noncovalently pattern enzymes in the capillary, enabling more cost-effective use of biological reagents that provide insight into glycan structures. This advancement allows for in- 
capillary electrophoretic mixing of a substrate and an enzyme to achieve similar rates irrespective of incubation times. These findings are important to study the MichaelisMenten constants of two enzymes obtaining different catalysis rates. With the knowledge of rates, a cheaper enzyme was used instead of an expensive enzyme to obtain similar information, deciphering glycan linkage and composition in a cost-effective manner. The identification of type-1-LacNac signature in glycoproteins was demonstrated with the use of an enzyme and lectin combination. The enzymes and lectins can be used individually, or in combination, to identify the monomer and linkage information in glycans. 


\section{Dedication}

This dissertation is dedicated to my parents, Gattu Parvathi Devi and Gattu Vinod

Kumar, whose affection, love, encouragement and prayers of day and night make me able to get such success and honor and for making me whom I am today.

I also thank my brother, Gattu Sandeep, my sister Harinarthini Madhuri, and in-laws

Harinarthini Sandeep and Gattu Samhitha Bhargavi for years of support, patience and belief in me, this endeavor would not have been possible. 


\section{Acknowledgements}

Firstly, I would like to express my sincere gratitude to my advisor Dr. Lisa A. Holland for the continuous support of my Ph.D study and related research, for her patience, motivation, and immense knowledge. Her guidance helped me in all the time of research and writing. I could not have imagined having a better advisor and mentor for my Ph.D study.

Besides my advisor, I would like to thank the rest of my thesis committee: Dr. Harry O. Finklea, Dr. Stephen J. Valentine, Dr. Justin A. Legleiter, and Dr. Slawomir Lukomski for their insightful comments and encouragement, but also for the hard question which incented me to widen my research from various perspectives.

I thank my fellow labmates (past and present): Dr. Brandon Durney, Dr. Tyler Davis, Vincent Nyakubaya, Cassandra Crihfield, Lloyd Bwanali, Marriah Ellington, Dr. Grace Lu and Dr. William Penny in for the stimulating discussions, for the sleepless nights we were working together before deadlines, and for all the fun we have had in the last five years. I would also like to thank my friends Sobith, Vikas, Haresh, Sravan, Swathi, Pragya and Apoorva for their support throughout my journey 


\section{Table of Contents}

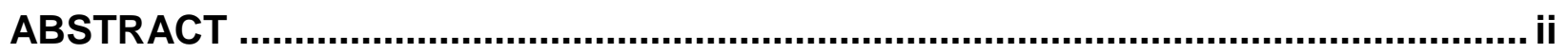

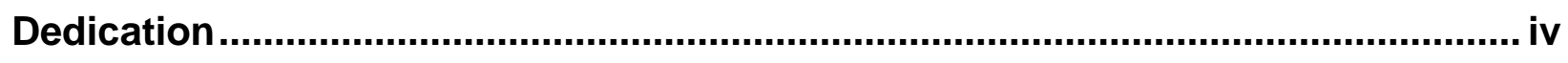

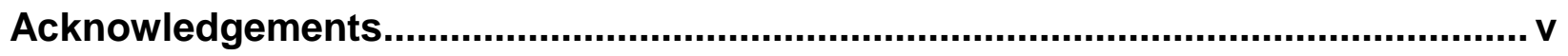

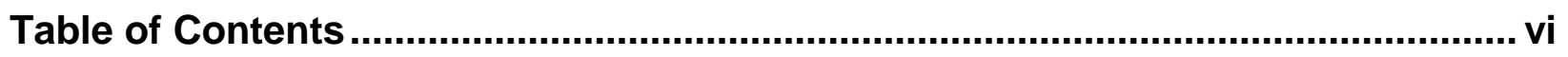

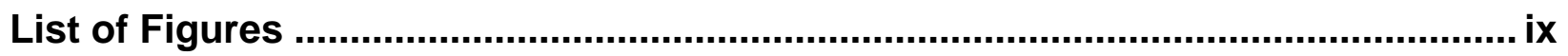

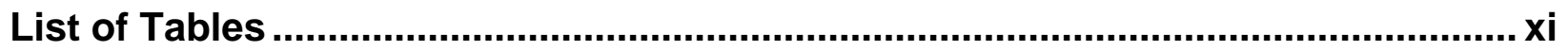

List of Symbols /Nomenclature................................................................................ xii

Chapter 1: Glycan characterization with capillary electrophoresis ......................... 1

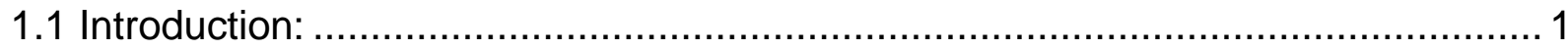

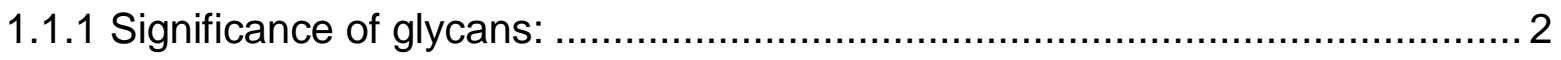

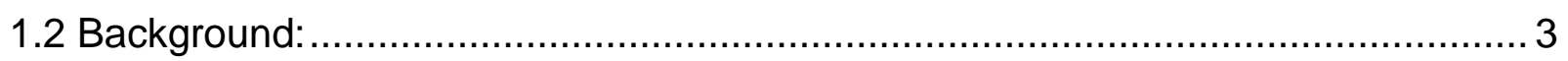

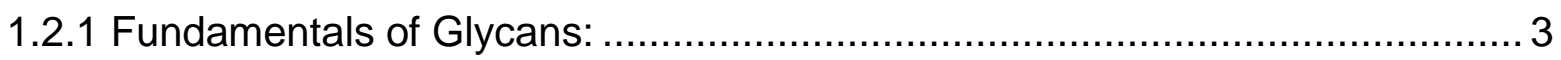

1.2.2 Fundamentals principles of Capillary Electrophoresis: ................................ 6

1.2.3 Analytical Technologies to characterize glycans:........................................ 9

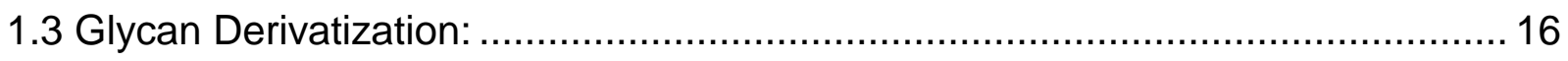

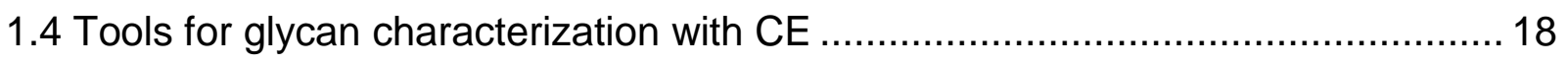

1.4.1 Glycan Identification with Exoglycosidases:............................................ 18

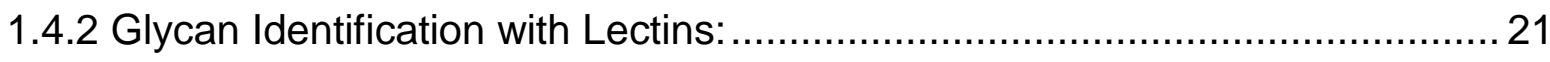

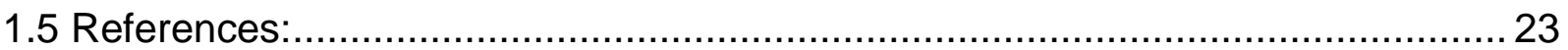

Chapter 2: Microscale Measurements of Michaelis-Menten Constants of

Neuraminidase with Nanogel Capillary Electrophoresis for the Determination of

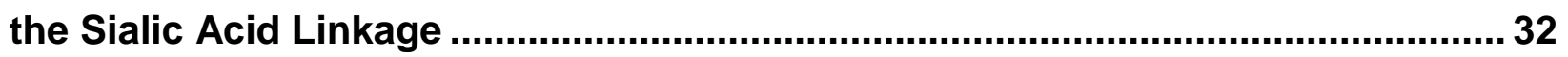

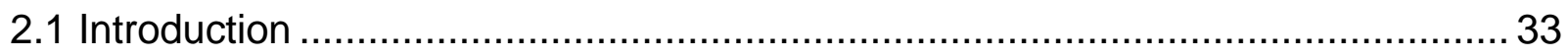

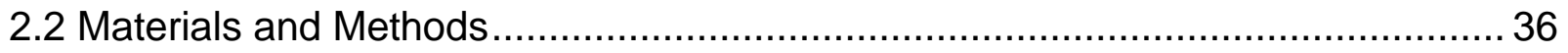

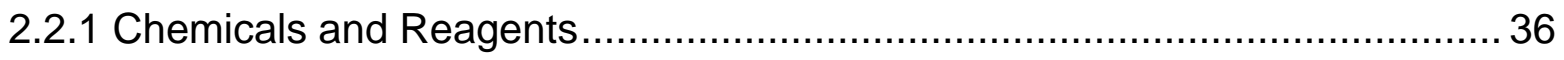

2.2.2 Preparation and Derivatization of Standards .............................................. 36 


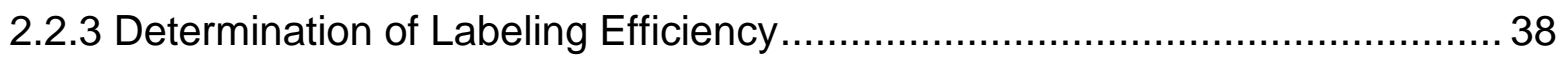

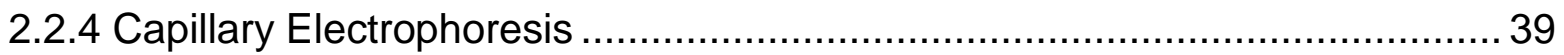

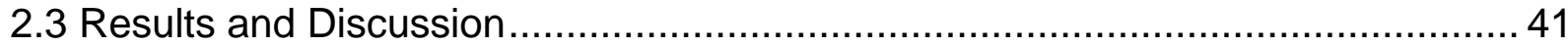

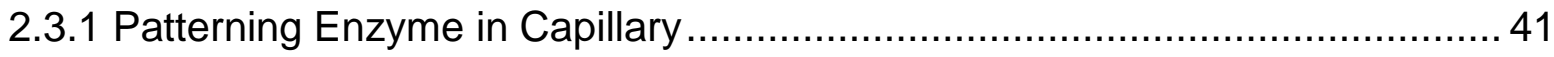

2.3.2 Effect of Phospholipid Nanogel on Enzyme Performance ........................... 44

2.3.3 Optimizing Incubation Times in the Fixed Enzyme Zone ........................... 46

2.3.4 Determination of Michaelis-Menten Constants for Neuraminidase ............... 51

2.3.5 Differentiating the Sialic Acid Linkage with Neuraminidase ......................... 58

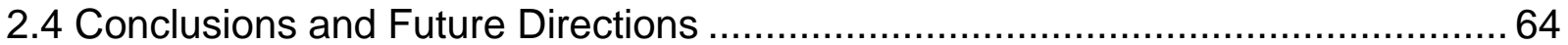

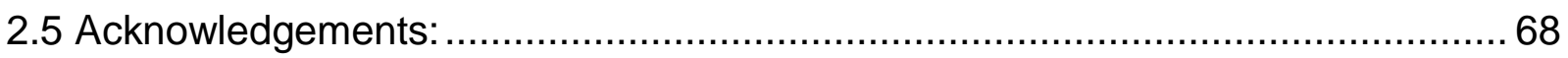

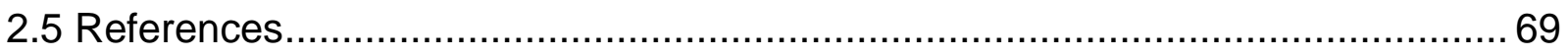

Chapter 3: Capillary electrophoresis with stationary nanogel zones of galactosidase and Erythrina cristagalli lectin for the determination of ( $\beta 1-3)$ -

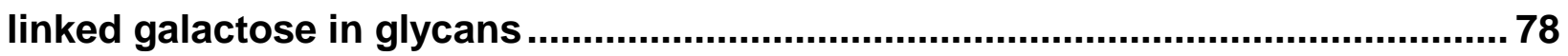

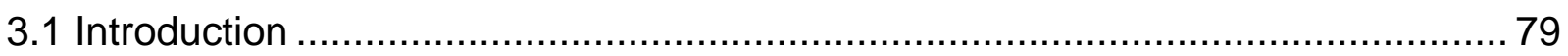

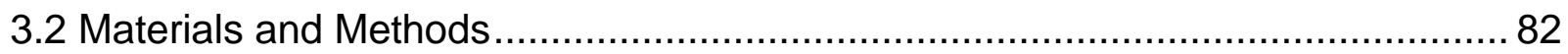

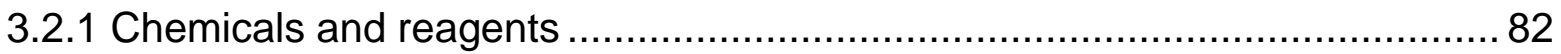

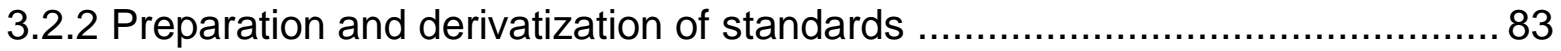

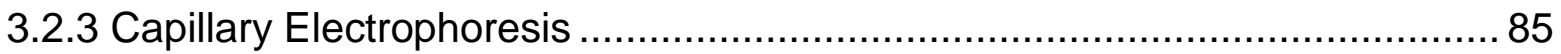

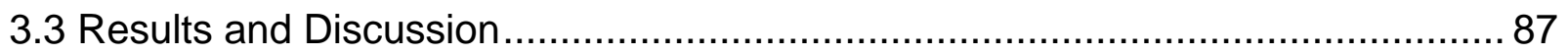

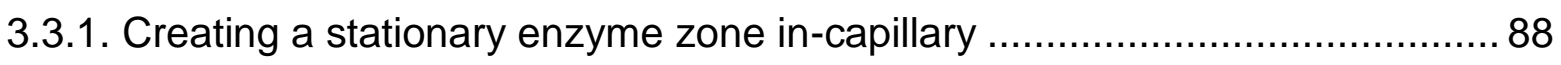

3.3.2. Effect of nanogel on $\beta(1-4)$-galactosidase activity and stability.................... 88

3.3.3. Effect of the stationary nanogel position on enzyme cleavage .................... 91

3.3.4. Other factors that influence $\beta(1-4)$-galactosidase performance .................... 95

3.3.5. Identification of $\beta(1-3)$-linked galactose using $\beta(1-4)$-galactosidase and

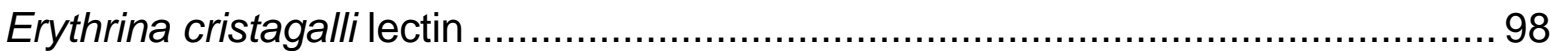

3.4. Conclusions and Future Directions ….................................................... 101

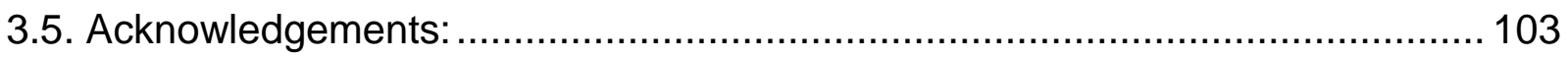

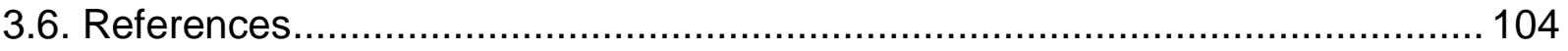

Chapter 4: Conclusions \& Future Directions:

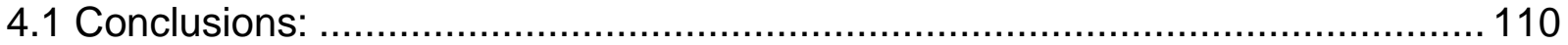

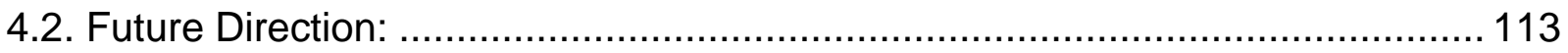


4.2.1: Charecterization of $\mathrm{N}$-glycan profiles relevant to clinical samples:

4.2.2: Michaelis Menten Studies of Exoglycosidases: ...................................... 115

4.2.3 Analysis of O-linked glycans: ............................................................. 116 


\section{List of Figures}

Figure 1.1 Six representative structures of monosaccharides commonly seen in $\mathrm{N}$ glycans.

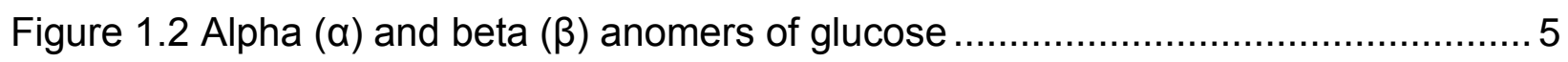

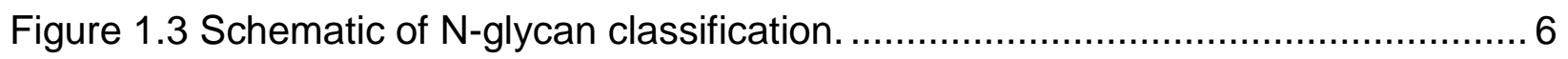

Figure 1.4 Schematic of capillary electrophoresis set up. ..................................... 7

Figure 1.5 Depiction of electro-osmotic flow in capillary electrophoresis....................... 9

Figure 1.6 Schematic of labelling reaction mechanism of carbohydrate with 2-AA or

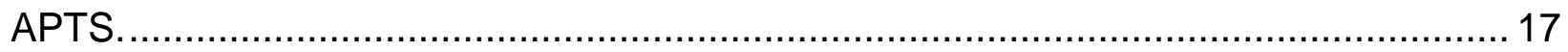

Figure 1.7 Schematic of glycan structure elucidation with exoglycosidases.................. 18

Figure 1.8 Conceptual diagrams demonstrating $\mathrm{K}_{\mathrm{M}}$ analysis using capillary electrophoresis.

Figure 2.1 Depiction of electrophoretic migration of substrate in-capillary containing enzyme in a fixed zone.

Figure 2.2 Demonstrates the use of $3.4 \mathrm{mM}$ 3'-sialyllactose to identify the beginning and end of the fixed enzyme zone. 43

Figure 2.3 Plot of enzyme activity. 46

Figure 2.4 Conceptual diagrams of multi-pass electrophoretic mixing for control of the incubation time in the enzyme.

Figure $2.5 \mathrm{Ohm}$ 's Law plot. The current is measured as a function of applied voltage for 40 minutes. 50

Figure 2.6 Electropherograms of 3'-sialyllactose substrate and the lactose product generated after enzymatic reaction.

Figure 2.7 Depicts the separation of 6'-sialyllactose and lactose after enzymatic reaction with 5 different concentrations of 6'-sialyllactose substrate. 56

Figure 2.8 Depicts the separation of 3'-sialyllactose and lactose after enzymatic reaction with 5 different concentrations of 3'-sialyllactose substrate. 57 
Figure 2.9 Electropherograms of 3' and 6'-sialyllactose to demonstrate the use of $\alpha 2-3$ neuraminidase to determine substrate linkages.

Figure 2.10 Electropherograms of 3'- and 6'-sialyllactose to demonstrate the use of neuraminidase to distinguish $3^{\prime}$ and 6 ' linkages.

Figure 2.11 Electropherograms of tri-sialylated triantennary complex N-glycan incubated in a2-3 neuraminidase to determine linkage position. 62

Figure 2.12 Electropherograms of tri-sialylated triantennary complex $\mathrm{N}$-glycan incubated in a2-3', 6', 8', 9' neuraminidase to determine the 3' versus 6' sialic acid composition. ... 64

Figure 3.1 Conceptual illustration of electrophoretic migration of substrate in-capillary containing enzyme in a stationary zone..

Figure 3.2 Depiction of electrophoretic migration of substrate in-capillary through a stationary zone of nanogel in two different positions.

Figure 3.3 Depicition of an aluminium spool that is placed in contact with the glass vial used as either the anode or cathode reservior.

Figure 3.4 Electropherograms of complex N-glycan obtained from asialofetuin incubated in $\beta$ (1-4)-galactosidase and Erythrina cristagalli lectin in different combination. 100 


\section{List of Tables}

Table 1.1 Commercial lectins most commonly used for glycan identification ................ 22

Table 2.1 Effect of Substrate Delivery on Rate ....................................................... 48

Table 2.2 Summary of Michaelis-Menten Parameters ${ }^{1}$............................................ 55

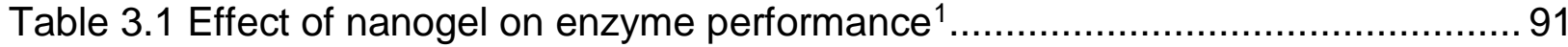

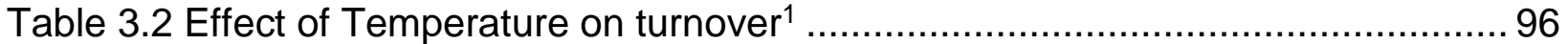

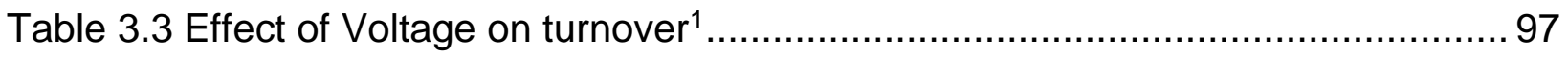

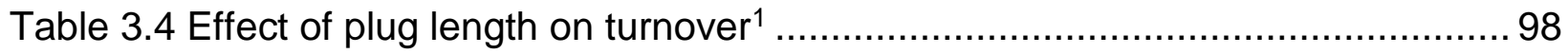




\section{List of Symbols /Nomenclature}

\begin{tabular}{|c|c|}
\hline CE & Capillary Electrophoresis \\
\hline V & Velocity \\
\hline$\mu$ & Electrophoretic mobility \\
\hline $\mathrm{E}$ & Electric field \\
\hline EOF & Electro Osmotic Flow \\
\hline $\mathrm{EPH}$ & Electrophoretic \\
\hline MS & Mass Spectrometry \\
\hline UV & Ultraviolet \\
\hline LIF & Laser Induced Fluorescence \\
\hline 2-AA & 2-Aminobenzoic Acid \\
\hline APTS & 8- Aminopyrene-1,3,6-Trisulfonic Acid \\
\hline $\mathrm{K}_{\mathrm{M}}$ & Michaelis Menten Constant \\
\hline v & Rate or velocity \\
\hline$V_{\max }$ & Maximum Velocity \\
\hline SNA & Sambucus nigra agglutinin \\
\hline MAL & Maackia amurensis lectin \\
\hline ECL & Erythrina Cristagalli lectin \\
\hline
\end{tabular}


GSL I-B4 Griffonia (Bandeiraea) simplicfolia Isolectin

PHAE Phaseolus vulgaris Erythroagglutinin

WGA Wheat germ agglutinin

Con A Concanavalin A

AAL Aleuria aurantia lectin

NeuAc N-acetylneuraminic acid

Gal Galactose

GU Glucose Unit

GlcNAc N-acetylglucosamine

Glc Glucose

Man Mannose

Fuc Fucose

EMMA Electrophoretically Mediated Micro Analysis

DMPC 1,2-dimyristoyl-sn-glycero-3-phosphocholine

DHPC 1,2-dihexanoyl-sn-glycero-3-phosphocholine

LacNac Type-1 N-acetyl-D-lactosamine 


\section{Chapter 1: Glycan characterization with capillary electrophoresis}

\subsection{Introduction:}

Capillary electrophoresis separations offer many advantages over chromatographic separations that make the method an attractive technique for enzyme and glycan analysis. Capillary electrophoresis (CE) uses nano- to picoliter sample volumes for each run. Electrophoresis runs are rapid, requiring minutes to complete. The high separation efficiency of capillary electrophoresis enables the separation of complex samples. Commercially available instruments are equipped with robotics, which automate the sample analyses. These benefits make capillary electrophoresis an excellent platform to study glycan structure with the use of enzymes and lectins.

The research work covered in this dissertation is the result of three published manuscripts. Chapter one discusses the significance and fundamentals of glycans and their analysis with CE using exoglycosidases and lectins. Chapter two covers the costeffective use of enzymes for kinetic studies and linkage analysis in carbohydrates and glycans. It also covers the effect of a phospholipid nanogel on enzyme performance and enzyme reaction optimization. Chapter three is about the applicability of using enzyme and lectin combinations to distinguish branched isomeric oligosaccharides linkages. Chapter four discusses the future directions in use of the developed methods for applying glycan structure characterization to clinical samples for bio-marker detection which aids in diagnosis and prognosis of cancer. This work covers research that was published in: 
Gattu, S.; Crihfield, C. L.; Lu, G.; Bwanali, L.; Veltri, L.M.; Holland, L. A., Advances in Enzyme Substrate Analysis with Capillary Electrophoresis. Methods 2018, 146, 93-106.

Gattu, S.; Crihfield, C. L.; Holland, L. A., Microscale Measurements of Michaelis - Menten Constants of Neuraminidase with Nanogel Capillary Electrophoresis for the Determination of Sialic Acid Linkage. Analytical Chemistry 2017, 89 (1), 929-936

Holland, L. A ,; Gattu, S.; Crihfield, C. L.; Bwanali, L., Capillary electrophoresis with stationary nanogel zones of galactosidase and Erythrina cristagalli lectin for the determination of ( $\beta 1-3)$ - linked galactose in glycans. Journal of Chromatography $A \mathbf{2 0 1 7}$, $1523,90-96$

\subsubsection{Significance of glycans:}

Carbohydrates (or sugars) are the most abundant among biological molecules and are fundamental molecules to signaling and energy..$^{1,2}$ These molecules play an important role in biological processes and are involved in cell-cell recognition, cell adhesion, and cellular regulation. ${ }^{3}$ The important role of glycans in signaling makes it a useful tool for disease diagnosis and prognosis. Changes in glycosylation patterns of glycans are the hallmarks of cancer and several other diseases. Protein glycosylation is significant, but challenging post-translational modification that must be monitored. ${ }^{4,5}$ Glycosylation modulates biological activity ${ }^{6}$ and strongly influences the functioning of proteins and antibodies. Different structural changes are relevant to different areas of biotechnology. For example, glycosylation effects the safety and efficacy of biological therapeutics and 
serves as biomarkers for disease. ${ }^{7,8}$ Characterizing glycosylation is difficult because these structures vary in their monomer sequence and monomer linkage.

\subsection{Background:}

\subsubsection{Fundamentals of Glycans:}

Glycans are compounds consisting of large numbers of monosaccharides linked together. Monosaccharides, the smallest unit that build glycans, can be roughly classified to contain the empirical formula $\mathrm{C}_{x}\left(\mathrm{H}_{2} \mathrm{O}\right)_{n}$, and mainly consist of glucose, mannose, galactose, fucose, N-Acetyl-D-glucosamine, and N-Acetyl-D-neuraminic acid. ${ }^{9}$ The structures are represented in Figure 1-1, demonstrating the differences in their structures. These monosaccharides can exist as open or cyclic hemiacetal forms and are usually depicted in the cyclic form in a chair conformation. 


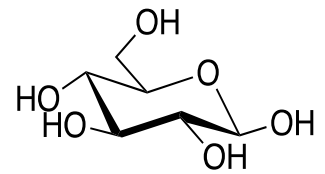

D-Glucose (O)

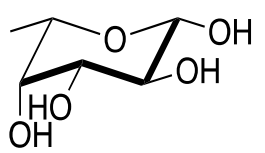

L-Fucose $(\nabla)$

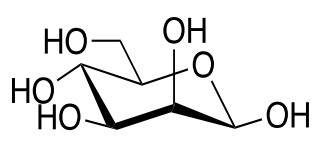

D-Mannose (O)

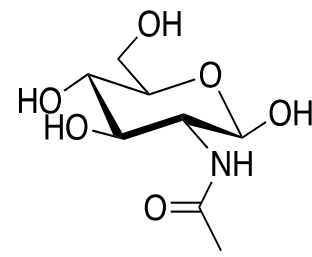

N-Acetyl-Dglucosamine

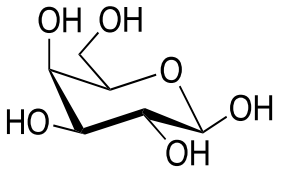

D-Galactose (O)

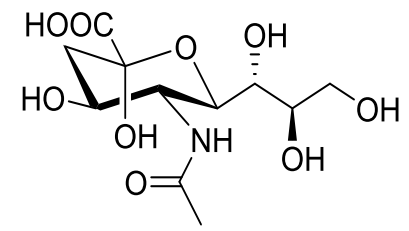

N-Acetyl-Dneuraminic acid $(\nabla)$

Figure 1.1 Six representative structures of monosaccharides commonly seen in N-glycans. All the monosaccharides shown are D-conformers except fucose. Figure adapted from reference [9]

$\mathrm{N}$-Glycans are all composed of a common core structure consisting of two GlcNac and three mannose sugars. The rest of the glycan structure can vary by the monomer position and the linkage. The linkage orientation can be either alpha or beta on carbon-1 of a monosaccharide. If both Carbon-1 and the highest numbered chiral carbon, $\mathrm{OH}$ group is pointed in opposite directions (axial up at highest chiral carbon and axial down at carbon1), then the linkage or anomericity is alpha. On the other hand, if both carbon-1 and the highest numbered chiral carbon, $\mathrm{OH}$ group is pointed in the same direction (axial up at highest chiral carbon and equatorial at carbon-1), then the linkage is beta, as shown in Figure 1-2. The carbon-1 of a monosaccharide combines with the hydroxyl group of the neighboring monosaccharide to form a glycosidic bond. Since a glycan contains a large number of monosaccharides linked together, a wide variety of linkages are possible. Even though the known biosynthetic pathways restrict the number of physiologically relevant 
structures, changes in linkage and position can occur during post-translational modification and affect signaling.
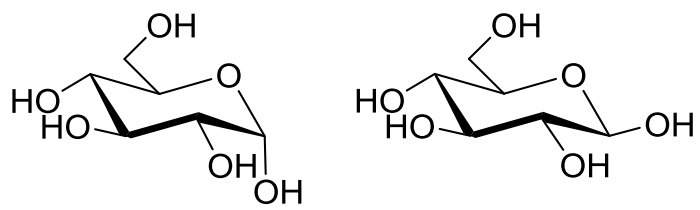

$\alpha$-D-Glucose (O) $\quad \beta$-D-Glucose (O)

Figure 1.2 Alpha ( $\alpha$ ) and beta ( $\beta$ ) anomers of glucose, where alpha anomer on the left and beta anomer on the right

Glycans derived from glycoproteins are either N- (aspargine) or O- (serine/threonine) linked to the polypeptide sequence of the protein. The focus of this dissertation is $\mathrm{N}$-linked glycans. These N-glycan structures can be further sub-divided into three types. These include high mannose glycans, complex glycans and hybrid glycans that integrate characteristics of the two glycan types as shown in Figure 1-3. These differences in Nglycan type, linkage, and position isomers add a great complexity in glycan structure elucidation. 


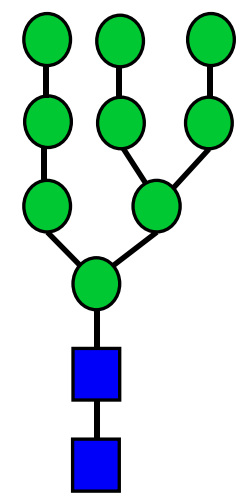

High Mannose

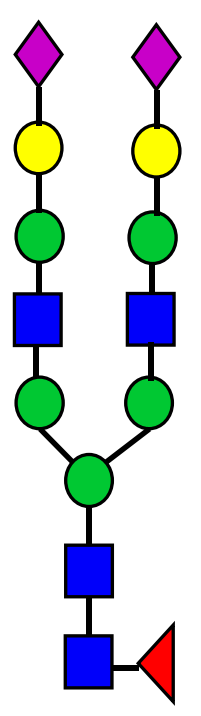

Complex

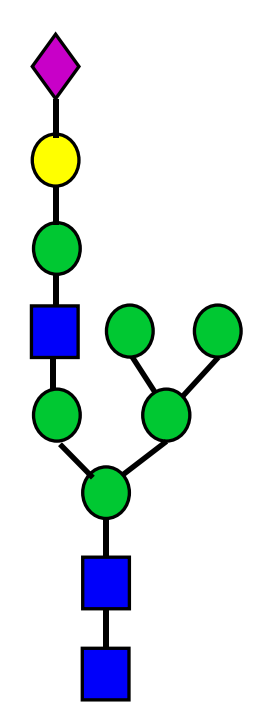

Hybrid
Linkage Position:

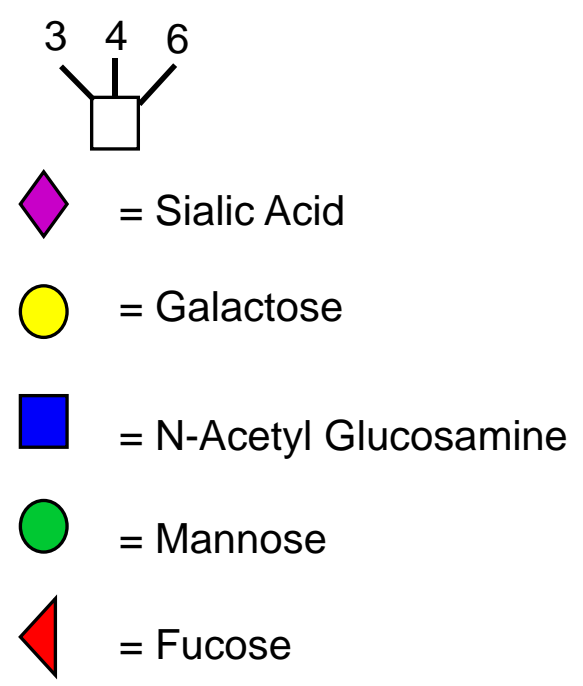

Figure 1.3 Schematic of $\mathrm{N}$-glycan classification. The N-glycan structures include high mannose, complex and hybrid glycans with key for linkage and glycan monomers were presented.

\subsubsection{Fundamentals principles of Capillary Electrophoresis:}

Separation in capillary electrophoresis is based on the charge-to-size ratio of analytes in an electric field.

$$
V=\mu E
$$

Where $V$ is the velocity of the ion, $\mu$ is the electrophoretic mobility of the ion and $E$ is the applied electric field. The electric field is a function of applied voltage and capillary length. A simple schematic of a capillary electrophoresis system ${ }^{10}$ is provided in Figure 1-4. Separations take place in a silica capillary filled with a background electrolyte. For methods employing optical detection, the polyimide coating on the outside of the capillary is removed to create a detection window which allows light to pass through to the detector. 
A high voltage power supply that can deliver up to 30,000 volts is used to apply an electric field across the capillary during the separation.

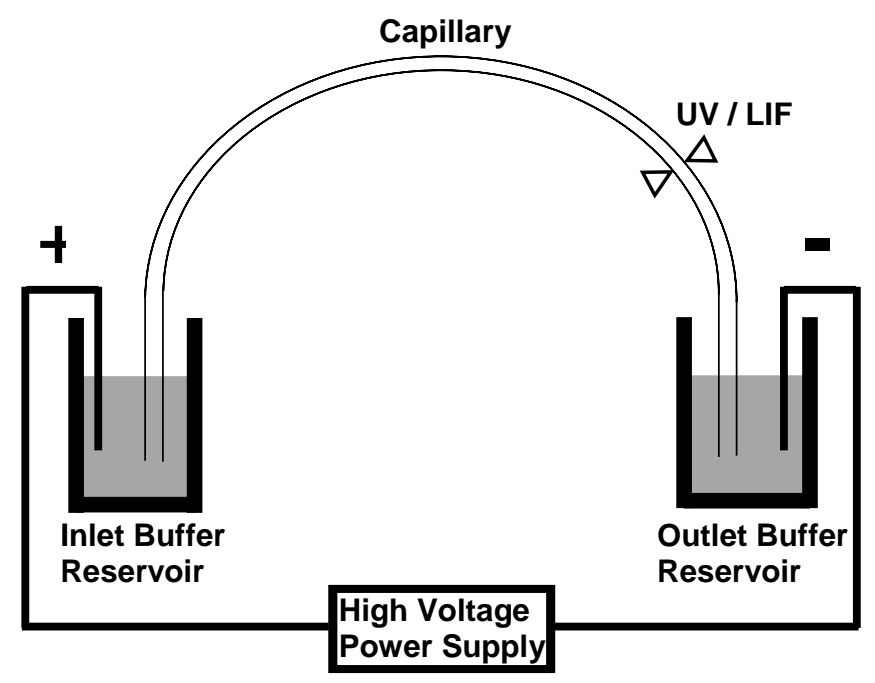

Figure 1.4 Schematic of capillary electrophoresis set up. It consists of capillary, buffer reservoirs containing background electrolyte and a detector. Analytes are separated in capillary under the influence of the electric field supplied by high voltage power supply. Figure reproduced from reference [10].

There are two modes of transport in capillary electrophoresis, electroosmotic flow and electrophoretic mobility. Electroosmotic flow, which is depicted by the thin black vector in Figure 1-5, is the bulk flow of liquid in the capillary. It occurs in the presence of the electric field as a consequence of the surface charge on the inner wall of the fused silica capillary. The surface of the fused silica is negatively charged at $\mathrm{pH}$ levels above 4 , so cations accumulate at the surface of the capillary. This results in a bulk flow of the liquid towards the cathode upon application of the electric field. Electrophoretic velocity, which is denoted by a thin grey vector in Figure 1-5, is based on the charge-to-size ratio of an analyte. A small cation with the same charge as a larger a cation will migrate toward the 
cathode faster than the larger cation. The net velocity of an analyte, represented by the large open arrow in Figure 1-5, is based on the sum of the vectors for electroosmotic flow and electrophoretic velocity. Electroosmotic flow is greater than electrophoretic velocity; therefore, cations, neutrals, and anions can be analyzed in a single run. For cations, the analytes with high charge-to-size ratio migrate to the detection window before those with a low charge-to-size ratio. However, the reverse is true for anions since the electrophoretic velocity is in the opposite directions. This is emphasized in the electropherogram in Figure 1-5, where the resulting order of migration is high charge-tosize ratio cations, low charge-to-size ratio cations, neutrals, low charge-to-size ratio anions, and high charge-to-size ratio anions. 

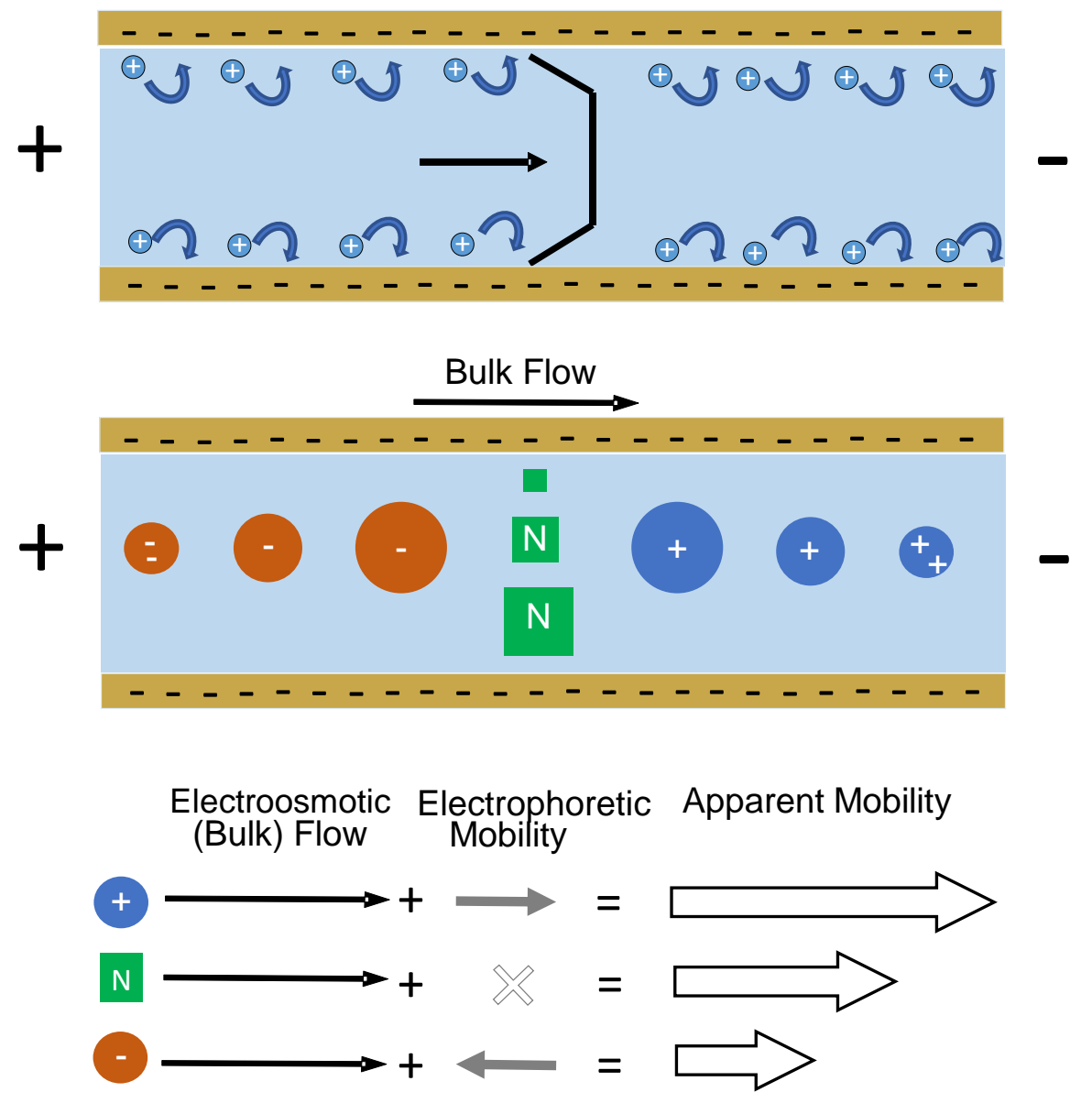

Figure 1.5 Depiction of electro-osmotic flow in capillary electrophoresis. The analytes are separated by the charge to size ratio. The vectors represent the electroosmotic flow (EOF), and the electrophoretic (EPH) and apparent mobilities of the analytes.

\subsubsection{Analytical Technologies to characterize glycans:}

\subsubsection{Mass Spectrometry:}

Mass Spectrometry is one of the commonly used techniques for glycan characterization, and provides a basis for glycan structure. Mass Spectrometry (MS) is used extensively even though it generates structural ambiguity for linkage position. As a result, these subtle 
differences have only been conclusively elucidated with sophisticated analyses that require excessive consumption of enzymes, substantial incubation time and sophisticated workflow. ${ }^{11-14}$ The latest approach, utilizes a variety of protonated carbohydrate structures to inspect gas-phase hydrogen-deuterium exchange for distinguishing isomeric carbohydrate ions. Where the exchange rates were different for different carbohydrate ions. ${ }^{15}$ The glycan linkage isomer analysis and glycan structure identification can also be analyzed through Ion mobility - Mass spectrometry. ${ }^{16-19}$ In combination with exoglycosidases, mass spectrometry analyses can distinguish the structures of isobaric glycans, but these methods must be modified to eliminate sodium after enzyme reaction. ${ }^{20,21}$ In addition, challenges in ionization and detection are due to the presence of negatively charged sialic acids for glycan structures. ${ }^{22}$ Sequence identification with electrospray ionization is complicated by the appearance of different charge states and fragmentation. When sequence identification is accomplished using matrix-assisted laser desorption ionization, a derivatization step is required to prohibit extensive fragmentation and provide quantitative analysis.

\section{Glycan sequencing with Mass Spectrometry:}

Complete glycan structure determination requires information about sequence, monosaccharide composition and linkage between two monosaccharide units. The structure verification with MS is routinely done using matrix assisted laser desorption ionization $^{23-26}$ and electrospray ionization as the ionization ${ }^{27-30}$ sources for $\mathrm{N}$-glycan analysis. Lichtenstein and co-workers have developed a two dimensional array for $\mathrm{N}$ glycan structure sequencing by analyzing the products using MALDI-TOF, where the first 
dimension is composed of various lectins immobilized on MALDI plate and the second dimension utilizes sequential exoglycosidase digestions to provide a sequencing tool for glycan structure analysis. ${ }^{31}$ The N-glycan structure identification using electrospray ionization was reported by several groups in conjunction with other techniques. ${ }^{29,}, 30,32$ Structure elucidation by tandem MS can be utilized to determine monosaccharide composition based on tandem mass tag to utilize fragments obtained from collision induced dissociation. ${ }^{30}, 33,34$ The connection between two monosaccharides units in glycans can be determined by the sequential cleavage of glycosidic bonds in low energy collision induced dissociation ${ }^{35}$ and the linkage positions can be identified by cross-ring cleavages using higher energy fragmentation conditions. ${ }^{36}$

\subsubsection{High Performance Liquid Chromatography:}

The glycan pool released from glycoprotein can be separated depending upon the properties of the glycans and type of high-performance liquid chromatography matrices used. Hydrophilic interaction chromatography, reverse phase, and high performance anion exchange chromatography are commonly used for separation of fluorescently labeled oligosaccharides containing sialylated and neutral glycans. ${ }^{37,} 38$ One of the limitations is the volume of sample consumed and time required for glycan analysis, and in some cases salts have to be purified for MS analysis.

\section{Microarrays for glycan sequence identification:}

Microarray is one of the critical tool for glycan structure determination. The microarray can be either a lectin based, enzyme based or the combination of both. ${ }^{39-42}$ In lectin 
microarray the individual lectins are deposited as discrete spots on a solid support that are either covalently linked or adsorbed onto the nitrocellulose membrane. In these studies, glycan is fluorescently labeled and is allowed to incubate with various lectins in the array to enable lectin-carbohydrate binding to occur. Although lectin microarray has many advantages with respect to throughput, analysis of wide range of target samples, it has limitations such as its inability to recognize specific glycan motifs where lectin does not have specificity and analysis between multiple complex samples is difficult. ${ }^{41} \mathrm{~A}$ combination of enzyme and lectin is required to overcome limitations of lectin array, and provide greater confidence in glycan structure assignment. ${ }^{40,42} \mathrm{~A}$ brief discussion about the glycan identification with exoglycosidases and lectins were presented in section 1.4.

\subsubsection{Capillary Electrophoresis:}

Capillary electrophoresis is one of the most widely used and powerful techniques for the characterization of glycans. CE provides high resolution capable of separating glycans by charge-to-size ratio. CE has developed methods capable of distinguishing linkage isomers and positional isomers resulted in the analysis of $\mathrm{N}$-glycans for bio-marker discovery and biological therapeutics. CE utilizes nanoliters to picoliters volumes of enzymes, lectins, and glycans making a cost-effective technique. In addition, the time required for analysis reduced from hours to few minutes compared to traditional bench top reactions used for other techniques. 


\section{Capillary Electrophoresis for glycan sequence identification:}

Capillary Electrophoresis is widely used for glycan sequence determination through use of exoglycosidases. The automated N-glycan sequencing in bio-pharmaceuticals was recently reported by Guttmann and co-workers where the sample was held in a storage compartment of the CE instrument was utilized for reaction temperature control and separation capillary as an enzyme delivery device. The exoglycosidase enzyme reactions are performed serially for complex glycan pools and obtaining information by digesting the monosaccharide from the non-reducing end of the glycan. The obtained exoglycosidase reaction products were identified by migration time shifts due to differences in charge to size ratio after each exoglycosidase treatment. CE utilizes migration time index for glycan structure identification.

The migration time of the glycan, or carbohydrate, is best identified by referencing a homologous glucose polymer ladder ${ }^{43}$ consisting of different glucose units. Guttmann and co-workers published glycan structure assignment based on glucose units (GUs), and direct comparison of GU values of known standard glycan or carbohydrate structures with GUs of the unknown analyte of interest is an essential task in glycan structure identification. ${ }^{44-47}$ In addition, referencing the analyte to GU values solves issues with reproducibility in migration time that may occur due to variability in separation conditions. The GU value of unknown glycan peak in the electropherogram is calculated as shown in the equation 2.

$$
G U_{X}=G_{N}+\frac{t_{X}-t_{N}}{t_{N+1}-t_{N}}
$$


Where GUx is the glucose unit value for analyte of interest, $G_{N}$ is the degree of polymerization of maltose units in the adjacent maltooligosaccharide peak. $t_{x}$ is the migration time of target glycan of interest and $t_{N}$ and $t_{N+1}$ are the migration times of maltooligosaccharide preceding and following the target glycan of interest. The application was improved with a built-in database GUcal for high throughput analysis reported as www.gucal.hu. This database calculates GU values of unknown peaks in the electropherogram automatically by loading the ASCII file of both the maltooligosaccharide ladder and the glycan sample.

The GU values have been used to quantify the monosaccharide and its linkage to identify the unknown glycan structure with changes in its hydrodynamic size based on the linkages present. The impact of temperature on the hydrodynamic size of both linear and branched oligosaccharides studied indicated that GU values are changing with change in temperature from 20 to $50^{\circ} \mathrm{C}$ due to differences in activation energies for linear and branched N-glycans. ${ }^{47,48}$ In addition, a recent report that implements co-injection of triple internal standard to alleviate the need for extra maltooligosaccharide run for GU calculation. ${ }^{46}$ This approach speeds up high throughput CE system processing time for glycan structure assignment through high precision of measured GU values based on direct comparison of GU values between known standards and the unknown analyte of interest. 
Alternative approaches for sequence identification include multiplexed CGE and CE-ESIMS. The N-glycan sequencing can also be established using multiplexed capillary gel electrophoresis. This technique was developed based on the instrument for DNA sequencing. Software's like glyXtoo ${ }^{49,} 50$ and glyXalign ${ }^{49,51}$ were developed to address shifts in migration time and peak assignment for glycan structure identification. This resulted in high throughput identification of $\mathrm{N}$-glycans required for diagnostic purposes. ${ }^{52}$ In addition, the $\mathrm{N}$-glycan structure identification was achieved by fragmentation with use of electrospray ionization coupled with CE separation. ${ }^{29,} 30$

\section{Commercial Kits for glycan processing and structural Analysis:}

There are several commercial kits available to prepare N-glycan with improved workflow and reducing the time required for glycan structure analysis. AB Sciex offers fast glycan sequencing, using a fully automated carbohydrate sequencer kit with a goal to decrease manual steps and analysis time from 1-5 days to 2 hours. ${ }^{53}$ This workflow requires one reaction vial with glycans and the capillary was used to deliver exoglycosidases to the nanovial (5 $\mu \mathrm{L}$ volume) and sequentially to add each enzyme after analysis of the exoglycosidases reaction. After completion of the reaction, the resulting products analyzed with CE-LIF are identified based on the GU values and the GU shifts of the

product peaks. The optimization of enzyme reaction temperatures, enzyme concentrations and incubation time sequencing of $\mathrm{N}$-glycans was achieved within 1 hour with semi-automated workflow and two hours for fully automated workflow. In this way, glycan structure was sequenced by using multiple exoglycosidases and automated the work flow for glycan structure identification. The $\mathrm{N}$-glycan sequencing can also be 
performed by using a sequencing kit from NewEngland Biolabs. ${ }^{54}$ The kit consists of seven well characterized exoglycosidases for identifying N-glycan structures. These exoglycosidases can be used sequentially or together and can be analyzed with CE or MS for structure determination. The availability of commercial kits for glycan sample preparation are also developed, which includes deglycosylation of the glycan from the glycoprotein, labeling of released glycans and purification of glycans for analysis. The entire process can be completed in 30 min of time using Rapiflour- MS N-glycan kit from Waters to quickly screen glycan samples. ${ }^{55}$

\subsection{Glycan Derivatization:}

A barrier to analyze carbohydrates is that they are not easily detected through optical methods. Derivatization of carbohydrate with chemical reagent is the most common method used to label glycans. Generally, carbohydrates lack chromophore or fluorophore groups which make them not suitable for UV-absorbance or laser- induced fluorescence (LIF) detection. For CE separations, majority of the carbohydrates are uncharged, except glycans containing sialic acid. Labelling a carbohydrate with a chromophore or fluorophore tag provides a charge, and thus aids in electrophoretic migration of the glycan through the capillary.

Several derivatization agents are available to label glycans. These include 2aminobenzoic acid (2-AA), ${ }^{56,57}$ and 8-aminopyrene-1,3,6 trisulfonic acid (APTS) ${ }^{56,58}$ .Among these reagents, glycan labelling with APTS remains the method of choice for CELIF separations. The labeling reaction scheme is shown in Figure 1-6. Generally, the 
glycans are labelled in a two-step reductive amination process with APTS or 2-AA. Under acidic conditions, carbohydrates exhibit an equilibrium between straight chain and ring structure. The first step in the formation of the labeled glycan is the carbonyl carbon of the sugar moiety is activated by the proton followed by the nucleophilic attack of amine from the dye provides a Schiff's base. The Schiff's base is then reduced to a stable labeled glycan by using a mild reducing agent such as sodium cyanoborohydride as shown in below mechanism. After the reduction of bond, a stable labeled glycan is formed.
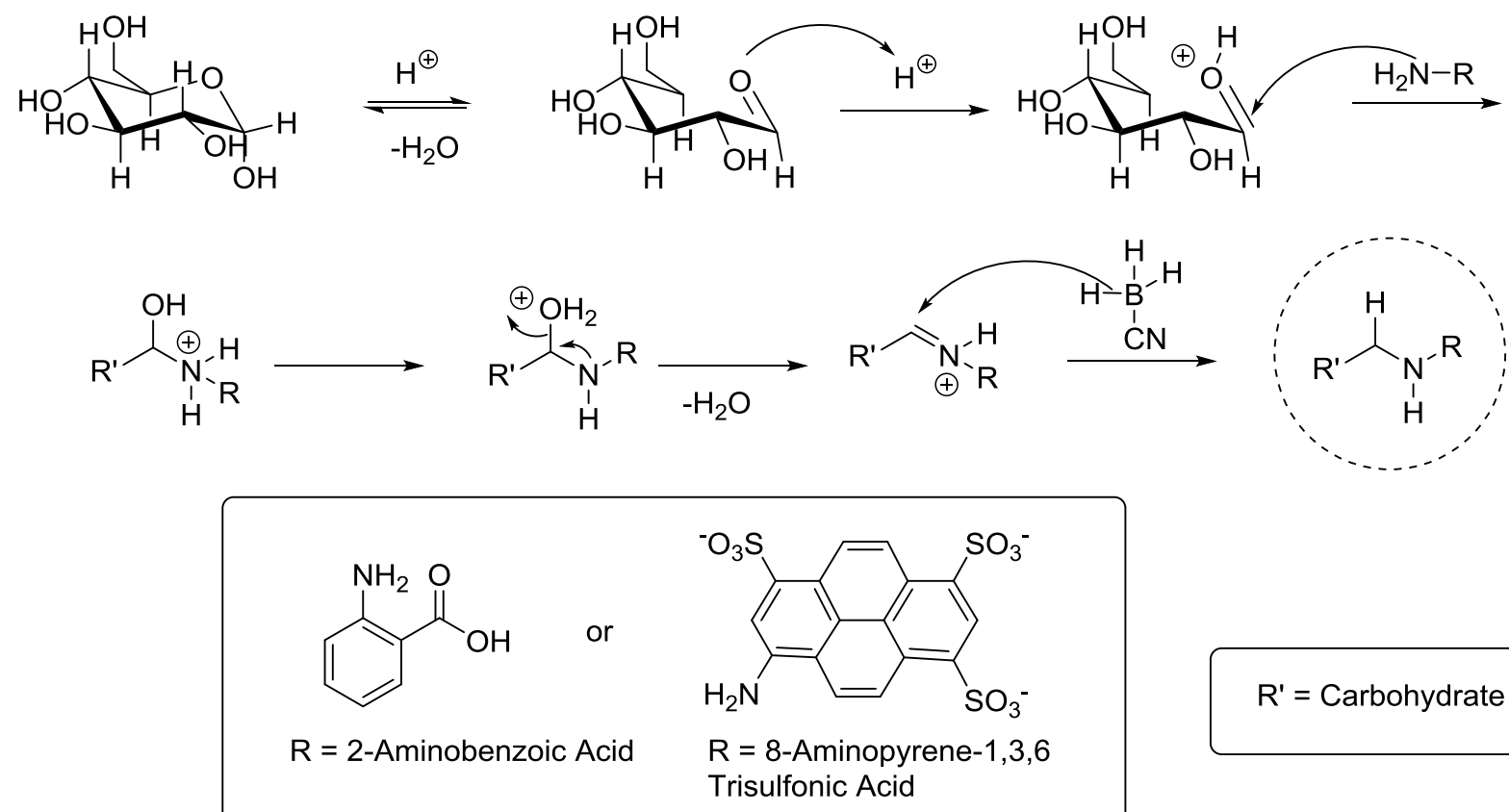

$\mathrm{R}^{\prime}=$ Carbohydrate

Figure 1.6 Schematic of labelling reaction mechanism of carbohydrate with 2-AA or APTS. The carbohydrate reacts with dye to form Schiff's base with reductive amination. The bond between carbohydrate and dye is further reduced by sodiumcyanoborohydride to form stable product. 


\subsection{Tools for glycan characterization with $\mathrm{CE}$}

\subsubsection{Glycan Identification with Exoglycosidases:}

Exoglycosidases are glycoside hydrolase enzymes that cleave the oligosaccharide from the non-reducing end of the glycan. These enzymes are selective for specific monomers in a glycan as shown in Figure 1-7. In addition to the monomer specificity, these enzymes have additional specificity with respect to linkage orientation ( $\alpha$ or $\beta$ ) or the position of carbon-carbon linkage in an oligosaccharide. The different types of exoglycosidases have differences in linkage specificity and the monomers are commercially available from different vendors.

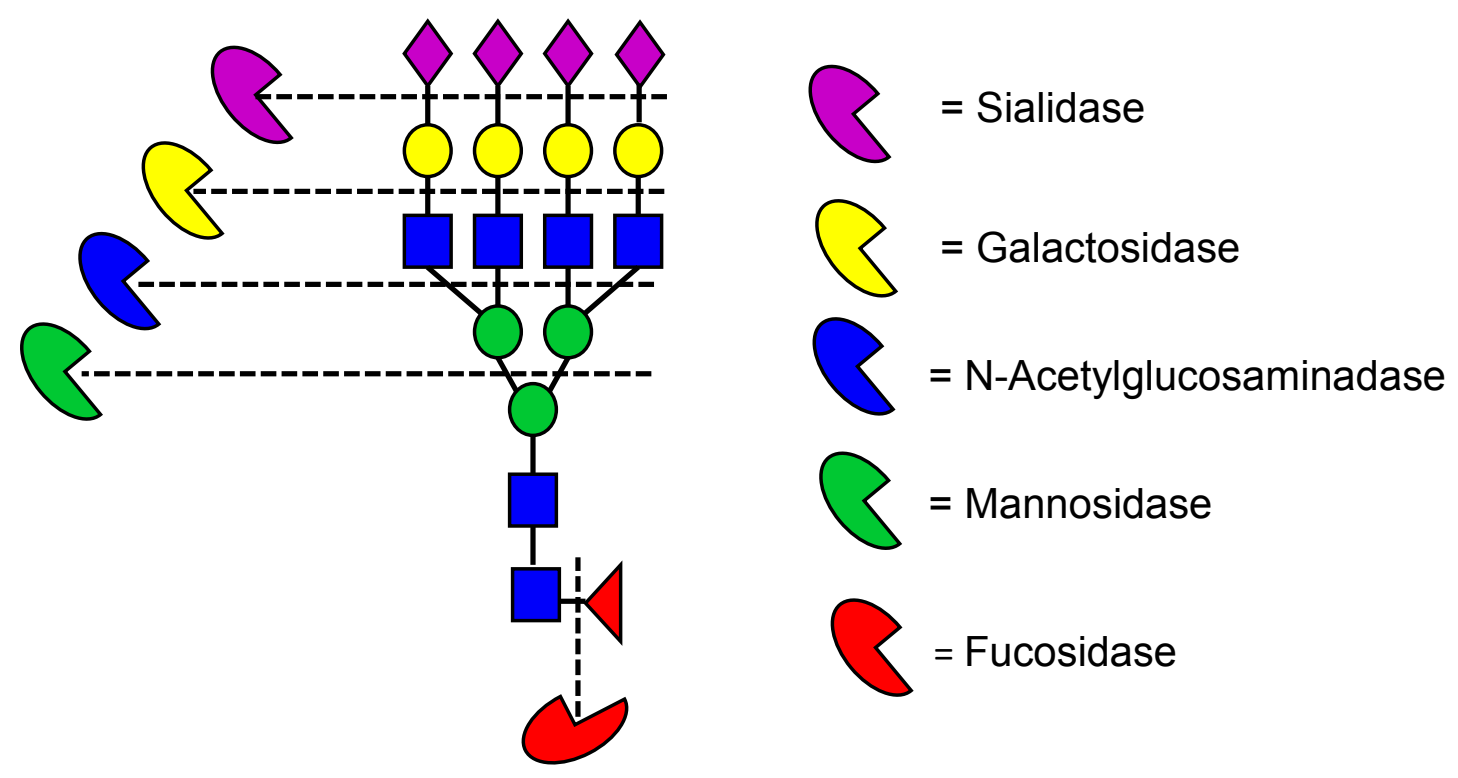

Figure 1.7 Schematic of glycan structure elucidation with exoglycosidases. The exoglycosidases can be used individually or in a sequence to identify glycan structure 


\subsubsection{Enzyme kinetic studies to evaluate enzyme performance}

The glycan structure can be elucidated by using highly specific exoglycosidases, either sequentially or in an array format to determine the sequence and structure of glycans. By utilizing positionally specific enzymes, the cleaved glycan residues can be identified by both the linkage and the monomer. For example, $\alpha$ 2-3 sialidase will remove sialic acid residues attached with a 2-3 sialic acid linkage, but not residues attached with a 2-6 or $\alpha$ 2-8 sialic acid linkages. The exoglycosidase $\alpha 2-3,6,8$ sialidase exhibit different cleavage rates, depending upon the sialic acid linkage. This rate dependent hydrolysis of exoglycosidases with different linkages and positions can be examined by kinetic studies to evaluate enzyme efficiency.

\subsubsection{Determining $K_{M}$ values}

Enzyme kinetics are commonly modeled based on the Michaelis-Menten equation, a rate equation originally proposed by Henri and applied by Michaelis and Menten. ${ }^{59}$ The catalytic efficiency is commonly defined by $\mathrm{K}_{\text {cat }} / \mathrm{K}_{\mathrm{M}}$; however, in order to define the $\mathrm{K}_{\text {cat }}$ value the true enzyme concentration must be known. The $\mathrm{K}_{\mathrm{M}}$ value is substrate dependent, which provides a better means to gauge enzyme performance for when it is utilized for a specific substrate. A small $\mathrm{K}_{\mathrm{M}}$ value means high turnover is achieved. The enzyme assays can be performed off-capillary or in-capillary for the determination of kinetic parameters.

The process requires that the substrate is incubated with enzyme for a specified time. As depicted in Figure 1-8, the reaction mixture is separated with capillary electrophoresis. The concentration of product is quantified, typically using an external calibration curve, and divided by the incubation time to yield rate. This change in the concentration of the generated product is evaluated for 
different substrate concentrations, all of which are incubated with the same concentration of enzyme. The rate of product formation is then plotted against the substrate concentration (Figure 1-8). It is useful to collect a minimum of five substrate concentration to fit a curve, provided they span the curve, as shown in Figure 1-8. The non-linear curve is fit using software to determine the $K_{M}$ value from the Michaelis-Menten equation. This is shown in equation 3

$$
v=\left(V_{\max } \cdot[\text { Substrate }]\right) /\left(K_{M}+[\text { Substrate }]\right)
$$

Where $v$ the rate or velocity of the reaction, Vmax is the maximum velocity at which substrate reaches saturation, and $\mathrm{K}_{\mathrm{M}}$ is the substrate concentration at which enzyme performs at half of the maximum velocity.
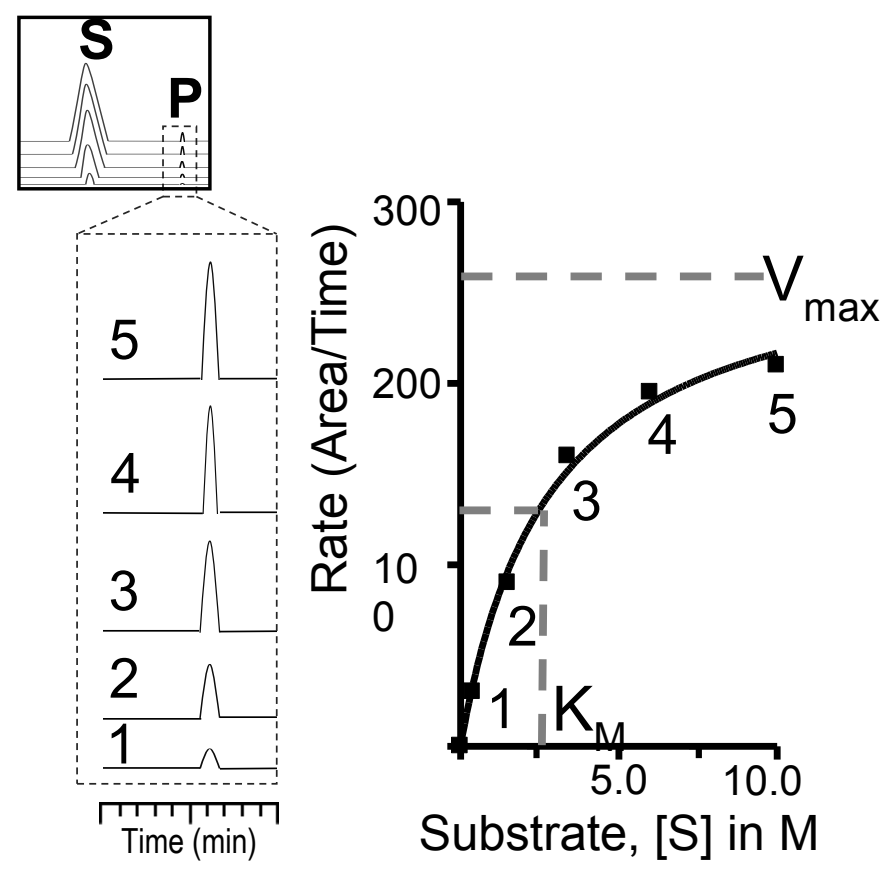

Figure 1.8 Conceptual diagrams demonstrating $\mathrm{K}_{\mathrm{M}}$ analysis using capillary electrophoresis. Electropherograms in inset show five different substrate concentrations and the products generated after the enzyme reactions. The generated products were zoomed to emphasize the product area increases as the initial substrate concentration increases. The curve on the right depicts the MichaelisMenten curve is generated by plotting the rate of product formation versus the substrate concentration. Reproduced from [9]. 


\subsubsection{Constraints of the Assay}

Before determining enzyme kinetics, there are some basic recommendations that should be implemented. The assumption of steady state, which refers to the condition under which the rate of formation and depletion of the enzyme-substrate complex are equal, requires that the analysis be performed when there is not a high accumulation of product. Initial rates in which the product formation or substrate consumption does not exceed more than $10 \%$ are used to avoid measuring the rate when the product concentration is too high, which will make the reversible reaction more favorable in accordance with Le Chatelier's principle. Furthermore, rate of enzyme turnover can decrease due to product accumulation.

\subsubsection{Glycan Identification with Lectins:}

Lectins are carbohydrate-binding proteins that are specific for sugar moieties of oligosaccharides, glycans, or glycoproteins. Lectins are harnessed to recognize the prevalence of general structural motifs and offer simple methods to screen glycosylation in glycans and also preparative scale isolation of glycoconjugates. These lectins bind to specific carbohydrate structures in the same way as antibodies bind to antigens. The binding affinities of carbohydrate-binding lectins are relatively weak when compared to carbohydrate-binding antibodies, providing distinct advantage to release glycoconjuates from lectin in mild conditions during lectin affinity chromatography. The specificity of lectin varies depending on the linkage and the position of the monosaccharide. For example, Sambucus nigra agglutinin (SNA) lectin binds only to alpha 2-6 sialic acids, while Maackia amurensis (MAL) lectin binds to alpha 2-3 sialic 
acids. The specificity of lectin for different monosaccharides and linkages are presented in Table 1.1

Table 1.1 Commercial lectins most commonly used for glycan identification

\begin{tabular}{|c|c|}
\hline$\underline{\text { Lectin }}$ & $\underline{\text { Preferred glyan signature }}^{a}$ \\
\hline \multicolumn{2}{|c|}{ Sialic acid Lectin } \\
\hline Sambucus nigra agglutinin (SNA) & NeuAca2-6Gal(NAc) ${ }^{60}$ \\
\hline Maackia amurensis lectin (MAL) & $\begin{array}{l}\text { NeuAca2-3Gal } \\
\beta 1-4 G l c N A c^{61}\end{array}$ \\
\hline \multicolumn{2}{|c|}{ Galactose Lectin } \\
\hline Erythrina Cristagalli lectin (MAL) & Galß1-4GIcNAc 60 \\
\hline $\begin{array}{l}\text { Griffonia (Bandeiraea) simplicfolia } \\
\text { Isolectin } \mathrm{B}_{4}(\mathrm{GSL} \text { I-B4) }\end{array}$ & Galß1-3GlcNAc ${ }^{60}$ \\
\hline \multicolumn{2}{|c|}{ N-Acetyl Glucosamine Lectin } \\
\hline Phaseolus vulgaris Erythroagglutinin (PHA-E) & $\begin{array}{l}\text { Bisecting GlcNac } \beta 1-4 \text { and } \\
\text { terminalGal (Biantennary) }^{62}\end{array}$ \\
\hline Wheat germ agglutinin (WGA) & $\mathrm{GlcNac}^{63}$ \\
\hline \multicolumn{2}{|c|}{ Glucose and Mannose lectin } \\
\hline Concanavalin A (Con A) & aMan, aGlu 63 \\
\hline
\end{tabular}

Fucose Lectin

Aleuria aurantia lectin (AAL) Fuca1-6, a1-360

a $\mathrm{N}$-acetylneuraminic acid (NeuAc), galactose (Gal), N-acetylglucosamine ( GlcNAc), glucose (Glc), mannose (Man), fucose (Fuc). 


\subsection{References:}

1. Pfrengle, F., Synthetic plant glycans. Curr. Opin. Chem. Biol. 2017, 40, 145-151.

2. Gabius, H.-J., The sugar code: Why glycans are so important. BioSystems 2018, $164,102-111$.

3. Varki, A., Biological roles of oligosaccharides - All of the theories are correct. Glycobiology 1993, 3 (2), 97-130.

4. Hajba, L.; Csanky, E.; Guttman, A., Liquid phase separation methods for Nglycosylation analysis of glycoproteins of biomedical and biopharmaceutical interest. A critical review. Analytica Chimica Acta 2016, 943, 8-16.

5. Yamamoto, S.; Kinoshita, M.; Suzuki, S., Current landscape of protein glycosylation analysis and recent progress toward a novel paradigm of glycoscience research. Journal of Pharmaceutical and Biomedical Analysis 2016, 130, 273-300.

6. Jefferis, R., Glyco-Engineering of Human IgG-Fc to Modulate Biologic Activities. Curr. Pharm. Biotechnol. 2016, $17(15)$, 1333-1347.

7. Kailemia, M. J.; Park, D.; Lebrilla, C. B., Glycans and glycoproteins as specific biomarkers for cancer. Analytical and Bioanalytical Chemistry 2017, 409 (2), 395-410.

8. Planinc, A.; Bones, J.; Dejaegher, B.; Van Antwerpen, P.; Delporte, C., Glycan characterization of biopharmaceuticals: Updates and perspectives. Analytica Chimica Acta 2016, 921, 13-27.

9. Lu, G.; Crihfield, C. L.; Gattu, S.; Veltri, L. M.; Holland, L. A., Capillary Electrophoresis Separations of Glycans. Chemical Reviews 2018, 118 (17), 7867-7885. 
10. Gattu; S.; Crihfield, C. L.; Lu, G.; Bwanali, L.; Veltri, L. M.; Holland, L. A., Advances with enzyme substrate analysis with capillary electrophoresis. Methods, 2018.

11. Saldova, R.; Shehni, A. A.; Haakensen, V. D.; Steinfeld, I.; Hilliard, M.; Kifer, I.; Helland, A.; Yakhini, Z.; Borresen-Dale, A. L.; Rudd, P. M., Association of NGlycosylation with Breast Carcinoma and Systemic Features Using High-Resolution Quantitative UPLC. Journal of Proteome Research 2014, 13 (5), 2314-2327.

12. Guttman, A.; Ulfelder, K. W., Exoglycosidase matrix-mediated sequencing of a complex glycan pool by capillary electrophoresis. Journal of Chromatography A 1997, $781(1-2), 547-554$.

13. Laroy, W.; Contreras, R.; Callewaert, N., Glycome mapping on DNA sequencing equipment. Nature Protocols 2006, 1 (1), 397-405.

14. Callewaert, N.; Geysens, S.; Molemans, P.; Contreras, R., Ultrasensitive profiling and sequencing of $\mathrm{N}$-linked oligosaccharides using standard DNA-sequencing equipment. Glycobiology 2001, 11 (4), 275-281.

15. Uppal, S. S.; Beasley, S. E.; Scian, M.; Guttman, M., Gas-Phase Hydrogen/Deuterium Exchange for Distinguishing Isomeric Carbohydrate lons. Analytical Chemistry 2017, 89 (8), 4737-4742.

16. Re, S.; Watabe, S.; Nishima, W.; Muneyuki, E.; Yamaguchi, Y.; MacKerell, A. D.; Sugita, Y., Characterization of Conformational Ensembles of Protonated N-glycans in the Gas-Phase. Scientific Reports 2018, 8 (1), 1644.

17. Pu, Y.; Ridgeway, M. E.; Glaskin, R. S.; Park, M. A.; Costello, C. E.; Lin, C., Separation and Identification of Isomeric Glycans by Selected Accumulation-Trapped 
Ion Mobility Spectrometry-Electron Activated Dissociation Tandem Mass Spectrometry. Analytical Chemistry 2016, 88 (7), 3440-3443.

18. Mu, Y.; Schulz, L. B.; Ferro, V., Applications of Ion Mobility-Mass Spectrometry in Carbohydrate Chemistry and Glycobiology. Molecules 2018, 23 (10).

19. Hofmann, J.; Pagel, K., Glycan Analysis by Ion Mobility-Mass Spectrometry. Angewandte Chemie-International Edition 2017, 56 (29), 8342-8349.

20. Geyer, H.; Schmitt, S.; Wuhrer, M.; Geyer, R., Structural analysis of glycoconjugates by on-target enzymatic digestion and MALDI-TOF-MS. Analytical Chemistry 1999, 71 (2), 476-482.

21. Yang, Y.; Orlando, R., Simplifying the exoglycosidase digestion MALDI-MS procedures for sequencing N-linked carbohydrate side chains. Analytical Chemistry 1996, 68 (3), 570-572.

22. Mechref, Y.; Kang, P.; Novotny, M. V., Differentiating structural isomers of sialylated glycans by matrix-assisted laser desorption/ionization time-of-flight/time-offlight tandem mass spectrometry. Rapid Commun. Mass Spectrom. 2006, 20 (8), 13811389.

23. Huang, C.; Liu, Y.; Wu, H.; Sun, D.; Li, Y., Characterization of IgG glycosylation in rheumatoid arthritis patients by MALDI-TOF-MSn and capillary electrophoresis. Analytical and Bioanalytical Chemistry 2017, 409 (15), 3731-3739.

24. Guttman, M.; Varadi, C.; Lee, K. K.; Guttman, A., Comparative glycoprofiling of HIV gp120 immunogens by capillary electrophoresis and MALDI mass spectrometry. Electrophoresis 2015, 36 (11-12), 1305-1313. 
25. Snyder, C. M.; Alley, W. R., Jr.; Campos, M. I.; Svoboda, M.; Goetz, J. A.;

Vasseur, J. A.; Jacobson, S. C.; Novotny, M. V., Complementary Glycomic Analyses of Sera Derived from Colorectal Cancer Patients by MALDI-TOF-MS and Microchip Electrophoresis. Analytical Chemistry 2016, 88 (19), 9597-9605.

26. Mitra, I.; Snyder, C. M.; Zhou, X. M.; Campos, M. I.; Alley, W. R.; Novotny, M. V.; Jacobson, S. C., Structural Characterization of Serum N-Glycans by Methylamidation, Fluorescent Labeling, and Analysis by Microchip Electrophoresis. Analytical Chemistry 2016, 88 (18), 8965-8971.

27. Biacchi, M.; Gahoual, R.; Said, N.; Beck, A.; Leize-Wagner, E.; Francois, Y.N., Glycoform Separation and Characterization of Cetuximab Variants by Middle-up OffLine Capillary Zone Electrophoresis-UV/Electrospray Ionization-MS. Analytical Chemistry 2015, 87 (12), 6240-6250.

28. Kammeijer, G. S. M.; Jansen, B. C.; Kohler, I.; Heemskerk, A. A. M.; Mayboroda, O. A.; Hensbergen, P. J.; Schappler, J.; Wuhrer, M., Sialic acid linkage differentiation of glycopeptides using capillary electrophoresis - electrospray ionization mass spectrometry. Scientific Reports 2017, 7.

29. Snyder, C. M.; Zhou, X.; Karty, J. A.; Fonslow, B. R.; Novotny, M. V.; Jacobson, S. C., Capillary electrophoresis-mass spectrometry for direct structural identification of serum N-glycans. Journal of Chromatography A 2017, 1523, 127-139.

30. Zhong, X.; Chen, Z.; Snovida, S.; Liu, Y.; Rogers, J. C.; Li, L., Capillary Electrophoresis-Electrospray Ionization-Mass Spectrometry for Quantitative Analysis of Glycans Labeled with Multiplex Carbonyl-Reactive Tandem Mass Tags. Analytical Chemistry 2015, 87 (13), 6527-6534. 
31. Tzur, Y.; Markovich, A.; Lichtenstein, R. G., A two-dimensional array for simultaneous sequencing of $\mathrm{N}$ - and O-glycans and their glycoforms on specific glycosylation sites. Journal of Proteome Research 2008, 7 (3), 1188-1198.

32. Morelle, W.; Michalski, J. C., Sequencing of oligosaccharides derivatized with benzlyamine using electrospray ionization-quadrupole time of flight-tandem mass spectrometry. Electrophoresis 2004, 25 (14), 2144-2155.

33. Yu, C.-Y.; Mayampurath, A.; Zhu, R.; Zacharias, L.; Song, E.; Wang, L.; Mechref, Y.; Tang, H., Automated Glycan Sequencing from Tandem Mass Spectra of NLinked Glycopeptides. Analytical Chemistry 2016, 88 (11), 5725-5732.

34. Khatri, K.; Klein, J. A.; Haserick, J. R.; Leon, D. R.; Costello, C. E.; McComb, M. E.; Zaia, J., Microfluidic Capillary Electrophoresis Mass Spectrometry for Analysis of Monosaccharides, Oligosaccharides, and Glycopeptides. Analytical Chemistry 2017, 89 (12), 6645-6655.

35. Lancaster, K. S.; An, H. J.; Li, B.; Lebrilla, C. B., Interrogation of N-Linked Oligosaccharides Using Infrared Multiphoton Dissociation in FT-ICR Mass Spectrometry. Analytical Chemistry 2006, 78 (14), 4990-4997.

36. Williams, J. P.; Pringle, S.; Richardson, K.; Gethings, L.; Vissers, J. P. C.; De Cecco, M.; Houel, S.; Chakraborty, A. B.; Yu, Y. Q.; Chen, W.; Brown, J. M., Characterisation of glycoproteins using a quadrupole time-of-flight mass spectrometer configured for electron transfer dissociation. Rapid Communications in Mass Spectrometry 2013, 27 (21), 2383-2390.

37. Pabst, M.; Altmann, F., Glycan analysis by modern instrumental methods. Proteomics 2011, 11 (4), 631-643. 
38. Zhang, L.; Luo, S.; Zhang, B. L., Glycan analysis of therapeutic glycoproteins. Mabs 2016, 8 (2), 205-215.

39. Kinoshita, M.; Kakehi, K., Capillary-Based Lectin Affinity Electrophoresis for Interaction Analysis Between Lectins and Glycans. In Lectins: Methods and Protocols, Hirabayashi, J., Ed. 2014; Vol. 1200, pp 131-146.

40. Reatini, B. S.; Ensink, E.; Liau, B.; Sinha, J. Y.; Powers, T. W.; Partyka, K.; Bern, M.; Brand, R. E.; Rudd, P. M.; Kletter, D.; Drake, R.; Haab, B. B., Characterizing Protein Glycosylation through On-Chip Glycan Modification and Probing. Analytical Chemistry 2016, 88 (23), 11584-11592.

41. Rakus, J. F.; Mahal, L. K., New Technologies for Glycomic Analysis: Toward a Systematic Understanding of the Glycome. Annual Review of Analytical Chemistry 2011, 4 (1), 367-392.

42. Klamer, Z.; Staal, B.; Prudden, A. R.; Liu, L.; Smith, D. F.; Boons, G.-J.; Haab, B., Mining High-Complexity Motifs in Glycans: A New Language To Uncover the Fine Specificities of Lectins and Glycosidases. Analytical Chemistry 2017, 89 (22), 1234212350.

43. Mittermayr, S.; Guttman, A., Influence of molecular configuration and conformation on the electromigration of oligosaccharides in narrow bore capillaries. Electrophoresis 2012, 33 (6), 1000-1007.

44. Guttman, A.; Chen, F. T. A.; Evangelista, R. A., Separation of 1-aminopyrene3,6,8-trisulfonate-labeled asparagine-linked fetuin glycans by capillary gel electrophoresis. Electrophoresis 1996, 17 (2), 412-417. 
45. Jarvas, G.; Szigeti, M.; Guttman, A., GUcal: An integrated application for capillary electrophoresis based glycan analysis. Electrophoresis 2015, 36 (24), 30943096.

46. Jarvas, G.; Szigeti, M.; Chapman, J.; Guttman, A., Triple-Internal Standard Based Glycan Structural Assignment Method for Capillary Electrophoresis Analysis of Carbohydrates. Analytical Chemistry 2016, 88 (23), 11364-11367.

47. Guttman, A.; Kerekgyarto, M.; Jarvas, G., Effect of Separation Temperature on Structure Specific Glycan Migration in Capillary Electrophoresis. Analytical Chemistry 2015, 87 (23), 11630-11634.

48. Szigeti, M.; Guttman, A., High-Resolution Glycan Analysis by Temperature Gradient Capillary Electrophoresis. Analytical Chemistry 2017, 89 (4), 2201-2204.

49. Huffman, J. E.; Pucic-Bakovic, M.; Klaric, L.; Hennig, R.; Selman, M. H. J.;

Vuckovic, F.; Novokmet, M.; Kristic, J.; Borowiak, M.; Muth, T.; Polasek, O.;

Razdorov, G.; Gornik, O.; Plomp, R.; Theodoratou, E.; Wright, A. F.; Rudan, I.;

Hayward, C.; Campbell, H.; Deelder, A. M.; Reichl, U.; Aulchenko, Y. S.; Rapp, E.; Wuhrer, M.; Lauc, G., Comparative Performance of Four Methods for High-throughput Glycosylation Analysis of Immunoglobulin G in Genetic and Epidemiological Research. Molecular \& Cellular Proteomics 2014, 13 (6), 1598-1610.

50. Thiesler, C. T.; Cajic, S.; Hoffmann, D.; Thiel, C.; van Diepen, L.; Hennig, R.; Sgodda, M.; Weissmann, R.; Reichl, U.; Steinemann, D.; Diekmann, U.; Huber, N. M. B.; Oberbeck, A.; Cantz, T.; Kuss, A. W.; Koerner, C.; Schambach, A.; Rapp, E.; Buettner, F. F. R., Glycomic Characterization of Induced Pluripotent Stem Cells Derived 
from a Patient Suffering from Phosphomannomutase 2 Congenital Disorder of Glycosylation (PMM2-CDG). Molecular \& Cellular Proteomics 2016, 15 (4), 1435-1452.

51. Behne, A.; Muth, T.; Borowiak, M.; Reichl, U.; Rapp, E., glyXalign: Highthroughput migration time alignment preprocessing of electrophoretic data retrieved via multiplexed capillary gel electrophoresis with laser-induced fluorescence detectionbased glycoprofiling. Electrophoresis 2013, 34 (16), 2311-2315.

52. Hennig, R.; Cajic, S.; Borowiak, M.; Hoffmann, M.; Kottler, R.; Reichl, U.;

Rapp, E., Towards personalized diagnostics via longitudinal study of the human plasma N-glycome. Biochimica Et Biophysica Acta-General Subjects 2016, 1860 (8), 17281738.

53. https://sciex.com/products/consumables/fast-glycan-analysis-and-labeling-for-the-pa800-plus, accessed on October 29,2018.

54. https://www.neb.com/products/e0577-n-glycan-sequencing-kit\#Product\%20Information, accessed on October 29, 2018.

55. http://www.waters.com/waters/en US/GlycoWorks-RapiFluor-MS-N-Glycan-

Kit/nav.htm?cid=134828150\&locale=en US, accessed on October 29, 2018.

56. Gattu, S.; Crihfield, C. L.; Holland, L. A., Microscale Measurements of MichaelisMenten Constants of Neuraminidase with Nanogel Capillary Electrophoresis for the Determination of the Sialic Acid Linkage. Analytical Chemistry 2017, 89 (1), 929-936. 57. Varadi, C.; Mittermayr, S.; Millan-Martin, S.; Bones, J., Quantitative twoplex glycan analysis using $12 \mathrm{C} 6$ and $13 \mathrm{C} 6$ stable isotope 2 -aminobenzoic acid labelling and capillary electrophoresis mass spectrometry. Anal. Bioanal. Chem. 2016, 408 (30), 8691-8700. 
58. Varadi, C.; Lew, C.; Guttman, A., Rapid Magnetic Bead Based Sample Preparation for Automated and High Throughput N-Glycan Analysis of Therapeutic Antibodies. Anal. Chem. (Washington, DC, U. S.) 2014, 86 (12), 5682-5687.

59. Cornish-Bowden, A., Fundamentals of enzyme kinetics, fourth edition.

Butterworths: London; Boston, 2012, pp. 28-31.

60. Iskratsch, T.; Braun, A.; Paschinger, K.; Wilson, I. B. H., Specificity analysis of lectins and antibodies using remodeled glycoproteins. Analytical Biochemistry 2009, $386(2), 133-146$.

61. Knibbs, R. N.; Goldstein, I. J.; Ratcliffe, R. M.; Shibuya, N., Charecterization of the carbohydrate binding - specificity of the leukoagglutinating lectin from MaackiaAmurensis-comparision with other sialic acid-specific lectins. Journal of Biological Chemistry 1991, 266 (1), 83-88.

62. Cummings, R. D.; Kornfeld, S., Charecterization of the structural determinants required for the high - affinity interaction of aspargine linked oligosaccharides with immobilized Phaseolus-Vulgaris leukoaglutinating and erythroagglutinating lectins. Journal of Biological Chemistry 1982, 257 (19), 1230-1234.

63. Debray, H.; Decout, D.; Strecker, G.; Spik, G.; Montreuil, J., Specificty of 12 lectins towards oligosaccharides and glycopeptides related to N-glycosylproteins. European Journal of Biochemistry 1981, 117 (1), 41-55. 
Chapter 2: Microscale Measurements of Michaelis-Menten Constants of Neuraminidase with Nanogel Capillary Electrophoresis for the Determination of the Sialic Acid Linkage

Reproduced from ${ }^{1}$

Gattu, S.; Crihfield, C. L.; Holland, L. A., Microscale Measurements of Michaelis - Menten

Constants of Neuraminidase with Nanogel Capillary Electrophoresis for the

Determination of Sialic Acid Linkage. Analytical Chemistry 2017, 89 (1), 929-936 


\subsection{Introduction}

Sialic acids, the common name for $\mathrm{N}$-acetyl neuraminic acids, are the terminal monomer on the non-reducing end of glycans. Sialic acids and enzymes associated with their synthesis or catabolism are involved in a number of cellular processes ${ }^{2}$ and are implicated in physiological dysfunctions including cancer, ${ }^{3-6}$ antibody function ${ }^{7}$ and inflammation. ${ }^{8}$ In proteins, asparagine-linked glycans contain a common core structure,$^{9}$ such that when sialic acids are present they are adjacent to a galactose residue. These sialic acidgalactose sequences are linked from carbon 2 on the sialic acid to carbon 3 or 6 on the adjacent monomer. The position of this linkage is relevant to cancer ${ }^{10}$ and as a result, the linkage chemistry is monitored. Although there is a critical need for routine sialic acid determinations, the challenges of linkage analysis, isomerization, and data interpretation make structural assignment difficult using current analytical technologies.

Oligosaccharides have been identified using bench-top sequencing with enzymes, but this requires a considerable amount of exoglycosidase and substantial incubation time. ${ }^{11-}$

15 The cost, stability, and sample preparation related to the use of the enzyme are limiting factors. Ultimately, separation strategies that reduce the sample handling and sample volume are critical. Micro-flow systems can efficiently screen chemical processes, are more stream-lined to develop and optimize reactions, and are used to predict the success of scaling up a method. There are a few barriers to rapidly assessing enzymatic processing on the microscale, which include the cost and lifetime of enzyme preparations. These barriers can be overcome with immobilized enzymes, which have increased 
stability and can have enhanced performance. ${ }^{16}$ Methods of covalent enzyme immobilization require mild derivatization conditions and extensive optimization. This has led to the development of new strategies to physically confine enzymes without covalent modification. ${ }^{17,18}$

To realize the full potential of enzymes in chemical assays, enzymes must be manipulated on the microscale without immobilization. In addition, the rate of enzyme catalysis must be established for different reaction conditions because the enzyme rate is specific for each substrate, and it is dependent upon the conditions used for the enzymatic reaction. Precise knowledge of enzyme activity can be quantified as Michaelis-Menten constants $\left(\mathrm{K}_{\mathrm{M}}\right)$ and it is important to harnessing enzymes for biomolecule recognition, sequencing, and assessment. With this information, enzyme-based microscale analyses have the potential to shed light on the relationship between the biomolecular structure of the substrate and enzyme function. However, new analytical tools that stabilize enzyme performance and consume small quantities of enzyme in shorter analyses times are required.

Capillary electrophoresis has been adapted to utilize enzymes to improve detection limits and separation specificity with electrophoretically mediated microanalysis, commonly referred to as EMMA. ${ }^{19}$ This method relies upon differences in electrophoretic mobility of enzyme, substrate, and ligand for the analysis. EMMA is rapid, consumes nanoliter volumes of enzyme, and is reported extensively $y^{20-23}$ as a method to enhance detection limits or provide indirect detection. While not as prevalent, the use of EMMA to determine 
$\mathrm{K}_{\mathrm{M}}$ is feasible if the electrophoretic differences of analyte, enzyme and product facilitate separation, the enzyme remains in the native state, and enzyme does not adsorb to the capillary surface. Significant optimization is required to ensure that the incubation conditions are compatible with the electrophoresis, and exquisite strategies to address this optimization have been described. ${ }^{24-26}$ These barriers are overcome with the use of phospholipid nanogels, which self-assemble to form a thermally-responsive material that is suitable as a replaceable gel to sieve DNA in capillary electrophoresis, ${ }^{27,}{ }^{28}$ as a viscosity switch to close and open channels in microfluidics, ${ }^{29,}, 30$ and as a viscous additive to improve capillary electrophoresis separations of oligosaccharides. ${ }^{31-33}$ Nanogels are biocompatible materials that immobilize and pattern enzymes in microscale channels.

This paper outlines a new approach to EMMA that utilizes nanogels to physically constrain an enzyme in a separation capillary. Reconstitution of the neuraminidase enzyme in nanogel at low concentration results in a longer lifetime upon storage. This provides a means to cost-effectively use a single enzyme stock solution to deliver the sub nanoliter volumes required for the capillary method. An electrophoretic mixing method is developed to circumvent diffusion limitation of static incubation. For the first time, nanogels are harnessed to precisely quantify the Michaelis-Menten constants of an enzyme with different degrees of stereospecificity in the presence of substrates with different linkage positions. The trisaccharide sialyllactose, which is $\mathrm{O}-(\mathrm{N}$-acetyl- $\alpha$ neuraminosyl)-[2 $\rightarrow 3$ (or $2 \rightarrow 6$ )]-O- $\beta$-D-galactopyranosyl-(1 $\rightarrow 4$ )-Dglucose, is used as a model substrate to characterize neuraminidase. The different catalysis rates obtained for sialic acid residues with $2-3$ or 2-6 linkages are used to analyze the linkage position 
of a mixture of $2-3$ and 2-6 sialyllactose and in the sialylated triantennary glycan substrate mixture that contained both Gal $\beta(1-3)$ GlcNAc and Gal $\beta(1-4)$ GlcNAc. Similar results are achieved when a specific and nonspecific enzyme are used. The approach extends the nanogel separation method to general as well as specific enzymes.

\subsection{Materials and Methods}

\subsubsection{Chemicals and Reagents}

The 3'-sialyllactose and 6'-sialyllactose were from Carbosynth (Berkshire, UK). The phospholipids 1,2-dimyristoyl-sn-glycero-3-phosphocholine (DMPC) and 1,2-dihexanoylsn-glycero-3-phosphocholine (DHPC), were from Avanti Polar Lipids (Alabaster, AL). Glyko tri-sialylated, galactosylated, triantennary complex N-glycan was from Prozyme (Hayward, CA). Acetic acid was from Fisher Scientific (Pittsburgh, PA). Lactose, 3-(Nmorpholino)-propanesulfonic acid, 8-aminopyrene-1,3,6-trisulfonic acid, 2-aminobenzoic acid, triethylamine, acetonitrile, methanol, sodium cyanoborohydride, sodium cyanoborohydride (dissolved in tetrahydrofuran), and general neuraminidase (\#N-2876) were from Sigma-Aldrich (St. Louis, MO). The neuraminidase specific for $\alpha 2-3$ (GE-20 and E-S007) was from QA Bio (Palm Desert, CA). Deionized water was from an Elga Purelab ultra water system (Lowell, MA).

\subsubsection{Preparation and Derivatization of Standards}

Enzyme studies with an anticipated $\mathrm{K}_{\mathrm{M}}$ in the $\mathrm{mM}$ range require that oligosaccharide substrate concentrations in the $\mathrm{mM}$ range be used to obtain a Michaelis-Menten curve. 
For the $\mathrm{K}_{\mathrm{M}}$ studies, the substrate was labeled with a chromophore detected by UV-visible absorbance. The chromophore 2-aminobenzoic acid was used as a reagent to label the oligosaccharides as reported previously. ${ }^{34}$ The reaction was performed with excess label to ensure $100 \%$ labeling efficiency to prevent any bias in the $\mathrm{K}_{\mathrm{M}}$ measurement. If the labeling reaction was not complete, then the concentration of the labeled substrate that was UV-absorbing would have been less than the total concentration of substrate (i.e. the combination of labeled and unlabeled substrate) and would confound the measurement of $K_{M}$. A ratio of $1400 \mathrm{nmol}$ 2-aminobenzoic acid: $200 \mathrm{nmol}$ sialyllactose (7:1) was achieved by reacting $1 \mu \mathrm{L}$ volume of $0.2 \mathrm{M}$ saccharide dissolved in water with $1 \mu \mathrm{L}$ volume of $1.39 \mathrm{M} \mathrm{2-aminobenzoic} \mathrm{acid} \mathrm{and} 23 \mu \mathrm{L}$ volume of $1 \mathrm{M}$ sodium cyanoborohydride at 65 ${ }^{\circ} \mathrm{C}$ for $2 \mathrm{~h}$ in $0.5 \mathrm{M}$ acetic acid (glacial acetic acid diluted with methanol). Once the reaction was complete the reaction mixture was evaporated to dryness on a Savant SpeedVac concentrator (Thermo Scientific, Waltham, MA). Excess 2-aminobenzoic acid was removed from the labelling reaction using a Discovery DPA-6S solid phase extraction cartridge (50 mg packing material, Supelco, Bellefonte, PA) with slight modifications to a previously established literature procedure. ${ }^{32}$ Specifically, once the sample was loaded in the extraction cartridge, the 2-aminobenzoic acid was eluted using $10-\mathrm{mL}$ of $95 \%$ acetonitrile, $5 \%$ aqueous $1 \mathrm{mM}$ triethylamine and the retained sugars were eluted from the cartridge using 3-mL of aqueous $25 \mathrm{mM}$ triethylamine. To ensure that all of the sialyllactose was labeled and recovered from the purification process, it was compared against a second reaction performed with excess sialyllactose as described in the determination of labelling efficiency. 


\subsubsection{Determination of Labeling Efficiency}

To ensure that all of the sialyllactose was labeled and recovered from the purification process, the amount of labeled sialyllactose was compared against that obtained with a second reaction performed with excess sialyllactose (1:50 2-aminobenzoic acid:sialyllactose) with no sample cleanup. The amount of labeled sialyllactose was quantified using the method of standard addition with capillary electrophoresis and UVvisible absorbance detection. Standard addition was accomplished by spiking three equivalent fractions of the 1:50 2-aminobenzoic acid:sialyllactose reaction with three different concentrations $(250,500,750 \mu \mathrm{M})$ of the purified sialyllactose obtained from the 7:1 2-aminobenzoic acid:sialyllactose reaction. To avoid bias due to differences in salt concentration, the samples were introduced with hydrodynamic injections at $3.5 \mathrm{kPa}(0.5$ psi) for $5 \mathrm{~s}$. A concentration of $500 \pm 20 \mu \mathrm{M}$ was experimentally obtained for a reaction expected to produce $500 \mu \mathrm{M}$ sialyllactose as it had been reacted at a ratio of 1:50 2aminobenzoic acid:sialyllactose.

Studies designed to distinguish the linkage position of sialyllactose or glycan were accomplished with substrate concentrations in the $\mathrm{nM}$ range. For these linkage position studies the substrate was labeled with a chromophore detected by fluorescence. The fluorescently conjugated oligosaccharides and glycans were labeled as previously described ${ }^{35}$ with slight modifications. Glycan labeling was accomplished using $100 \mathrm{mM}$ 8-aminopyrene-1,3,6-trisulfonic acid in $20 \%$ acetic acid for a reaction of $7 \mathrm{nmol}$ glycan: $250 \mathrm{nmol}$ dye in a total reaction volume of $5 \mu \mathrm{L}$. The labeled glycan sample was purified 
using a 1kDa molecular weight cutoff filter (\#MCP001C41, Pall Corporation, Ann Arbor, MI). Sialyllactose labeling was accomplished using $100 \mathrm{mM}$ 8-aminopyrene-1,3,6trisulfonic acid in $20 \%$ acetic acid for a reaction of $5 \mathrm{nmol}$ glycan: $250 \mathrm{nmol}$ dye in a total reaction volume of $5 \mu \mathrm{L}$. The labeled sialyllactose samples were purified using the DPA$6 S$ column as described for labeling with 2-aminobenzoic acid. Once purified, the samples were dried in a SpeedVac concentrator before reconstituting to $100 \mu \mathrm{L}$ in water and storing at $-20^{\circ} \mathrm{C}$.

Neuraminidase in powder is reconstituted to a concentration of $33.6 \mathrm{mUnits} / \mu \mathrm{L}$ in $50 \mathrm{mM}$ potassium phosphate with the $\mathrm{pH}$ adjusted to 5.2 using $1 \mathrm{M}$ sodium hydroxide. The appropriate volume of master stock (i.e. less than or equal to $0.52 \mu \mathrm{L}$ ) is diluted with $10 \%$ nanogel to a final volume of $50 \mu \mathrm{L}$. For both neuraminidase enzymes 1 Unit is defined as the amount of enzyme required to produce $1 \mu$ mole of methylumbelliferone in $1 \mathrm{~min}$ at $37^{\circ} \mathrm{C}, \mathrm{pH} 5.0$ from 2'-(4-methyl-umbelliferyl)-alpha-D-N acetylneuraminic acid. ${ }^{36,37}$

\subsubsection{Capillary Electrophoresis}

Analyses were performed using a P/ACE MDQ or MDQ Plus (Sciex, Redwood City, CA) configured by the manufacturer with laser induced fluorescence detection $(3 \mathrm{~mW}$ air cooled argon ion laser or $3 \mathrm{~mW}$ solid state laser, with $\lambda_{\mathrm{ex}}=488 \mathrm{~nm}, \lambda_{\mathrm{em}}=520 \mathrm{~nm}$ ) and a photodiode array or UV-visible absorbance detector (monitored at $214 \mathrm{~nm}$ ). A $25 \mu \mathrm{m}$ internal diameter, $360 \mu \mathrm{m}$ outer diameter fused silica capillary (Polymicro Technologies, Phoenix, AZ) was used for separation. Each day capillaries were prepared as previously reported. ${ }^{33}$ Unless otherwise noted, the background electrolyte was $100 \mathrm{mM} 3-(\mathrm{N}$ - 
morpholino)-propanesulfonic acid buffered to $\mathrm{pH}$ 7. Phospholipids were prepared as described previously, aliquoted, and stored at $-20{ }^{\circ} \mathrm{C} .3^{32,} 33,38$ The phospholipid preparation that is $q=2.5$ (i.e. [DMPC]:[DHPC] $=2.5$ ) and $10 \%$ phospholipid by weight has low viscosity below the gel phase transition temperature and is easily introduced in the capillary at a temperature of $19^{\circ} \mathrm{C}$ or lower. Prior to each run the capillary was held at $19{ }^{\circ} \mathrm{C}$ and prepared as previously reported ${ }^{32}$ with slight modification as described in the methods. Data collection and analysis were performed using 32 Karat Software version 7.0 (MDQ) or 10.2 (MDQ Plus). The Michaelis-Menten curves were fit using GraphPad Prism version 4.03 (San Diego, CA).

For Michaelis-Menten studies, the fixed enzyme zone was introduced at $69 \mathrm{kPa}$ (10 psi) for $7 \mathrm{~s}$ followed by injection of background electrolyte at $138 \mathrm{kPa}(20 \mathrm{psi})$ for $15 \mathrm{~s}$. For glycan analyses, this protocol was modified to include a flush of $10 \%$ phospholipid at 172 $\mathrm{kPa}(25 \mathrm{psi})$ for $3 \mathrm{~min}$ prior to loading the nanogel-enzyme zone at $69 \mathrm{kPa}$ (10 psi) for 7 $\mathrm{s}$ and background electrolyte at $69 \mathrm{kPa}(10 \mathrm{psi})$ for $45 \mathrm{~s}$. The purpose of the $45 \mathrm{~s}$ introduction of background electrolyte was to push the enzyme to the thermostable region of the capillary. The amount of enzyme in the nanogel required for the separation is 15 $\mu \mathrm{L}$ if a PCR vial is used, or $5 \mu \mathrm{L}$ if lower volume vials from the instrument manufacturer are used (Sciex nanovials product number 5043467). After the capillary was filled, the temperature of the separation was increased to $37^{\circ} \mathrm{C}$ for the sample injection, incubation, and separation. Injections included a background electrolyte pre-plug of $6.9 \mathrm{kPa}(1.0 \mathrm{psi})$ for $7 \mathrm{~s}$ and a background electrolyte post-plug of $3.4 \mathrm{kPa}(0.5 \mathrm{psi})$ for $5 \mathrm{~s}$. After a run was complete, a $172 \mathrm{kPa}(25 \mathrm{psi})$ background electrolyte flush for five min was applied in the 
reverse direction to push out any remaining protein toward the site of injection. Ambient thermal control of the room and instrument was maintained using a portable air conditioner described previously

\subsection{Results and Discussion}

\subsubsection{Patterning Enzyme in Capillary}

The nanogel fixed enzyme zone was achieved by creating a pseudo-stationary enzyme plug in phospholipid nanogel, as depicted in Figure 2-1. Enzyme prepared in the nanogel was introduced into the capillary at $19^{\circ} \mathrm{C}$, which was a temperature that maintains fluidlike viscosity of the material. ${ }^{29,} 30$ At this temperature, the enzyme was positioned in the thermally controlled region of the capillary to ensure that the desired temperature was maintained during analyses. The temperature was then increased to $37^{\circ} \mathrm{C}$ to form a viscous ge ${ }^{29}$ that maintained the enzyme position within the capillary and supported the enzyme reaction. Two model substrates, sialyllactose with different linkages shown in Figure 2-1, were used. Once the fixed enzyme zone was patterned in the capillary, as seen in Figure 2-1, the substrate was electrokinetically driven into the enzyme zone. Following incubation substrate was then separated from product (Figure 2-1). The catalysis rate of neuraminidase was quantified by monitoring the conversion of substrate to the lactose product (Figure 2-1). 
1. inject 2 incubate in enzyme 3 3. separate, quantify

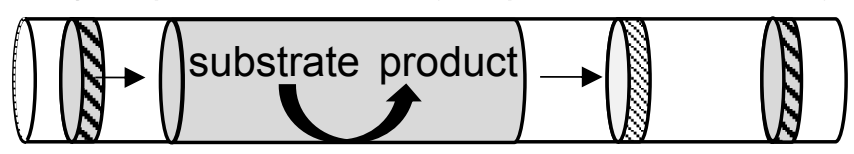

product substrate

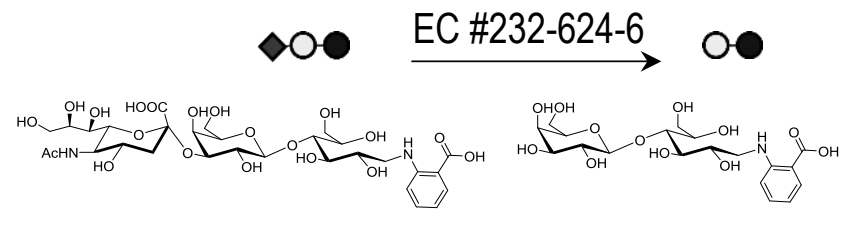

3' substrate product

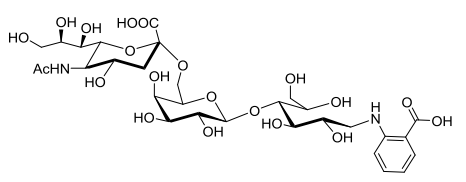

6' substrate

Figure 2.1 Depiction of electrophoretic migration of substrate in-capillary containing enzyme in a fixed zone. The 3'- or 6'-sialyllactose was incubated in enzyme and converted to lactose. The nonreducing end of the oligosaccharide was labeled with a chromophore (e.g. 2-aminobenzoic acid, for UV-absorbance detection). Figure reproduced from [1]. Copyright 2017 American Chemical Society

The separation of sialyllactose and lactose did not require the use of phospholipid nanogel to resolve these analyte peaks. Therefore, the fixed enzyme zone was embedded in an aqueous background electrolyte solution of $100 \mathrm{mM}$ background electrolyte buffered to $\mathrm{pH}$ 7. The position of the enzyme zone within the capillary was established by migrating the substrate to a particular position, incubating substrate with enzyme, and then separating and quantifying the peak areas of the substrate and 
enzymatically generated product. The substrate positions that generated larger product peak area coincided with the position of the enzyme zone, as summarized in Figure 2-2. With the position of the enzyme zone established, the impact of nanogel on the enzyme catalysis rate was determined.

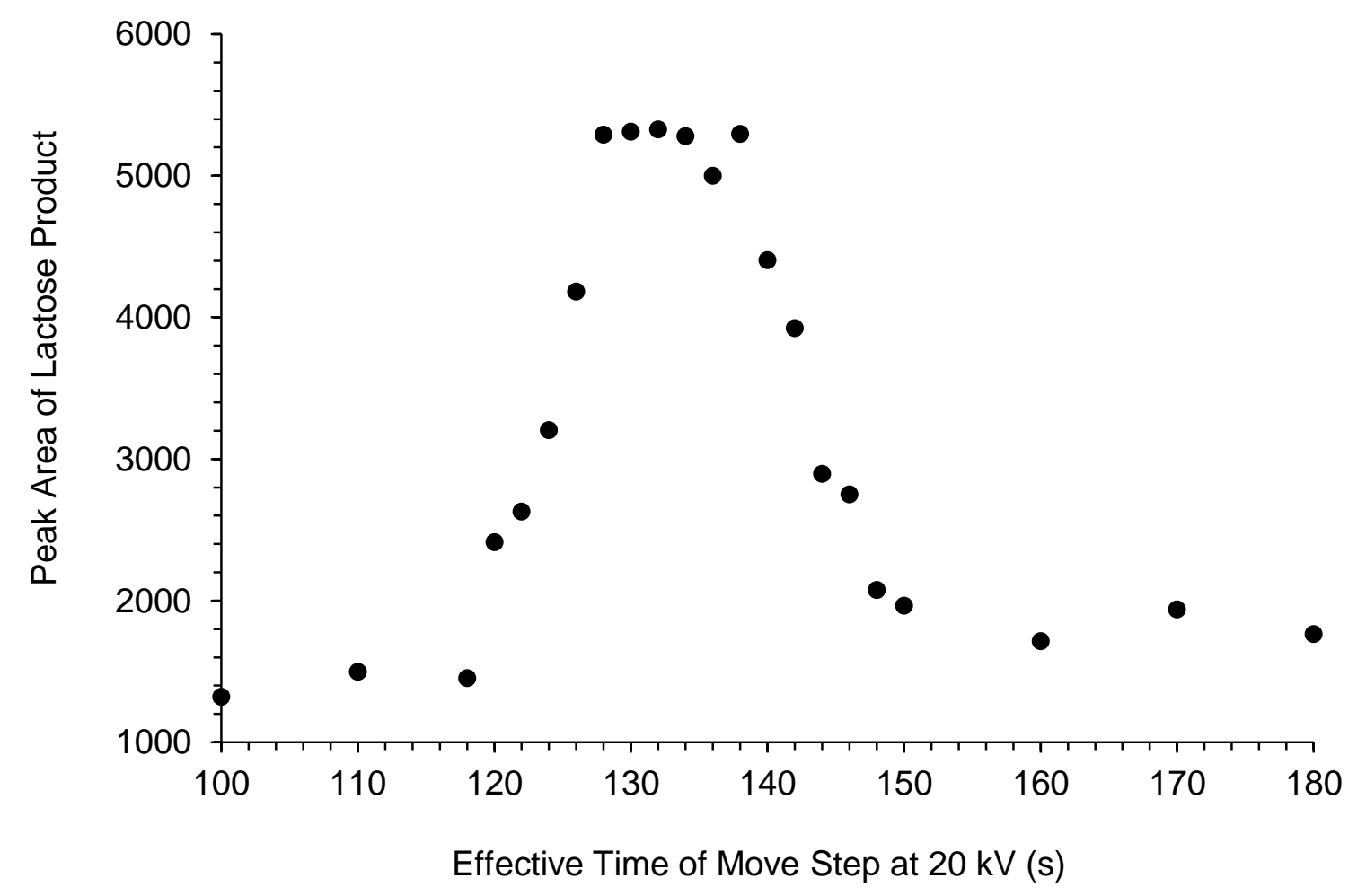

Figure 2.2 Demonstrates the use of $3.4 \mathrm{mM}$ 3'-sialyllactose to identify the beginning and end of the fixed enzyme zone. In each study the substrate was electrokinetically migrated into the capillary and incubated for 30 seconds $\left(37^{\circ} \mathrm{C}\right)$ in $336 \mu \mathrm{Units} / \mu \mathrm{L} \alpha 2-3,6,8,9$ neuraminidase suspended in phospholipid nanogel. The position was changed and the amount of product generated quantified. Separations were performed at $37^{\circ} \mathrm{C}$ in a $25 \mu \mathrm{m}$ i.d. capillary, with an effective length of $30 \mathrm{~cm}$ and $E=500 \mathrm{~V} / \mathrm{cm}$ (reverse polarity). Figure reproduced from [1]. Copyright 2017 American Chemical Society 


\subsubsection{Effect of Phospholipid Nanogel on Enzyme Performance}

Proteins are reconstituted in a variety of additives to maintain structure and function. ${ }^{39-42}$ These additives influence both stability and activity in a complex manner. ${ }^{43}$ Phospholipids are used widely to reconstitute membrane proteins. ${ }^{44}$ Physical constraint of enzymes with lipids has been reported using edge stabilized phospholipid nanodiscs to study enzyme catalysis of membrane protein. ${ }^{45,46}$ Although phospholipids are used to eliminate non-specific adsorption of proteins to surfaces, ${ }^{47-49}$ they are underexplored as an additive for soluble proteins.

To evaluate the effect of phospholipid nanogel on neuraminidase, the enzyme performance was monitored either in traditional aqueous solution of $50 \mathrm{mM}$ potassium phosphate adjusted to a $\mathrm{pH}$ of 5.2 with sodium hydroxide or nanogel comprised of phospholipid dissolved in the same aqueous solution. The preparations of neuraminidase were diluted to a concentration of 350,250 , or $150 \mu \mathrm{Units} / \mu \mathrm{L}$, and the enzyme activity was evaluated by quantifying the rate of conversion of sialyllactose substrate to lactose. The rates summarized in Figure 2-3 demonstrated that in the presence of nanogel the enzyme retained high activity for the 30-day period regardless of concentration. The stability of the enzyme diluted in the aqueous buffer was concentration-dependent. The $350 \mu \mathrm{Units} / \mu \mathrm{L}$ did not change (Figure 2-3A). However, the $250 \mu$ Units $/ \mu \mathrm{L}$ (Figure 2-3B) and $150 \mu \mathrm{Units} / \mu \mathrm{L}$ (Figure 2-3C) enzyme solutions decreased in activity until there was no detectable activity on day 3 and 1 , respectively. The reaction velocity of 350,250 , and $150 \mu \mathrm{Units} / \mu \mathrm{L}$ enzyme was $1100 \pm 50,830 \pm 50$, and $500 \pm 40$, respectively. At the highest concentration (i.e. $350 \mu \mathrm{Units} / \mu \mathrm{L}$ ), the reaction velocity in nanogel was 1.5 times higher 
than the reaction velocity in aqueous electrolyte $(750 \pm 60 \mu \mathrm{M}$ lactose/min $)$. For the lower enzyme concentrations the reaction velocity in nanogel as compared to that obtained in aqueous electrolyte on day 1 was $1.7(500 \pm 10 \mu \mathrm{M}$ lactose/min), and $2.5(200 \pm 10 \mu \mathrm{M}$ lactose/min) times higher. These findings were in agreement with literature evidence that phospholipid monolayers improve the performance of exoglycosidase enzymes including galactosidase ${ }^{50-52}$ and neuraminidase.$^{53}$ The improvement in stability observed at the lower enzyme concentration may be due to molecular crowding. The compaction of the enzyme by molecules in the solution maintained enzyme in a folded state and impacted the enzyme rate if the effective concentration of active protein was increased. ${ }^{54,55}$ The activity of protein at low concentration is independent of its own concentration and it is dependent upon size, shape and concentration of other macromolecules. The confinement can enhance the tendency to compact particles and affect chemical potential and reactivity. In addition, phospholipids provide the hydrophilic and hydrophobic interactions required for an enzyme to keep in its confirmation and improving stability. 
A.

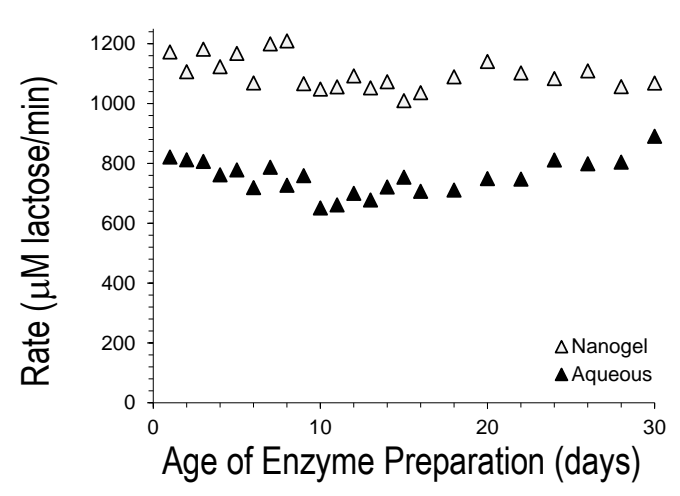

B.

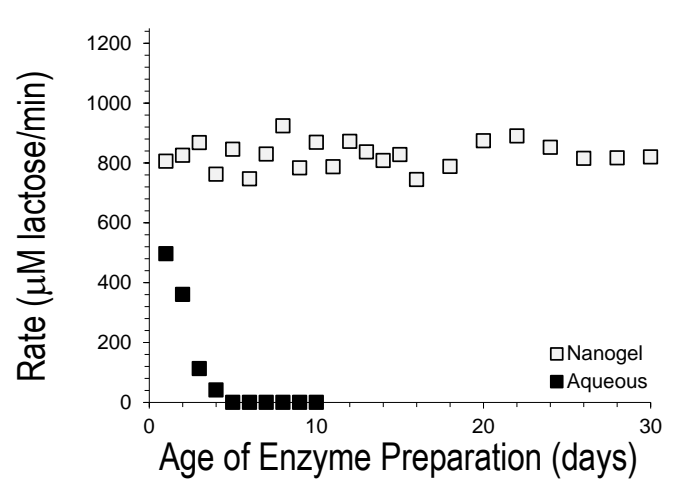

c.

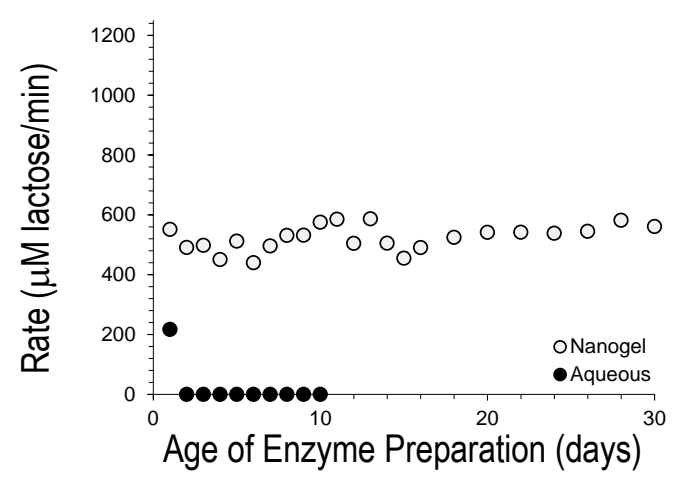

Figure 2.3 Plot of enzyme activity. Substrate was incubated in $\alpha 2-3,6,8,9$ neuraminidase suspended in phospholipid nanogel $(10 \%$ lipid with [DMPC]/[DHPC] = 2.5 in $50 \mathrm{mM}$ potassium phosphate $\mathrm{pH}$ adjusted to 5.2 with sodium hydroxide) or in the same aqueous solution devoid of phospholipid at an enzyme concentration of 350

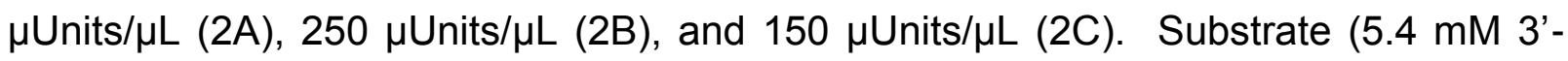
sialyllactose) was incubated in enzyme for $2 \min$ at $37^{\circ} \mathrm{C}$ and separated. Separations were performed at $37^{\circ} \mathrm{C}$ in a $25 \mu \mathrm{m}$ i.d. capillary, with an effective length of $30 \mathrm{~cm}$ and $\mathrm{E}=500 \mathrm{~V} / \mathrm{cm}$ (reverse polarity). Figure reproduced from [1]. Copyright 2017 American Chemical Society 


\section{Optimizing Incubation Times in the Fixed Enzyme Zone:}

When enzyme catalysis was performed in-capillary using static incubations, the measured velocity (Table 2-1) decreased with increasing incubation time. The hypothesis regarding this observation is that it is due to diffusion limited incubation. When substrate molecules are allowed to incubate, the substrate molecules are moving by Brownian motion, and the diffusion of substrate is important for enzyme reaction to occur. It is also assumed that the decreasing rate of product formation observed with increasing incubation time is due to product accumulation and formation of a substrate depletion layer near each enzyme. In addition, some exoglycosidases function as hydrolase and transferases, conjugating the liberated monosaccharide back to a oligosaccharide

terminus or glycan. ${ }^{56,57}$ This assumption is based on the fact that this enzyme is not behaving like transferase. A literature search in Scifinder database was conducted using terms (Does neuraminidase from clostridium perfringens acts as a transferase, Does sialidase from clostridium perfringens acts as a transferase) and found other enzymes that act as transferase but not this particular enzyme. This change in rate of product formation observed with different static incubation times posed a barrier to the quantitative determination of enzyme performance (i.e. $\mathrm{K}_{M}$ values) because enzyme rates must be consistent with different incubation times. 
Table 2.1 Effect of Substrate Delivery on Rate

\begin{tabular}{|c|c|c|}
\hline 40 & $13.9 \pm 0.6$ & $9.9 \pm 0.9$ \\
\hline 60 & $11.6 \pm 0.3$ & $9.5 \pm 0.5$ \\
\hline 100 & $8.4 \pm 0.3$ & $8.5 \pm 0.4$ \\
\hline 200 & $7.3 \pm 0.1$ & $8.4 \pm 0.5$ \\
\hline$A v e^{4}$ & $10 \pm 3(30 \%)$ & $9.1 \pm 0.7(9 \%)$ \\
\hline \multicolumn{3}{|c|}{$\begin{array}{l}\text { 'data are averages }(n=3) \text { using } 5.4 \mathrm{mM} 3 \text { 'sialyllactose } \\
\text { labeled with } 2 \text {-aminobenzoic acid and } 336 \mu \text { Units } \mu \mathrm{L} \alpha 2- \\
3,6,8,9 \text { neuraminidase in nanogel at } 37^{\circ} \mathrm{C} \\
2^{2} \text { incubation performed with } \mathrm{E}=0 \mathrm{~V} / \mathrm{cm} \text { after driving the } \\
\text { substrate to center of the fixed enzyme zone } \\
3 \text { performed by electrophoresing substrate through the } \\
\text { enzyme with } \mathrm{E}=250 \mathrm{~V} / \mathrm{cm} \text { for multiple forward }(\mathrm{F}) \text { and } \\
\text { reverse }(\mathrm{R}) \text { passes of: } 40 \mathrm{sec}(20 \mathrm{~F}-10 \mathrm{R}-10 \mathrm{~F}), 60 \mathrm{sec} \\
(20 \mathrm{~F}-20 \mathrm{R}-20 \mathrm{R}), 100 \mathrm{sec}\left([20 \mathrm{~F}-20 \mathrm{R}]_{2}-20 \mathrm{~F}\right) \text { or } 200 \mathrm{sec} \\
\left.\text { ([20F-20R }]_{4}-20 \mathrm{~F}-10 \mathrm{R}-10 \mathrm{~F}\right) \\
{ }_{\text {data are averages of rates at } 4 \text { incubation times }} \\
\text { Copyright } 2017 \text { American Chemical Society }\end{array}$} \\
\hline
\end{tabular}

In nanogel electrophoresis, the limitations of diffusion-based transport of substrate and product were overcome by electrophoretic mixing. In this electrophoretic mixing approach, the sustained contact between substrate and enzyme was achieved by alternating the polarity of the applied voltage to reversibly drive the substrate through the enzyme zone as depicted in Figure 2-4. This electromigration is a form of stirring or mixing and eliminates, depletion layers as the substrate is moving continuously back and forth in the enzyme plug. The electrophoretic mixing overcomes the performance of static incubation by which the rate of product formation decreases with time. 


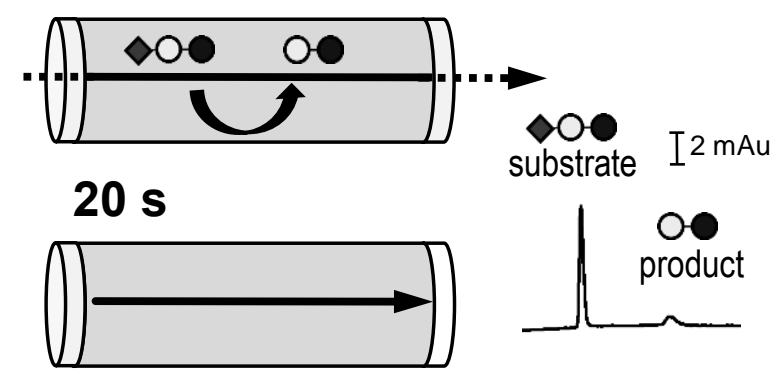

\section{0 s mixing}
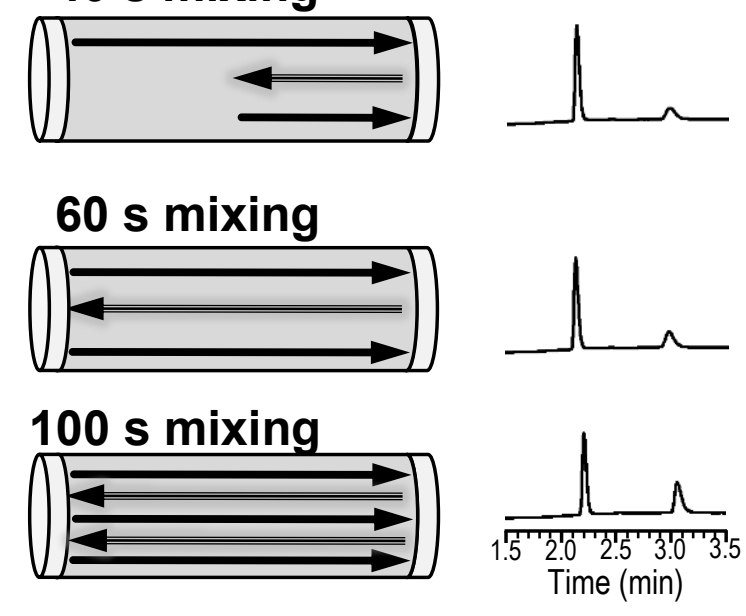

Figure 2.4 Conceptual diagrams of multi-pass electrophoretic mixing for control of the incubation time in the enzyme. The mixing duration was determined by the total time the substrate passes through the zone. Mixing may require that passes of different times are combined as in the case of a 40 second incubation. The position of the arrows in zone are conceptual and do not imply that the substrate traversed from the top of the zone to the bottom with each successive pass. The electropherograms were obtained using substrate of $5.4 \mathrm{mM}$ 3 '-sialyllactose and $336 \mu \mathrm{Units} / \mu \mathrm{L}$ of $\alpha 2-3,6,8,9$ neuraminidase that was suspended in phospholipid nanogel. Experimental conditions as described in Figure 2-3. Figure reproduced from [1]. Copyright 2017 American Chemical Society

The number of passes and length of each pass were selected to achieve the desired incubation time. The process of mixing in the fixed zone was feasible when the position of the enzyme was profiled in the capillary to determine the zone boundaries as 
summarized in Figures 2-2. The rate of enzyme catalysis increased with the electrophoretic velocity due to the increased probability of enzyme-substrate collision. An Ohm's law plot was performed as shown in Figure 2-5 to confirm that this was not due to Joule heating. As summarized in Table 2-1, electrophoretic mixing generated catalysis with a precision of $9 \%$ relative standard deviation for 4 different electrophoretic sweep times as compared to $30 \%$ relative standard deviation for 4 different static incubation times.

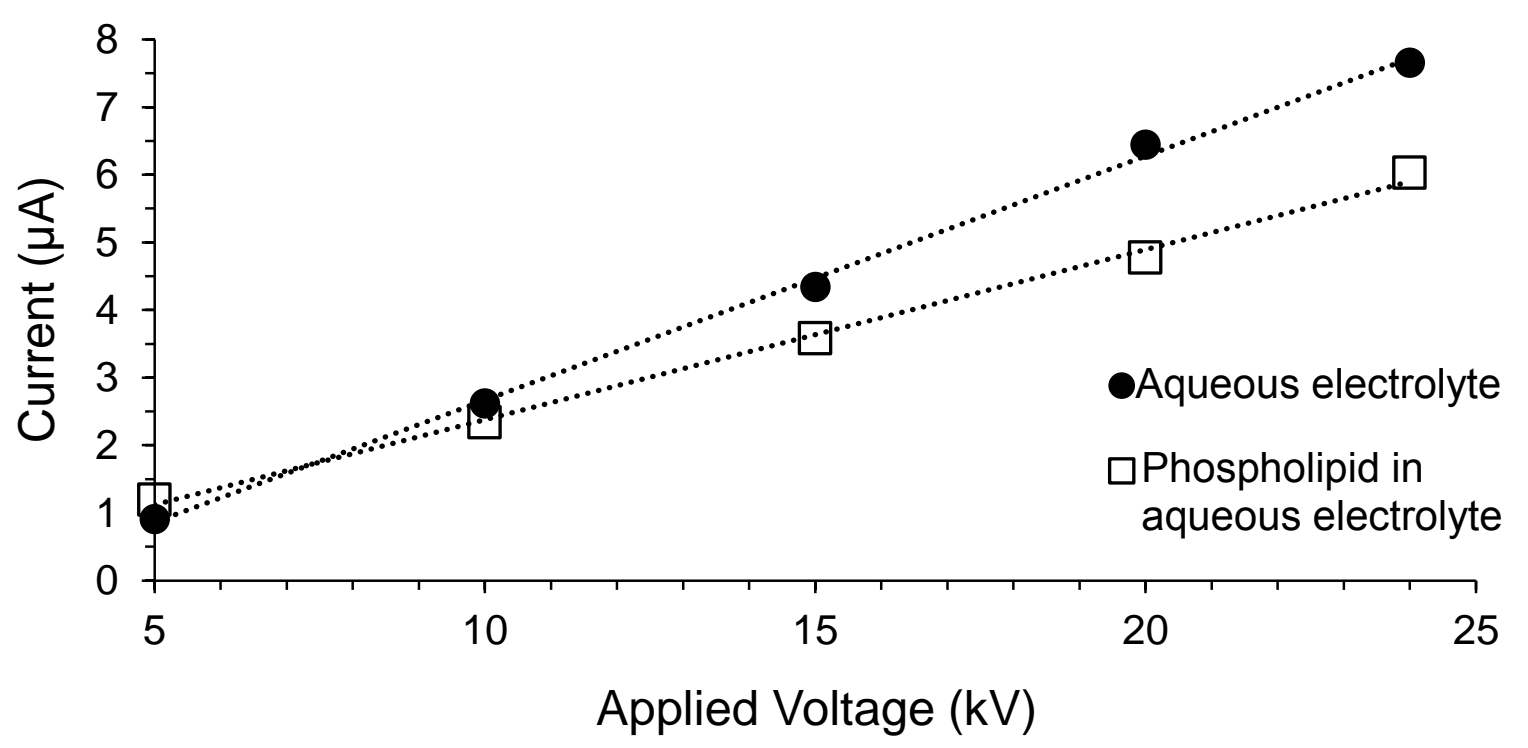

Figure 2.5 Ohm's Law plot. The current is measured as a function of applied voltage for 40 minutes. The average current (6 to $40 \mathrm{~min}$ ) is plotted against the applied voltage and fit using linear regression. The correlation coefficient is 0.998 for aqueous background electrolyte and 0.997 for phospholipid nanogel. All separations were performed at $37^{\circ} \mathrm{C}$ in a $25 \mu \mathrm{m}$ i.d. capillary, with an effective length of $30 \mathrm{~cm}$ for buffer and $50 \mathrm{~cm}$ for phospholipid. Figure reproduced from [1]. Copyright 2017 American Chemical Society. 


\subsubsection{Determination of Michaelis-Menten Constants for Neuraminidase}

The in-capillary enzymatic method was well-suited to characterize the relationship between the substrate concentration and the rate of enzyme production. The velocity of product formation was calculated as product concentration/incubation time and then plotted to determine the Michaelis-Menten constant. An accurate measurement of enzyme performance required that the classical rules derived for $\mathrm{K}_{\mathrm{M}}$ determinations were followed. ${ }^{58}$ In particular, no more than $10 \%$ of the substrate could be converted to product because the presence of product inhibits the rate of reaction as the rate of enzyme turnover can decrease due to product accumulation. An additional consideration was that the amount of product formed must fall within the linear range of quantification for the method of detection. A $\mathrm{K}_{\mathrm{M}}$ curve fit using non-linear regression required 2 points at or near saturation and an additional 3 points distributed across the region where the velocity changes significantly with substrate concentration.

The application of nanogel for in-capillary determination of enzyme activity was demonstrated with a neuraminidase that cleaves sialic acid with a 2-3, 2-6, 2-8, or 2-9 linkage. Each determination utilized nanogel enzymolysis with mixing at an enzyme concentration of $336 \mu \mathrm{Units} / \mu \mathrm{L}$ prepared in nanogel. Incubations were performed at 37 ${ }^{\circ} \mathrm{C}$. Electrophoretic mixing was performed during the incubation period to obviate the time-related dependence of velocity on incubation time observed in static incubations. A set of five electropherograms was obtained with 3'-sialyllactose at concentrations of 0.40 , $1.25,3.4,5.4$, and $7.4 \mathrm{mM}$ (Figure 2-6A). The peak area for the lactose product obtained 
in each separation was quantified (Figure 2-6A inset). The rate of enzymatic conversion was calculated as the concentration of lactose produced over the incubation time. These determinations were performed in triplicate; 15 values were plotted as shown in Figure 2$6 \mathrm{~B}$ and fit using nonlinear regression to obtain the $\mathrm{K}_{\mathrm{M}}$ of $3.3 \mathrm{mM}$ with a standard deviation of $0.8 \mathrm{mM}$. 

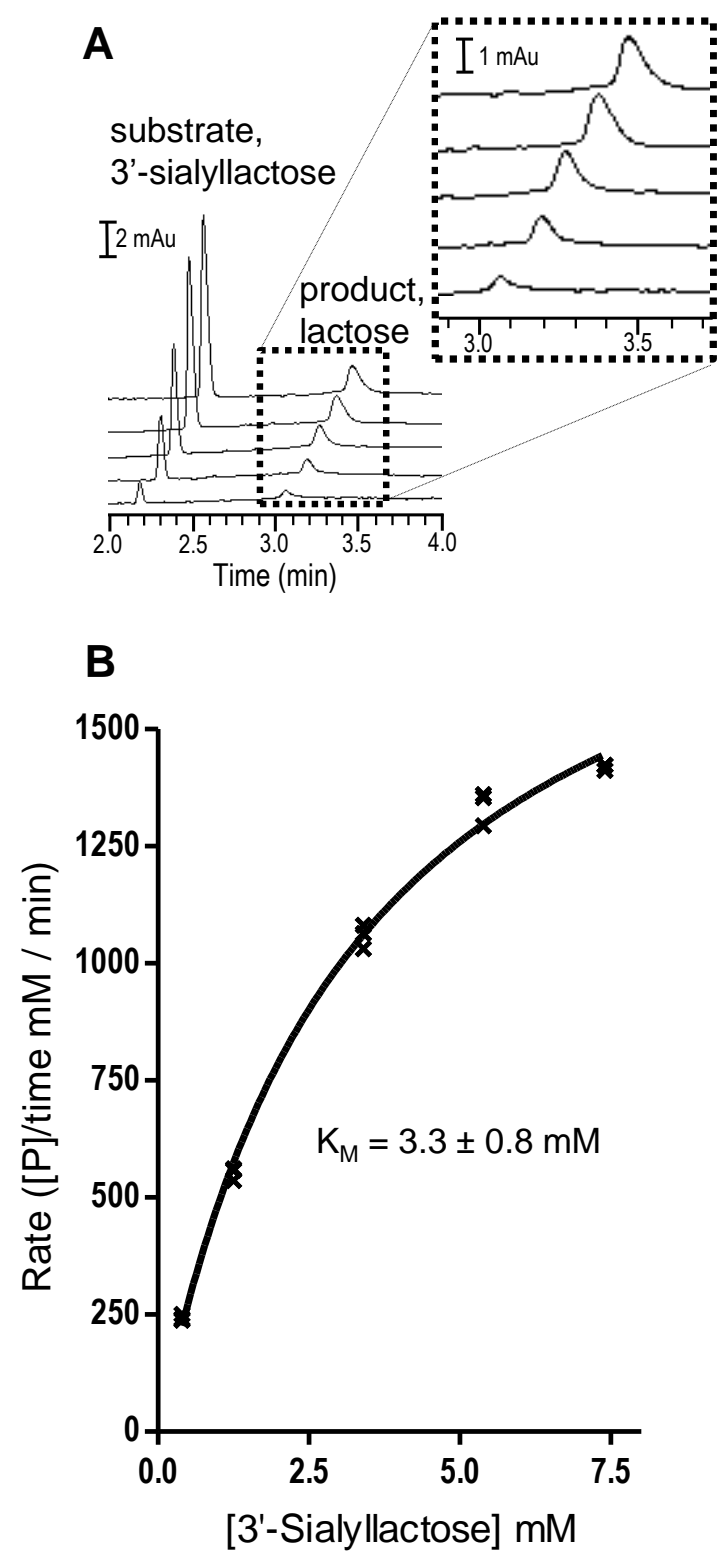

Figure 2.6 Electropherograms of 3'-sialyllactose substrate and the lactose product generated after enzymatic reaction. The traces were offset in time by $0.1 \mathrm{~min}$ for visualization from the lower to upper traces at the following 3'-sialyllactose concentrations: $0.40 \mathrm{mM}, 1.25 \mathrm{mM}, 3.4 \mathrm{mM}, 5.4 \mathrm{mM}$, and $7.4 \mathrm{mM}$. The increase in the area of lactose with increasing 3'-sialyllactose concentration is depicted in the inset. The MichaelisMenten curve (4B) was generated by plotting the substrate concentration versus the rate of product formation for 3'-sialyllactose with $336 \mu$ Units/ $\mu \mathrm{L} \alpha 2-3,6,8,9$ neuraminidase in nanogel. Experimental conditions as described in Figure 2-2. Figure reproduced from [1]. Copyright 2017 American Chemical Society 
Literature values have been reported for neuraminidase from Clostridium perfringens with related sialyllactose substrate. A KM value of 2.4 with unlabeled 3'-sialyllactose was obtained using potassium acetate buffered at $\mathrm{pH} 4.5,37^{\circ} \mathrm{C}$, quantifying the product concentration with thiobarbituric-facilitated colorimetric detection with the alkali-Ehrlich method. ${ }^{59}$ A KM value of $2.2 \pm 0.3 \mathrm{mM}$ with unlabeled 3'-sialyl- $N$-acetyllactosamine was obtained using $50 \mathrm{mM}$ potassium phosphate at a $\mathrm{pH}$ adjusted to 5.16 with sodium hydroxide, $37^{\circ} \mathrm{C}$, quantifying the product with anion exchange chromatography coupled to electrochemical detection. ${ }^{60} \mathrm{~K}_{\mathrm{M}}$ values are difficult to compare given that slight differences exist in the hydrolysis reaction conditions. In addition, the substrate used in this work was labeled with 2-aminobenzoic acid. In light of these differences in reactions, the experimental $\mathrm{K}_{\mathrm{M}}$ value is similar as it is approximately 1.5 times higher than these literature values.

The applicability of nanogel for enzyme characterization was extended to study changes in the rate of catalysis for different substrates and different neuraminidase enzymes. The activity and specificity of $\alpha 2-3,6,8,9$ neuraminidase on 6'-sialyllactose, a substrate with different linkage position, were examined using the nanogel capillary electrophoresis. The results demonstrated the application of the method to screen enzymes of different specificity for the conversion of different substrate molecules. The values in Table 2-2, were obtained under identical $\mathrm{pH}$, ionic strength, substrate concentration, and active enzyme concentration. 
Table 2.2 Summary of Michaelis-Menten Parameters ${ }^{1}$

\begin{tabular}{|c|c|c|c|}
\hline & $\alpha 2-3,6,8,9$ & euraminidase & 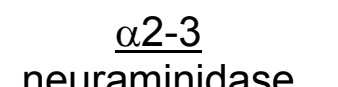 \\
\hline $\mathrm{K}$ & $\begin{array}{c}\text { 3'-sialyllactose }{ }^{2} \\
33+08\end{array}$ & $\begin{array}{c}\text { 6'-sialyllactose } \\
2+1\end{array}$ & $\begin{array}{c}\text { 3'-sialyllactose } e^{4} \\
3+2\end{array}$ \\
\hline $\begin{array}{l}\mathrm{V}_{\max } \pm \mathrm{s} . \mathrm{d} . \\
(\mu \mathrm{M} / \min )\end{array}$ & $2100 \pm 200$ & $400 \pm 100$ & $900 \pm 300$ \\
\hline $\begin{array}{l}{ }^{1} \text { Enzyme conce } \\
0.40,1.25,3.4 \\
n=15 \text { rates to }\end{array}$ & $\begin{array}{l}\text { ion is } 336 \mu \text { Units } \\
\text { or } 7.4 \mathrm{mM} \text { substra } \\
\left.\text { rmine } \mathrm{K}_{\mathrm{M}}, \mathrm{V}_{\max }\right) \text {. }\end{array}$ & $\begin{array}{l}\mathrm{L} \text {, all curves deter } \\
\text { in triplicate }(5 \text { poi }\end{array}$ & $\begin{array}{l}\text { ned at substrate }= \\
\text { per concentration, }\end{array}$ \\
\hline $\begin{array}{l}{ }^{2} 30 \text { s } 3 \text {-pass } \\
\text { coefficient for }\end{array}$ & $\begin{array}{l}\text { ation (20 s forwa } \\
\text { eear fit is } 0.996\end{array}$ & $-5 \mathrm{~s}$ reverse $-5 \mathrm{~s}$ & rward), correlation \\
\hline $\begin{array}{l}{ }^{3} 40 \mathrm{~s} 3 \text {-pass in } \\
\text { coefficient for } r\end{array}$ & $\begin{array}{l}\text { tion }(20 \mathrm{~s} \text { forwar } \\
\text { hear fit is } 0.950\end{array}$ & $10 \mathrm{~s}$ reverse-10 s & rward), correlation \\
\hline $\begin{array}{l}{ }^{4} 40 \text { s } 3 \text {-pass ir } \\
\text { coefficient for } \\
\text { Copyright } 2017\end{array}$ & $\begin{array}{l}\text { ion ( } 20 \mathrm{~s} \text { forwar } \\
\text { ear fit is } 0.961 \\
\text { ican Chemical } \mathrm{S}\end{array}$ & $\begin{array}{l}10 \mathrm{~s} \text { reverse-10 s } \\
\text { jety }\end{array}$ & ward), correlation \\
\hline
\end{tabular}

The $\mathrm{K}_{\mathrm{M}}$ value from the Michaelis-Menten curve for the general neuraminidase acting on 6'-sialyllactose was quantified as $2 \pm 1 \mathrm{mM}$ as shown in Figure 2-7. A similar $\mathrm{K}_{\mathrm{M}}$ value of $1.2 \mathrm{mM}$ was reported for general neuraminidase and 6'-sialyllactose with slightly different reaction conditions (i.e. $100 \mathrm{mM}$ sodium/potassium phosphate $\mathrm{pH}$ adjusted to $\left.5.4,37^{\circ} \mathrm{C}\right) .61$ 

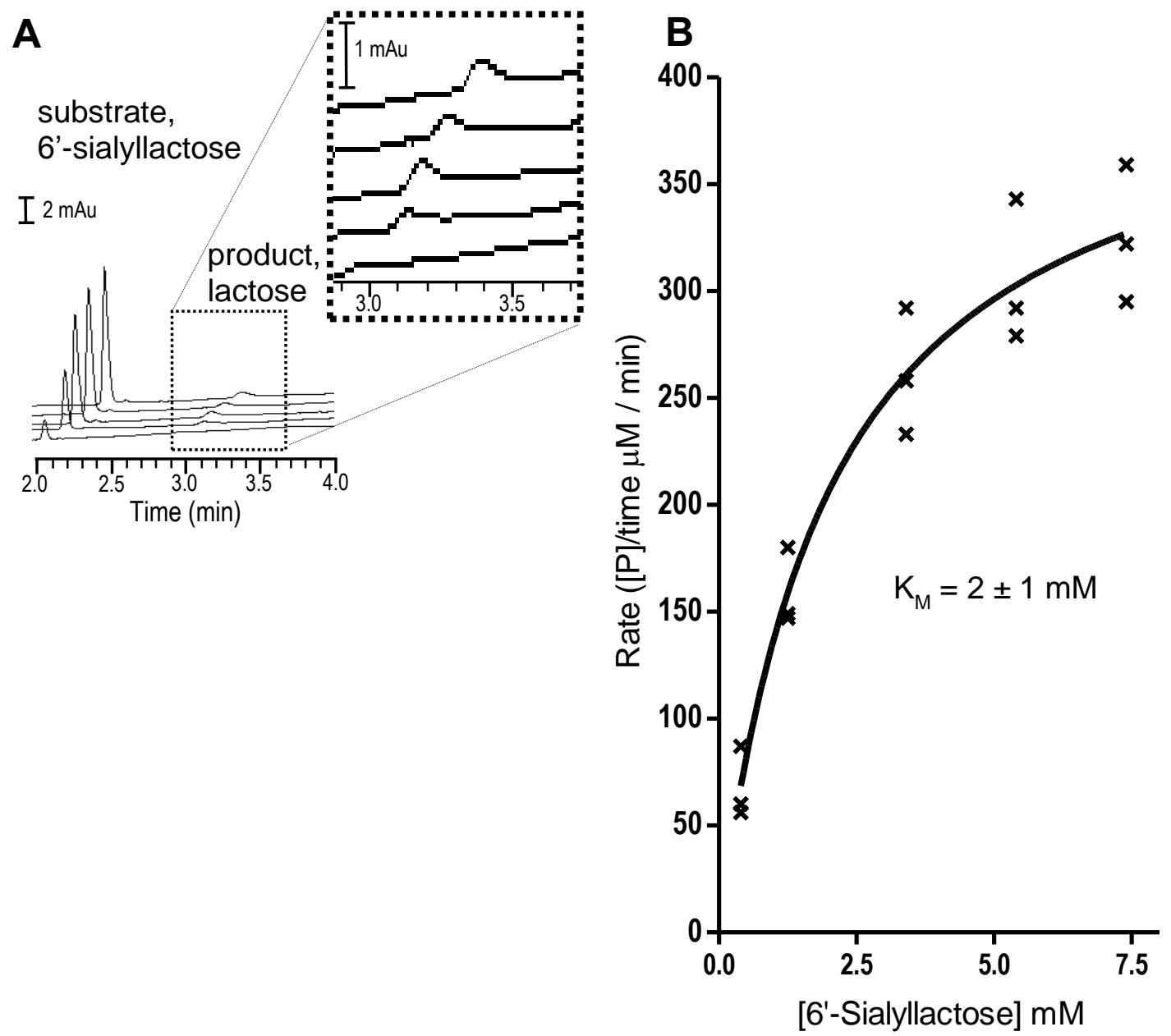

Figure 2.7 Depicts the separation of 6'-sialyllactose and lactose after enzymatic reaction with 5 different concentrations of 6'-sialyllactose substrate. The traces are offset in time for visualization from the lower to upper traces at the following 3'sialyllactose concentrations: $0.40 \mathrm{mM}$ ( $x$ offset $=0 \mathrm{~min}), 1.25 \mathrm{mM}$ ( $x$ offset $=0.10 \mathrm{~min}$ ), $3.4 \mathrm{mM}$ ( $x$ offset $=0.20 \mathrm{~min}$ ), $5.4 \mathrm{mM}$ ( $x$ offset $=0.30 \mathrm{~min}$ ), and $7.4 \mathrm{mM}$ ( $x$ offset $=0.40$ $\mathrm{min})$. The inset depicts the increase in the area of the lactose product with increasing 3'-sialyllactose concentration. B depicts the Michaelis-Menten curve that is generated by plotting the substrate concentration and the rate of product formation for 6'sialyllactose with $336 \mu \mathrm{U} / \mu \mathrm{L}$ a2-3,6,8,9 neuraminidase in nanogel. Experimental conditions as described in Figure 2-2. Figure reproduced from [1]. Copyright 2017 American Chemical Society 
sialyllactose, as shown in Figure 2-8. Incubation of the $\alpha 2-3$ neuraminidase with 6'sialyllactose resulted in no production of lactose, confirming that the specific enzyme was effective at cleaving only 3' sialic acid residues.
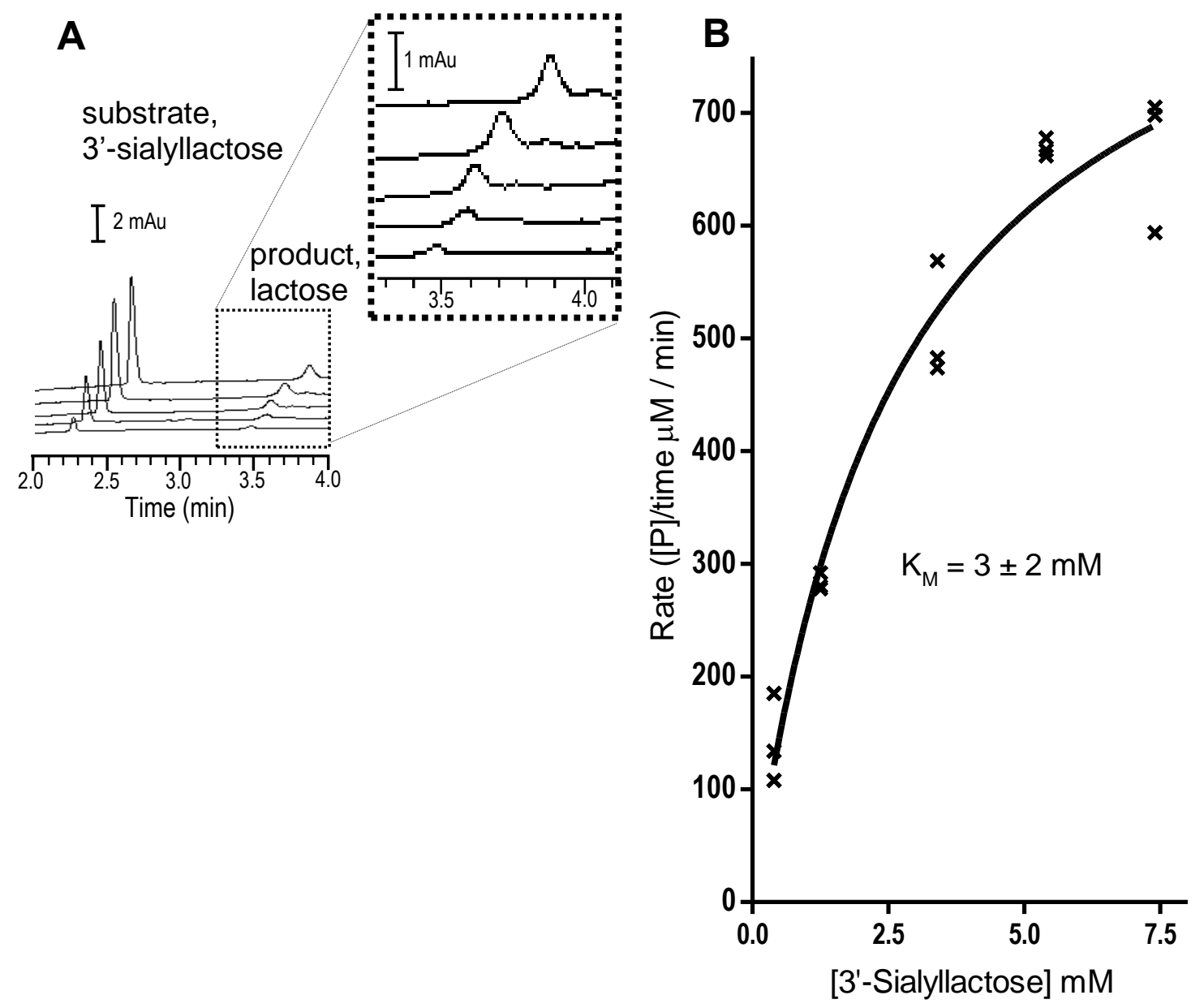

Figure 2.8 Depicts the separation of 3'-sialyllactose and lactose after enzymatic reaction with 5 different concentrations of 3 '-sialyllactose substrate. The traces are offset in time for visualization from the lower to upper traces at the following 3'-sialyllactose concentrations: $0.40 \mathrm{mM}$ ( $x$ offset $=-0.08 \mathrm{~min}$ ), $1.25 \mathrm{mM}$ ( offset $=0.10 \mathrm{~min}$ ), $3.4 \mathrm{mM}$ ( $x$ offset $=0.20 \mathrm{~min}$ ), $5.4 \mathrm{mM}$ ( $x$ offset $=0.30 \mathrm{~min}$ ), and $7.4 \mathrm{mM}$ ( $x$ offset $=0.35 \mathrm{~min}$ ). The inset depicts the increase in the area of the lactose product with increasing 3'-sialyllactose concentration. B depicts the Michaelis-Menten curve that is generated by plotting the substrate concentration and the rate of product formation for 3'-sialyllactose with $336 \mu \mathrm{U} / \mu \mathrm{L} \alpha 2-3$ neuraminidase in nanogel. Experimental conditions as described in Figure 2-2. Figure reproduced from [1]. Copyright 2017 American Chemical Society 
The $K_{M}$ value was independent of enzyme concentration, while $V_{\max }$ was dependent upon neuraminidase concentration. Curves were obtained at the same enzyme concentration of $336 \mu \mathrm{Units} / \mu \mathrm{L}$. For this enzyme, the manufacturer reported that the rate was greater for 2-3 than 2-6. ${ }^{62}$ The $V_{\max }$ values (Table 2-2), which describe the rate of enzyme catalysis when fully saturated by substrate, indicated that catalytic rate of the general enzyme (i.e. $\alpha 2-3,6,8,9$ neuraminidase) was five times faster for 2-3 substrate when compared to the 2-6 substrate. Furthermore, for conversion of 2-3 sialic acid substrate, the general enzyme was twice as fast as the 3' specific enzyme. These findings were utilized to apply neuraminidase to rapidly distinguish the sialic acid linkage.

\subsubsection{Differentiating the Sialic Acid Linkage with Neuraminidase}

With knowledge of the enzyme catalysis, the application of a fixed zone of neuraminidase to distinguish sialyllactose linkage position was demonstrated. A nanogel separation (Fig 2-9 trace A) of the 6' and the 3' - sialyllactose in the absence of enzyme revealed that the 2-6 and the 2-3 sialyllactose linkages were separated. When a mixture of 2-3 and 2-6 sialyllactose was subjected to a fixed enzyme zone of $8 \mathrm{mUnits} / \mu \mathrm{L}$ neuraminidase specific for 2-3 sialic acid linkage, only the 2-3 sialyllactose was converted to lactose (Fig 2-9 trace $B)$. 


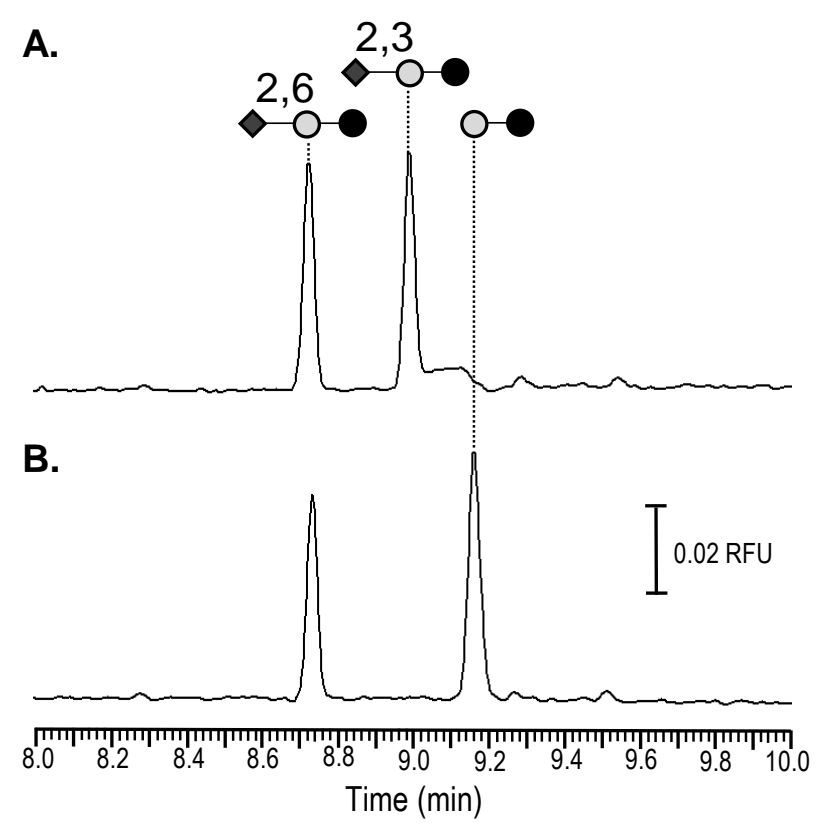

Figure 2.9 Electropherograms of 3' and 6'-sialyllactose to demonstrate the use of a2-3 neuraminidase to determine substrate linkages. The separation of 3' and 6'-sialyllactose in trace $A$ was obtained in the absence of enzyme. Trace $B$ incorporated a fixed zone of a2-3 neuraminidase (loaded at $69 \mathrm{kPa}$ for $7 \mathrm{~s}$ ) suspended in phospholipid nanogel (10\% lipid with $[\mathrm{DMPC}] /[\mathrm{DHPC}]=2.5 \mathrm{in} 50 \mathrm{mM}$ potassium phosphate $\mathrm{pH}$ adjusted to 5.2 with sodium hydroxide) at a concentration of $8 \mathrm{mUnits} / \mu \mathrm{L}$ to distinguish 2-3 from 2-6 sialyllactose by cleaving all the sialic acid on the 3'-sialyllactose. Separations and incubations were performed at $37^{\circ} \mathrm{C}$ in a $25 \mu \mathrm{m}$ i.d. capillary filled with nanogel, with an effective length of $50 \mathrm{~cm}$ and $E=400 \mathrm{~V} / \mathrm{cm}$ (reverse polarity). Figure reproduced from [1]. Copyright 2017 American Chemical Society

Triplicate runs with and without the fixed enzyme zone generated peaks that had a relative standard deviation in area of $4 \%$ and in time of $1 \%$. These studies were performed using fluorescence detection. Data found in Figure 2-10 was expanded on these analyses by incorporating a fixed enzyme zone of $0.6 \mathrm{mUnits} / \mu \mathrm{L}$ a2-3 
neuraminidase to confirm 3'-sialyllactose was converted to lactose and not just shifted in time.

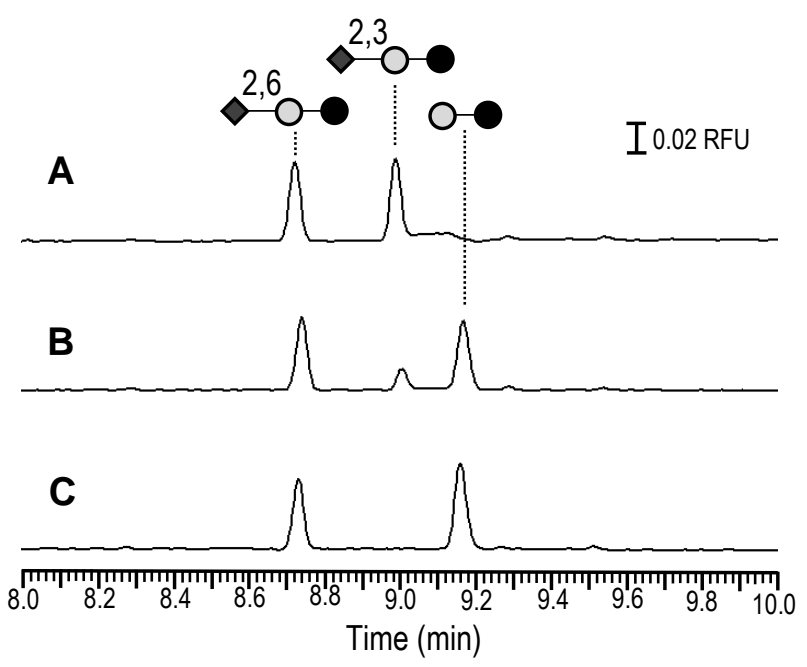

Figure 2.10 Electropherograms of 3'- and 6'-sialyllactose to demonstrate the use of neuraminidase to distinguish 3' and 6' linkages. The 3'- and 6'-sialyllactose peaks were resolved in phospholipid nanogel (10\% lipid with [DMPC]/[DHPC] $=2.5)$ devoid of enzyme in trace A. The 3'-sialyllactose was partially converted to lactose in the presence of a2-3 neuraminidase at a concentration of $0.6 \mathrm{mU} / \mu \mathrm{L}$ in trace $B$ and entirely converted at a concentration of $8 \mathrm{mU} / \mu \mathrm{L}$ in trace $\mathrm{C}$. Separations and incubations were performed at $37{ }^{\circ} \mathrm{C}$ in a $25 \mu \mathrm{m}$ i.d. capillary, with an effective length of $50 \mathrm{~cm}$ and $\mathrm{E}=400 \mathrm{~V} / \mathrm{cm}$ (reverse polarity). Figure reproduced from [1]. Copyright 2017 American Chemical Society

A similar strategy to identify the sialic acid linkage was applied to the mixture of trisialylated triantennary complex $\mathrm{N}$-glycan shown in Figure 2-11. The N-glycan determinations were accomplished using the fixed nanogel enzyme zone embedded in capillary filled with an enzyme-free nanogel. A nanogel separation (Fig 2-11 trace A) of the $\mathrm{N}$-glycan in the absence of enzyme revealed that the $\mathrm{N}$-glycan was fully sialylated and contained both Gal $\beta(1-3)$ GlcNAc and Gal $\beta(1-4)$ GlcNAc. These isomers were 
resolved electrophoretically when the capillary was filled with nanogel. ${ }^{31}$ The separation in trace $B$ was obtained with a fixed zone of $80 \mathrm{mUnits} / \mu \mathrm{L} \alpha 2-3$ neuraminidase, resulting in complete cleavage of the 2-3 linked sialic acid. A higher concentration and larger fixed enzyme zone was required to desialylate the tri-sialylated $\mathrm{N}$-glycan than for the sialyllactose, which increased relative standard deviation in area to $11 \%$ and in time to $2 \%(n=3)$. No product peaks were generated that contain two sialic acids. (This is known by the fact that at lower plug lengths of enzyme a disialylated triantennary glycan peak migrates at that time). A product peak associated with asialo $\mathrm{N}$-glycan is seen in trace $\mathrm{A}$, but comprised $<1 \%$ of the area of the $\mathrm{N}$-glycan peaks. The peaks obtained in these traces indicated that two-thirds of the sialic acid linkages were 2-3, while one-third were 2-6. 


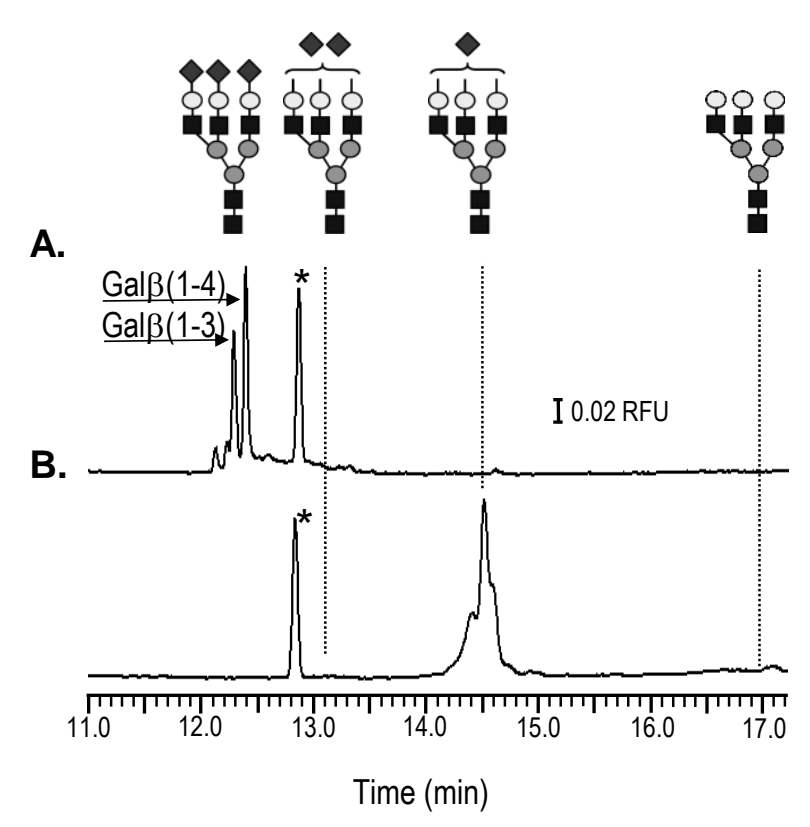

Figure 2.11 Electropherograms of tri-sialylated triantennary complex $\mathrm{N}$-glycan incubated in a2-3 neuraminidase to determine linkage position. Trace $A$ was obtained without enzyme, while trace $B$ was obtained using 80 mUnits $/ \mu L \mu 2-3$ neuraminidase suspended in phospholipid nanogel. The fixed zone of $\mu 2-3$ neuraminidase (loaded at $69 \mathrm{kPa}$ for 35 s) generated an electropherogram of $\mathrm{N}$-glycan devoid of all 2-3 linked sialic acid. The peak marked with the asterisk was present in the reaction blank. Experimental conditions were the same as those used in Figure 2-10. Figure reproduced from [1]. Copyright 2017 American Chemical Society

To demonstrate that different catalytic rates of general neuraminidase for $2-3$ vs $2-6$ sialic acid linkage could be harnessed to distinguish linkage position, the experiment was repeated using general neuraminidase. The separation in trace A of Figure 2-12 was obtained without enzyme, while the separation in trace B was obtained with a fixed enzyme zone of $4 \mu \mathrm{Units} / \mu \mathrm{L}$ general neuraminidase three times larger than those used for specific enzyme. This resulted in complete cleavage of the 2-3 linked sialic acid. 
Triplicate runs with the fixed general enzyme zone generated peaks that had a relative standard deviation in area of $10 \%$ and in time of $2 \%$. No product peaks were generated that contained two sialic acids. The separation in trace C of Figure 2-12 was obtained with a fixed zone of $2 \mathrm{mUnits} / \mu \mathrm{L}$ general neuraminidase, resulting in near complete cleavage of sialic acid. The same sialic acid linkage composition obtained with specific enzyme was obtained using general enzyme by controlling the concentration of the general neuraminidase. 


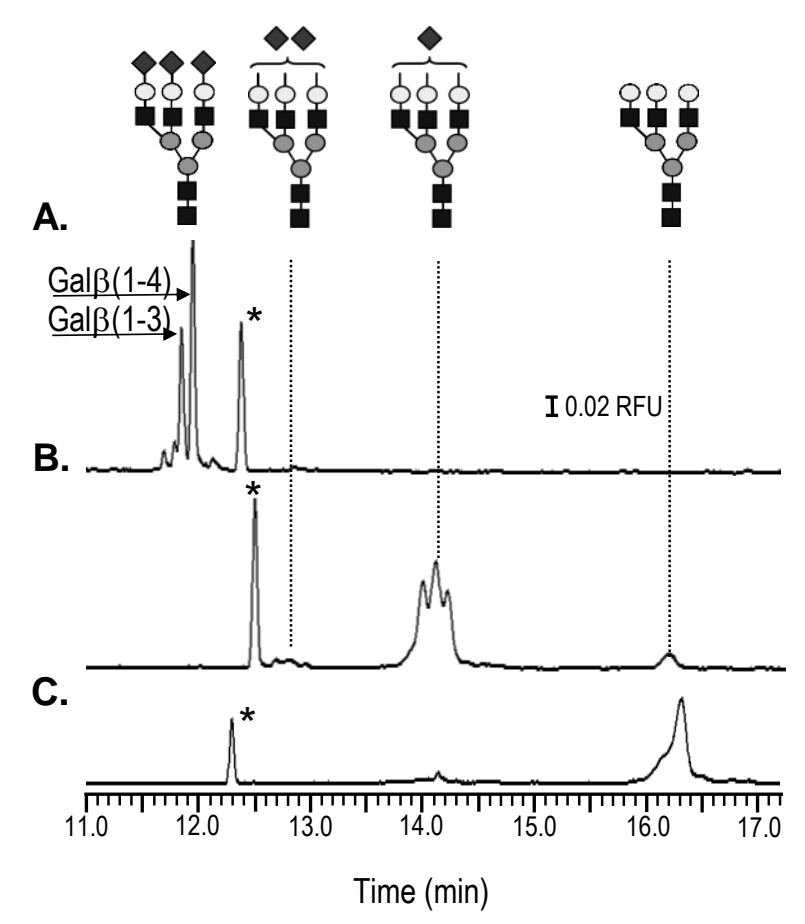

Figure 2.12 Electropherograms of tri-sialylated triantennary complex $\mathrm{N}$-glycan incubated in a2-3', 6', 8', 9' neuraminidase to determine the 3' versus 6' sialic acid composition. The separation in trace $A$ was obtained in the absence of enzyme. The separation in trace $B$ was obtained using $4 \mu$ Units/ $\mu \mathrm{L}$ a2-3,6,8,9 neuraminidase suspended in phospholipid nanogel (loaded at $69 \mathrm{kPa}$ for $21 \mathrm{~s}$ ) and generated an electropherogram of $\mathrm{N}$-glycan devoid of all 2-3 linked sialic acid. The fixed zone of $2.4 \mathrm{mUnits} / \mu \mathrm{L} \alpha 2-3,6,8,9$ neuraminidase used in trace $\mathrm{C}$ (loaded at $69 \mathrm{kPa}$ for $21 \mathrm{~s}$ ) generated an electropherogram of $\mathrm{N}$-glycan devoid of all sialic acid. Experimental conditions are the same as those used in Figure 2-10. Figure reproduced from [1]. Copyright 2017 American Chemical Society

\subsection{Conclusions and Future Directions}

This method enables rapid quantification of Michaelis-Menten constants for different substrates studied and provided a means to quantify linkage ( $\alpha 2-3$ versus $\alpha 2-6)$ of sialic acids. A significant finding of this work was that the general sialidase enzyme which digests both $\alpha 2-3$ and $\alpha 2-6$ sialic acid could be used to quantity sialic acid linkage 
composition in a substrate containing mixed linkages. This is particularly useful in cases where a specific enzyme is not readily available (e.g., $\alpha 2-8$ or $\alpha 2-9$ specific sialidases) or is prohibitively expensive.

Nanogel preparations are inexpensive, costing $\$ 0.09$ for $5 \mu \mathrm{L} .{ }^{63,64}$ The nanogel enzyme analyses provide an inexpensive, rapid, and simple means to analyze and quantify linkage composition of oligosaccharides. Nanogels are a biocompatible separation additive were shown to enhance the stability and performance of the exoglycosidase enzyme Neuraminidase and was used to create a fixed zone of enzyme in the capillary. At a concentration of $150 \mu$ Units/ $\mu \mathrm{L}$, enzyme reconstituted in aqueous electrolyte has a rate that is approximately half of what is obtained when it is reconstituted in nanogel made in the same aqueous solution. Furthermore, when the preparation does not contain nanogel, the activity decreases dramatically at low enzyme concentration such that product was not detectable on the second day of measurement. In contrast, neuraminidase reconstituted in nanogel maintained a rate of $500 \pm 40 \mu \mathrm{M}$ lactose/min as seen in the generation of the product measured throughout a 30-day period. A single enzyme stock in nanogel is a cost-effective means to deliver the nanoliter volumes required for the capillary method.

To circumvent the imitations of diffusion during static incubations for online enzyme reaction studies, the incubation period is reproducibly achieved by varying the number of forward and reverse passes of the substrate through the fixed enzyme zone (polarity cycling). To accomplish this, the position of fixed enzyme zone in the capillary should be 
clearly defined. The rate of enzyme catalysis increased with the electrophoretic velocity due to the increased probability of enzyme-substrate collision with polarity cyclic mixing. For $\mathrm{K}_{\mathrm{M}}$ studies, polarity cyclic mixing was utilized, and for substrate analysis, the labeling reaction was performed with an excess label to ensure $100 \%$ labeling efficiency to prevent any bias in $\mathrm{K}_{\mathrm{M}}$ measurement from an unlabeled substrate. $A \mathrm{~K}_{M}$ value of $3.3 \pm 0.8 \mathrm{mM}$ $\left(V_{\max }, 2100 \pm 200 \mu \mathrm{M} / \mathrm{min}\right.$ ) was obtained for 3'-sialyllactose labeled with 2-aminobenzoic acid using neuraminidase from Clostridium perfringens that cleaves sialic acid monomers with an $\alpha 2-3,6,8,9$ linkage, which is similar to values reported in the literature that required bench-top analyses. The enzyme cleaves the 2-3 linkage faster than the 2-6, and a $K_{M}$ of $2 \pm 1 \mathrm{mM}\left(\mathrm{V}_{\max }, 400 \pm 100 \mu \mathrm{M} / \mathrm{min}\right)$ was obtained for 6'-sialyllactose substrate. The rate of cleavage is approximately five times faster for 2-3 linkage than 2-6 linkage. Alternative neuraminidase selective for 2-3 sialic acid linkages generated a $K_{M}$ value of 3 $\pm 2 \mathrm{mM}\left(\mathrm{V}_{\max }, 900 \pm 300 \mu \mathrm{M} / \mathrm{min}\right)$ for 3'-sialyllactose.

With the knowledge of enzyme catalysis, the application of fixed zone of enzyme specific neuraminidase was used to distinguish sialyllactose linkage positions in a mixture of 3 ' and 6' sialyllactose standards demonstrating the specific enzyme clips of 2-3 linked sialic acids only in a sample consisting of a mixture of 2-3 and 2-6 sialyllactose. The study was extended to identify the sialic acid linkages for trisialylated triantennary complex $\mathrm{N}$-glycan and the peaks obtained indicated that two-thirds of the sialic acid linkages were 2-3, while one third were 2-6. The same sialic acid linkage composition obtained with specific neuraminidase was obtained using general neuraminidase by controlling the concentration and plug length of the general neuraminidase in a cost-effective manner. 
The method will be harnessed to determine the linkage composition in mixtures of complex N-glycans. Future efforts will also center on adapting the method for different enzymes.

Some speculations are presented to justify the hypothesis of diffusion limited incubations lead to decrease in enzyme rate with increase in incubation time. It would be interesting to expand this study and this system from first principles but several complications prevented this analysis. The true concentration of enzyme is not known; It is difficult to estimate the number of active enzyme molecules present, and there is no way to calculate the average distance between two enzyme molecules without knowing the true enzyme concentration. Second, to our knowledge, there is no data present in the literature on the diffusion coefficient of the substrate in the nanogel at the temperature of the experiment. The diffusion coefficient of the substrate can be determined experimentally in nanogel in the future to address this knowledge gap. Third, there was limited evidence in the Brenda database (E.C 3.2.1.18) and in the literature regarding enzyme structure, to specify that enzyme exists as a monomer, as a multimer or coexists as both structures under the conditions of the experiment. A literature search in Scifinder database was conducted using terms (Does neuraminidase from clostridium perfringens exist as a monomer or multimer, Does neuraminidase from clostridium perfringens exist as a monomer or oligomer, Does sialidase from clostridium perfringens exist as a monomer or oligomer) without any pertinant citations found. Fourth, some hydrolase enzymes have different rates as a monomer or oligomer. A hydrolase enzyme was reported in literature, where the rate per active site calculated 
for tetramer structure is approximately $15 \%$ smaller than its monomer structure. ${ }^{65}$ If neuraminidase from clostridium perfringens exist in both monomeric and multimeric states there could be a possibility of rate differences for these states. Consequently, while our hypothesis of diffusion limited enzyme conversion rate is aligned with our experimental observations, it cannot be supported by calculations. However, it is clear that the polarity cycling method addresses the problem.

\subsection{Acknowledgements:}

This material is based upon work supported by the NIH Grant No. R01GM114330. CLC acknowledges a National Science Foundation IGERT fellowship, DGE \#1144676 for her work. Srikanth Gattu contributed to the manuscript preparation, experimental design, data collection, data analysis, and data interpretation associated with the following: Figures

2.2, 2.3, 2.4, 2.5, 2.7, 2.8, 2.9, 2.10, 2.11, 2.12, as well as Table 2.1, 2.2. This also includes the APTS/AA labeling reactions and the optimization of the purification process for AA labeled oligosaccharides. Cassandra Crihfield contributed to the manuscript preparation, experimental design, data collection, data analysis, and data interpretation associated with the following: Figures 2.2, 2.3, 2.6, 2.12, as well as Table 2.2. This also includes the APTS/AA labeling reactions. Lisa Holland contributed to manuscript preparation, experimental design, data analyses, and data interpretation for all aspects of the work 


\subsection{References}

1. Gattu, S.; Crihfield, C. L.; Holland, L. A., Microscale Measurements of MichaelisMenten Constants of Neuraminidase with Nanogel Capillary Electrophoresis for the Determination of the Sialic Acid Linkage. Analytical Chemistry 2017, 89 (1), 929-936.

2. Varki, A., Sialic acids as ligands in recognition phenomena. The FASEB Journal $1997,11(4), 248-55$.

3. Wang, P.-H., Altered glycosylation in cancer: sialic acids and sialyltransferases. $J$ Cancer Mol 2005, 1 (2), 73.

4. Dall'Olio, F.; Malagolini, N.; Trinchera, M.; Chiricolo, M., Mechanisms of cancerassociated glycosylation changes. Front Biosci 2012, 17, 670-99.

5. Miyagi, T.; Wada, T.; Yamaguchi, K.; Hata, K., Sialidase and malignancy: A minireview. Glycoconj. J. 2003, 20 (3), 189-198.

6. Miyagi, T.; Takahashi, K.; Hata, K.; Shiozaki, K.; Yamaguchi, K., Sialidase significance for cancer progression. Glycoconj. J. 2012, 29 (8-9), 567-77.

7. Jassal, R.; Jenkins, N.; Charlwood, J.; Camilleri, P.; Jefferis, R.; Lund, J., Sialylation of Human IgG-Fc Carbohydrate by Transfected Rat a2,6-

Sialyltransferase. Biochem. Biophys. Res. Commun. 2001, 286 (2), 243-249.

8. Kaneko, Y.; Nimmerjahn, F.; Ravetch, J. V., Anti-Inflammatory Activity of Immunoglobulin G Resulting from Fc Sialylation. Science 2006, 313 (5787), 670673.

9. Stanley P, S. H., Taniguchi N. , N-Glycans. . In Essentials of Glycobiology. 2nd edition. , Editors: Ajit Varki; Richard D Cummings; Jeffrey D Esko; Hudson H 
Freeze; Pamela Stanley; Carolyn R Bertozzi; Gerald W Hart; Etzler, M. E., Eds. Cold Spring Harbor Laboratory Press: Cold Spring Harbor (NY), 2009; p Chapter 8. Available from: https://www.ncbi.nlm.nih.gov/books/NBK1917/.

10. Dall'Olio, F.; Trere, D., Expression of alpha 2,6-sialylated sugar chains in normal and neoplastic colon tissues. Detection by digoxigenin-conjugated Sambucus nigra agglutinin. Eur J Histochem 1993, 37 (3), 257-65.

11. Saldova, R.; Asadi Shehni, A.; Haakensen, V. D.; Steinfeld, I.; Hilliard, M.; Kifer, I.; Helland, Å.; Yakhini, Z.; Børresen-Dale, A.-L.; Rudd, P. M., Association of N-Glycosylation with Breast Carcinoma and Systemic Features Using HighResolution Quantitative UPLC. J. Proteome Res. 2014, 13 (5), 2314-2327.

12. Guttman, A.; Ulfelder, K. W., Exoglycosidase matrix-mediated sequencing of a complex glycan pool by capillary electrophoresis. J. Chromatogr. A 1997, 781 (12), 547-554.

13. Laroy, W.; Contreras, R.; Callewaert, N., Glycome mapping on DNA sequencing equipment. Nat. Protoc. 2006, 1 (1), 397-405.

14. Callewaert, N.; Geysens, S.; Molemans, F.; Contreras, R., Ultrasensitive profiling and sequencing of $\mathrm{N}$-linked oligosaccharides using standard DNAsequencing equipment. Glycobiology 2001, 11 (4), 275-281.

15. Song, T.; Ozcan, S.; Becker, A.; Lebrilla, C. B., In-Depth Method for the Characterization of Glycosylation in Manufactured Recombinant Monoclonal Antibody Drugs. Anal. Chem. 2014, 86 (12), 5661-5666. 
16. Szigeti, M.; Bondar, J.; Gjerde, D.; Keresztessy, Z.; Szekrenyes, A.; Guttman, A., Rapid N-glycan release from glycoproteins using immobilized PNGase F microcolumns. J. Chromatogr. B 2016, 1032, 139-143.

17. Edet, E., Current trend in enzyme immobilization: a review. Int. J. Mod. Biochem. 2013, $2(1), 31$.

18. Brady, D.; Jordaan, J., Advances in enzyme immobilisation. Biotechnol. Lett. 2009, 31 (11), 1639-1650.

19. Bao, J.; Regnier, F. E., Ultramicro enzyme assays in a capillary electrophoretic system. J. Chromatogr. A 1992, 608 (1-2), 217-224.

20. Bao, J. J.; Fujima, J. M.; Danielson, N. D., Determination of minute enzymatic activities by means of capillary electrophoretic techniques. J. Chromatogr. $B$ 1997, $699(1), 481-497$.

21. Fan, Y.; Scriba, G. K. E., Advances in-capillary electrophoretic enzyme assays. J. Pharm. Biomed. Anal. 2010, 53 (5), 1076-1090.

22. Van Dyck, S.; Kaale, E.; Nováková, S.; Glatz, Z.; Hoogmartens, J.; Van Schepdael, A., Advances in capillary electrophoretically mediated microanalysis. Electrophoresis 2003, 24 (22-23), 3868-3878.

23. Nováková, S.; Van Dyck, S.; Van Schepdael, A.; Hoogmartens, J.; Glatz, Z., Electrophoretically mediated microanalysis. J. Chromatogr. A 2004, 1032 (1-2), 173-184.

24. Montes, R. E.; Gomez, F. A.; Hanrahan, G., Response surface examination of the relationship between experimental conditions and product distribution in 
electrophoretically mediated microanalysis. Electrophoresis 2008, 29 (2), 375380.

25. Riveros, T. A.; Porcasi, L.; Muliadi, S.; Hanrahan, G.; Gomez, F. A., Application of artificial neural networks in the prediction of product distribution in electrophoretically mediated microanalysis. Electrophoresis 2009, 30 (13), 23852389.

26. Montes, R.; Dahdouh, F.; Riveros, T. A.; Hanrahan, G.; Gomez, F. A., Chemometrical Experimental Design-Based Optimization Studies in Capillary Electrophoresis Applications. LC-GC North America 2008, 26 (8), 712-721.

27. Durney, B. C.; Lounsbury, J. A.; Poe, B. L.; Landers, J. P.; Holland, L. A., A Thermally Responsive Phospholipid Pseudogel: Tunable DNA Sieving with Capillary Electrophoresis. Anal. Chem. 2013, 85 (14), 6617-6625.

28. Durney, B. C.; Bachert, B. A.; Sloane, H. S.; Lukomski, S.; Landers, J. P.; Holland, L. A., Reversible phospholipid nanogels for deoxyribonucleic acid fragment size determinations up to 1500 base pairs and integrated sample stacking. Anal. Chim. Acta 2015, 880 (0), 136-144.

29. Pappas, T.; Holland, L., Fluid steering in a microfluidic chip by means of thermally responsive phospholipids. Sens. Actuators, B, Chem. 2008, 128, 427434.

30. Wu, X.; Langan, T. J.; Durney, B. C.; Holland, L. A., Thermally responsive phospholipid preparations for fluid steering and separation in microfluidics. Electrophoresis 2012, 33 (17), 2674-81. 
31. Luo, R.; Archer-Hartmann, S. A.; Holland, L. A., Transformable capillary electrophoresis for oligosaccharide separations using phospholipid additives. Anal. Chem. 2010, 82 (4), 1228-33.

32. Archer-Hartmann, S. A.; Sargent, L. M.; Lowry, D. T.; Holland, L. A., Microscale exoglycosidase processing and lectin capture of glycans with phospholipid assisted capillary electrophoresis separations. Anal. Chem. 2011, 83 (7), 2740-7.

33. Archer-Hartmann, S. A.; Crihfield, C. L.; Holland, L. A., Online enzymatic sequencing of glycans from Trastuzumab by phospholipid-assisted capillary electrophoresis. Electrophoresis 2011, 32 (24), 3491-8.

34. Sato, K.; Okubo, A.; Yamazaki, S., Optimization of derivatization with 2aminobenzoic acid for determination of monosaccharide composition by capillary electrophoresis. Anal. Biochem. 1998, 262 (2), 195-197.

35. Váradi, C.; Lew, C.; Guttman, A., Rapid Magnetic Bead Based Sample Preparation for Automated and High Throughput N-Glycan Analysis of Therapeutic Antibodies. Anal. Chem. 2014, 86 (12), 5682-5687.

36. Sigma Aldrich, Certificate of Analysis Product Number N2876 Batch Number SLBM0746V.

\section{http://www.sigmaaldrich.com/Graphics/COfAlnfo/SigmaSAPQM/COFA/N2/N2876} /N2876-BULK SLBM0746V .pdf (accessed accessed June 04, 2016).

37. QA bio, E-S007 Product Documentation Specifications-Protocol. http://www.qabio.com/docs/QA-Bio.E-S007.specsheet.pdf (accessed accessed June 04, 2016). 
38. Mills, J. O.; Holland, L. A., Membrane-mediated capillary electrophoresis: interaction of cationic peptides with bicelles. Electrophoresis 2004, 25 (9), 123742.

39. Gekko, K.; Timasheff, S. N., Mechanism of protein stabilization by glycerol: preferential hydration in glycerol-water mixtures. Biochemistry 1981, 20 (16), 4667-4676.

40. Iyer, P. V.; Ananthanarayan, L., Enzyme stability and stabilization-Aqueous and non-aqueous environment. Process Biochem. 2008, 43 (10), 1019-1032.

41. Chang, B. S.; Mahoney, R. R., Enzyme thermostabilization by bovine serum albumin and other proteins: evidence for hydrophobic interactions. Biotechnol. Appl. Biochem. 1995, 22 ( Pt 2), 203-14.

42. Sola-Penna, M.; Meyer-Fernandes, J. R., Stabilization against Thermal Inactivation Promoted by Sugars on Enzyme Structure and Function: Why Is Trehalose More Effective Than Other Sugars? Arch. Biochem. Biophys. 1998, $360(1), 10-14$.

43. Shahid, S.; Ahmad, F.; Hassan, M. I.; Islam, A., Relationship between protein stability and functional activity in the presence of macromolecular crowding agents alone and in mixture: An insight into stability-activity trade-off. Arch. Biochem. Biophys. 2015, 584, 42-50.

44. Cserháti, T.; Szögyi, M., Interaction of phospholipids with proteins, peptides and amino acids. New advances 1987-1989. Int. J. Biochem. 1991, 23 (2), 131-145. 
45. Frank, D. J.; Denisov, I. G.; Sligar, S. G., Analysis of Heterotropic Cooperativity in Cytochrome P450 3A4 Using a-Naphthoflavone and Testosterone. J. Biol. Chem. 2011, 286 (7), 5540-5545.

46. Kawai, T.; Caaveiro, J. M.; Abe, R.; Katagiri, T.; Tsumoto, K., Catalytic activity of MsbA reconstituted in nanodisc particles is modulated by remote interactions with the bilayer. FEBS Lett. 2011, 585 (22), 3533-7.

47. Cunliffe, J. M.; Baryla, N. E.; Lucy, C. A., Phospholipid bilayer coatings for the separation of proteins in capillary electrophoresis. Anal. Chem. 2002, 74, 776783.

48. White, C. M.; Luo, R.; Archer-Hartmann, S. A.; Holland, L. A., Electrophoretic screening of ligands under suppressed EOF with an inert phospholipid coating. Electrophoresis 2007, 28 (17), 3049-55.

49. Wells, S. S.; De La Toba, E.; Harrison, C. R., Metal cation control of electroosmotic flow magnitude in phospholipid-coated capillaries. Electrophoresis 2016, $37(10), 1303-9$.

50. Sánchez, J. M.; Nolan, V.; Perillo, M. A., $\beta$-Galactosidase at the membranewater interface: A case of an active enzyme with non-native conformation. Colloids Surf., B 2013, 108, 1-7.

51. Sanchez, J. M.; Perillo, M. A., Membrane adsorption or penetration differentially modulates $\beta$-galactosidase activity against soluble substrates. Colloids Surf., $B$ 2002, 24 (1), 21-31.

52. Sanchez, J. M.; Perillo, M. A., Membrane topology modulates $\beta$-galactosidase activity against soluble substrates. Biophys. Chem. 2002, 99 (3), 281-295. 
53. Perillo, M. A.; Yu, R. K.; Maggio, B., Modulation of the activity of Clostridium perfringens neuraminidase by the molecular organization of gangliosides in monolayers. Biochim. Biophys. Acta - Biomembr. 1994, 1193 (1), 155-164.

54. Minton, A. P.; Wilf, J., Effect of macromolecular crowding upon the structure and function of an enzyme: glyceraldehyde-3-phosphate dehydrogenase.

Biochemistry 1981, 20 (17), 4821-4826.

55. Minton, A. P., Confinement as a determinant of macromolecular structure and reactivity. Biophys. J. 1992, 63 (4), 1090-1100.

56. Vera, C.; Cordova, A.; Aburto, C.; Guerrero, C.; Suarez, S.; Illanes, A. Synthesis and purification of galacto-oligosaccharides: state of the art. World Journal of Microbiology \& Biotechnology 2016, 32 (12).

57. Harrison, J. A.; Kartha, K. P. R.; Turnbull, W. B.; Scheuerl, S. L.; Naismith, J. H.; Schenkman, S.; Field, R. A. Hydrolase and sialyltransferase activities of Trypanosoma cruzi trans-sialidase towards NeuAc-alpha-2,3-Gal-beta-O-PNP. Bioorganic \& Medicinal Chemistry Letters 2001, 11 (2), 141.

58. Voet, D.; Voet, J. G., Biochemistry, 4th Edition. John Wiley and Sons, page 489: New York, 2010.

59. Cassidy, J. T.; Jourdian, G. W.; Roseman, S., The Sialic Acids: VI. Purification and Properties of Sialidase from Clostridium Perfringens. J. Biol. Chem. 1965, 240 (9), 3501-3506.

60. Thobhani, S.; Ember, B.; Siriwardena, A.; Boons, G.-J., Multivalency and the Mode of Action of Bacterial Sialidases. J. Am. Chem. Soc. 2003, 125 (24), 71547155. 
61. Bouwstra, J. B.; Deyl, C. M.; Vliegenthart, J. F., Purification and kinetic properties of sialidase from Clostridium perfringens. Biol Chem Hoppe Seyler 1987, 368 (3), 269-75.

62. Sigma Aldrich, N2876 Product Description.

http://www.sigmaaldrich.com/catalog/product/sigma/n2876?lang=en\&region=US (accessed accessed June 04, 2016).

63. Avanti Polar Lipids, Product 850305, 1,2-dihexanoyl-sn-glycero-3-

phosphocholine $1 \mathrm{~g}$ at $\$ 315$. http://avantilipids.com/product/850305/ (accessed accessed June 04, 2016).

64. Avanti Polar Lipids Product 850345, 1,2-dimyristoyl-sn-glycero-3-phosphocholine 1g at $\$ 140$. http://avantilipids.com/product/850345/ (accessed accessed June 04, 2016).

65. Gorfe, A. A.; Lu, B.; Yu, Z.; McCammon, J. A. Enzymatic activity versus structural dynamics: the case of acetylcholinesterase tetramer. Biophysical journal 2009, 97 (3), 897. 
Chapter 3: Capillary electrophoresis with stationary nanogel zones of galactosidase and Erythrina cristagalli lectin for the determination of ( $\beta 1-3)$ linked galactose in glycans

Reproduced from ${ }^{1}$

Holland, L. A ,; Gattu, S.; Crihfield, C. L.; Bwanali, L., Capillary electrophoresis with stationary nanogel zones of galactosidase and Erythrina cristagalli lectin for the determination of ( $\beta 1-3)$ - linked galactose in glycans. Journal of Chromatography A 2017, $1523,90-96$ 


\subsection{Introduction}

Protein glycosylation is a significant, but challenging post-translational modification that must be monitored. ${ }^{2,3}$ Characterizing glycosylation is difficult because these structures vary in their monomer sequence and monomer linkage. Different structural changes are relevant to different areas of biotechnology. For example, glycosylation affects the safety and efficacy of biological therapeutics and serves as a biomarker of disease. ${ }^{4-6}$ The $\mathrm{N}$ glycans that are associated with dysfunction arise from alterations of a predictable base structure that contains a mannose core with galactose as the outermost residue. ${ }^{7}$ In glycoproteins found in animals, galactose residues are generally linked to an $N$ acetylglucosamine residue through a $\beta(1-4)$ linkage, (Gal $\beta(1-4) G l c N A c)$. Exceptions to this linkage specificity are rare, but occur in protein modifications related to embryogenesis and in oncogenesis. The occurrence of a $\beta(1-3)$ linkage between galactose and $N$-acetylglucosamine $(\mathrm{Gal} \beta(1-3)$ GlcNAc) is realized as a type- $1 \mathrm{~N}$-acetylD-lactosamine (LacNAc) modification to the N-glycan. This type-1 LacNAc modification has recently been reported in pluripotent cells ${ }^{8}$ and as a potential biomarker of ovarian cancer. ${ }^{9}$ Although type-1 LacNAc is recognized as an important structural feature, it is difficult to detect. Lectins and exoglycosidase enzymes hold potential to elucidate this and other structural features on glycans.

Lectins are harnessed to recognize the prevalence of general structural motifs and offer a simple method to screen glycosylation. However, lectins cannot easily be used to sequence glycan structure nor can they provide information about the linkages that compose the structure. Lectins are often used in an array format, and the level of detail 
obtained with an array scales with the size of the array itself. Arrays require surface printing, sample introduction, and processing. Expanding the size of the lectin array increases the amount of sample and lectin that is consumed. To alleviate the lack of structural specificity of microarrays, they can be combined with exoglycosidases that have a high specificity for a monomer and in some cases for a monomer linkage. This has recently been demonstrated with a microarray that combined 2 neuraminidases and 7 lectins to provide information about both the structural motifs present in glycoproteins and the sialic acid linkage. ${ }^{10}$

Exoglycosidases that cleave the terminal monomers on the non-reducing end of a glycan can have different degrees of monomer and linkage specificity. Exoglycosidases with high specificity can be used without lectins to probe the linkage and composition of terminal glycan monomers. The selectivity offered by these enzymes can be used in conjunction with capillary electrophoresis separations. Enzyme analyses of this type are performed off-line, with any change in the glycan size detected by a shift in the migration time obtained with capillary electrophoresis. ${ }^{11-18}$ Off-line enzyme reactions are conducted for incubation times of several hours and consume significant enzyme quantities. Although most off-line exoglycosidase analyses are performed on glycans derived from glycoproteins, analyses of intact proteins can be accomplished with capillary electrophoresis. ${ }^{16,19}$

The limitations of off-line enzyme processing have led to new integrated analyses of glycans with capillary electrophoresis. Methods of partial filling, plug-plug, and serial plug 
analyses have been used with either a lectin $20-22$ or with an exoglycosidase..$^{21-24}$ Combinations of lectins and enzymes in capillary electrophoresis have not been fully exploited. Stationary zones of enzymes with nanogels have recently been described that offer new benefits to in-line analyses including the ability to increase the duration of the substrate incubation with electrophoretic mixing and to extend the lifetime of highly specific exoglycosidases, some of which are costly. ${ }^{25}$ The performance of nanogel as a separation additive in capillary electrophoresis offers an additional advantage for separations of complex mixtures of glycans. ${ }^{22,26}$

The success of in-capillary enzyme reactions is promising for the detection of $\beta(1-3)$ linked galactose once a few complications involving the use of galactosidases are addressed. In particular, the stability of galactosidase is a concern. The potential of some galactosidase enzymes to simultaneously function as a transferase as well as an exoglycosidase must also be considered. ${ }^{27}$ Additionally, the specificity, catalytic rate, and conditions required for the enzyme reaction must be defined. ${ }^{28}$ To expand research in glycan characterization, analytical technologies are required that are inexpensive, simple to implement and have potential for automated analysis.

A new approach is developed to enable the detection of galactose residues that contain a $\beta(1-3)$-linkage by integrating enzyme and lectin in the separation capillary. An exoglycosidase enzyme specific for $\beta(1-4)$-linked galactose is used in combination with a lectin that can bind to galactose that is $\beta(1-3,4)$-linked to $N$-acetylglucosamine. Galactosidase and Erythrina cristagalli lectin are each prepared in nanogel to create 
stationary zones within a capillary electrophoresis separation. By combining the specificity of an exoglycosidase enzyme with the structural recognition of a lectin, $\beta(1-3)$ linked galactose residues found in glycans are rapidly detected. The stability of neuraminidase in nanogels makes this method attractive. ${ }^{25}$ In this report, it is demonstrated for the first time that nanogel stabilizes $\beta(1-4)$-galactosidase. Moreover, nanogels can easily be patterned in-capillary and then used in an analysis, expelled, and replaced repeatedly. This innovation increases the analytical throughput because the approach does not require printing or covalent immobilization of the enzyme or lectin. The implementation of this method and practical factors that impact the conversion, selection, and separation of glycans that contain $\beta(1-3)$-linked galactose are discussed in this report. The benefits of this strategy are demonstrated with fetuin glycosylation.

\subsection{Materials and Methods}

\subsubsection{Chemicals and reagents}

The asialo-, agalacto-, biantennary complex N-glycan, herein referred to as agalactosylated biantennary N-glycan (GKC-004300), the asialo-, monogalactosylated biantennary complex $\mathrm{N}$-glycan, herein referred to as monogalactosylated biantennary $\mathrm{N}$ glycan (GKC-014300), the asialo-, galactosylated biantennary complex N-glycan, herein referred to as galactosylated biantennary N-glycan (GKC-024300), and the $\beta(1-4)$ galactosidase (GKX-5014) were from Prozyme (Hayward, CA). Acetic acid was from Fisher Scientific (Pittsburgh, PA). Sodium phosphate, calcium chloride, 3-(N-morpholino)propanesulfonic acid, 8-aminopyrene-1,3,6-trisulfonic acid, triethylamine, acetonitrile, 
asialofetuin and sodium cyanoborohydride (dissolved in tetrahydrofuran) were from Sigma-Aldrich (St. Louis, MO). Rapid peptide N-glycosidase (PNGase F) was obtained from New England Biolabs (Ipswich, MA). Erythrina cristagalli lectin was from Vector Labs (Burlingame, CA). Deionized water was from an Elga Purelab ultra water system (Lowell, MA). The phospholipids 1,2-dimyristoyl-sn-glycero-3-phosphocholine (DMPC) and 1,2-dihexanoyl-sn-glycero-3-phosphocholine (DHPC), were from Avanti Polar Lipids (Alabaster, AL). Phospholipid nanogels were prepared as described previously, aliquoted, and stored at $-20{ }^{\circ} \mathrm{C} .22,24,26$ The nanogel preparation was composed of $[\mathrm{DMPC}] /[\mathrm{DHPC}]=2.5$, with a final concentration of $10 \%$ lipid by weight.

\subsubsection{Preparation and derivatization of standards}

The glycans were labeled with a fluorescent chromophore as previously described. ${ }^{25}$ Glycan samples were purified, removing excess APTS and APTS labeled by-products with DPA-6S stationary phase extraction cartridges as described previously. ${ }^{22}$ Once purified, the samples were dried in a SpeedVac concentrator and then reconstituted in water and stored at $-20^{\circ} \mathrm{C}$. For further analysis glycan samples were diluted at least $50-$ fold in $50 \mathrm{mM}$ sodium phosphate buffered to $\mathrm{pH} 6$.

For the stability study, the $\beta(1-4)$-galactosidase was reconstituted to a final concentration of $200 \mu \mathrm{Unit} / \mu \mathrm{L}$ in two separate solutions that differed only by the presence of the selfassembled phospholipids that form nanogel. In one preparation the enzyme was suspended in $50 \mathrm{mM}$ sodium phosphate with $\mathrm{pH}$ adjusted to 6 . In the second preparation the enzyme was suspended in $10 \%$ nanogel that was made using $50 \mathrm{mM}$ sodium 
phosphate with $\mathrm{pH}$ adjusted to 6 . To create the $\beta(1-4)$-galactosidase in nanogel a $20 \%$ nanogel preparation was made in $50 \mathrm{mM}$ sodium phosphate buffered to $\mathrm{pH}$. The $\beta(1-$ 4)-galactosidase was reconstituted with aqueous buffer and then mixed $1: 1$ with a $20 \%$ nanogel preparation. This 1:1 dilution of nanogel ensured that the concentration was precisely $10 \%$, which was important because the viscosity of the non-Newtonian nanogel was dependent upon the concentration of the preparation. ${ }^{29}$ For $\beta(1-4)$-galactosidase enzyme, 1 Unit was defined as the amount of enzyme required to hydrolyze $1 \mu$ mole 2nitrophenyl $\beta$-D-galactopyranoside per min at $\mathrm{pH} 6.0$ and $37^{\circ} \mathrm{C} .{ }^{30}$

Erythrina cristagalli lectin comes from the manufacturer with lactose added as a stabilizer. The lactose was removed using a $10 \mathrm{kDa}$ molecular weight cut off filter (28-9322-47, Pall Corporation, Ann Arbor, MI) to avoid competition with the glycan binding. The lectin was rinsed with a solution of $0.1 \mathrm{mM}$ calcium chloride, $100 \mathrm{mM}$ 3-(N-morpholino)propanesulfonic acid buffered to $\mathrm{pH} 7$. The Erythrina cristagalli lectin was then collected from the molecular weight cutoff filter. The volume of this collected fraction, which is less than or equal to $20 \mu \mathrm{L}$, was measured with a pipette. A $10 \mu \mathrm{L}$ volume of $50 \mathrm{mM}$ sodium phosphate buffered to $\mathrm{pH} 6.4$ and containing $0.1 \mathrm{mM}$ calcium chloride was then added to the upper compartment of the molecular weight cutoff filter, mixed, removed, and combined with the fraction containing the protein. This lectin sample was then mixed 1:1 with a $20 \%$ nanogel preparation that contained $50 \mathrm{mM}$ sodium phosphate buffered to $\mathrm{pH}$ 6.4. The final concentration of the Erythrina cristagalli lectin preparation was $130 \mu \mathrm{M}$ lectin in $10 \%$ nanogel. 


\subsubsection{Capillary Electrophoresis}

Analyses were performed using a P/ACE MDQ or MDQ Plus (Sciex, Redwood City, CA) configured by the manufacturer with laser induced fluorescence detection ( $3 \mathrm{~mW}$ air cooled argon ion laser or $3 \mathrm{~mW}$ solid state laser, with $\lambda_{\mathrm{ex}}=488 \mathrm{~nm}, \lambda_{\mathrm{em}}=520 \mathrm{~nm}$ ). A 25 $\mu \mathrm{m}$ internal diameter, $360 \mu \mathrm{m}$ outer diameter fused silica capillary (Polymicro Technologies, Phoenix, AZ) was used for separation. Each day capillaries were prepared as previously reported. ${ }^{22}$ Briefly, a semi-permanent lipid coating composed of a $5 \%$ solution of phospholipid with [DMPC]/[DHPC] equal to 0.5 that also contained $12.5 \mathrm{mM}$ calcium was applied to the separation capillary at the beginning of each day and between each run. This semi-permanent coating suppressed the electroosmotic flow. The separations were performed using reversed polarity to separate the negatively-charged APTS-labeled glycans (anodic reservoir near detector, cathodic reservoir near the site of injection). Unless otherwise noted, the background electrolyte was sodium phosphate buffered to $\mathrm{pH} 6$. Ambient thermal control of the room and instrument was maintained using a portable air conditioner as was described previously. ${ }^{26}$ The lipid-based nanogel was easily introduced in the capillary at a temperature of $19{ }^{\circ} \mathrm{C}$. Prior to each run the capillary was held at $19{ }^{\circ} \mathrm{C}$. Data collection and analyses were performed using 32 Karat Software version 7.0 or 10.2 .

Each day, capillaries were prepared by flushing with the following sequence: $1 \mathrm{M} \mathrm{NaOH}$ for $30 \mathrm{~min}$ at $170 \mathrm{kPa}(25 \mathrm{psi})$, deionized water for $15 \mathrm{~min}$ at $170 \mathrm{kPa}(25 \mathrm{psi}), 15 \mathrm{~min}$ with methanol at $170 \mathrm{kPa}(25 \mathrm{psi})$, deionized water for $15 \mathrm{~min}$ at $170 \mathrm{kPa}(25 \mathrm{psi})$, and $3 \mathrm{~min}$ $50 \mathrm{mM}$ sodium phosphate buffered to $\mathrm{pH} 6$ at $170 \mathrm{kPa}(25 \mathrm{psi})$. The capillary was then 
coated with $\mathrm{q}=0.5,5 \%$ phospholipid containing $1.25 \mathrm{mM}$ calcium for $20 \mathrm{~min}$ at $170 \mathrm{kPa}$ (25 psi), followed by a $3 \mathrm{~min}, 170 \mathrm{kPa}(25 \mathrm{psi})$ rinse with $50 \mathrm{mM}$ sodium phosphate buffered to $\mathrm{pH}$ 6. Prior to each run, the capillary was held at $19^{\circ} \mathrm{C}$ and flushed as follows: 3 min of $\mathrm{q}=0.5,5 \%$ coating phospholipid at $170 \mathrm{kPa}(25 \mathrm{psi}), 5 \mathrm{~min}$ of $50 \mathrm{mM}$ sodium phosphate buffered to $\mathrm{pH} 6$ at $170 \mathrm{kPa}$ (25 psi), 3 min of $\mathrm{q}=2.5,10 \%$ phospholipid, at $170 \mathrm{kPa}(25 \mathrm{psi})$, and $5 \mathrm{~min}$ of $50 \mathrm{mM}$ sodium phosphate buffered to $\mathrm{pH} 6$ at $170 \mathrm{kPa}(25$ psi).

For studies related to enzyme characterization and optimization, the stationary enzyme zone was introduced at $69 \mathrm{kPa}(10 \mathrm{psi})$ for $7 \mathrm{~s}$ followed by injection of background electrolyte at $69 \mathrm{kPa}(10 \mathrm{psi})$ for $21 \mathrm{~s}$. The purpose of the $21 \mathrm{~s}$ introduction of background electrolyte was to push the enzyme to the thermostable region of the capillary. To determine the terminal residue in asialofetuin glycans the stationary lectin zone was introduced at $69 \mathrm{kPa}$ (10 psi) for $7 \mathrm{~s}$, followed by injection of background electrolyte at 69 $\mathrm{kPa}(10 \mathrm{psi})$ for $7 \mathrm{~s}$, and then the stationary enzyme zone was introduced at $69 \mathrm{kPa}(10$ psi) for $14 \mathrm{~s}$. After the capillary was filled, the temperature of the separation was increased to $35{ }^{\circ} \mathrm{C}$ for the sample injection, incubation, and separation. Injections included a background electrolyte pre-plug of $6.9 \mathrm{kPa}(1.0 \mathrm{psi})$ for $7 \mathrm{~s}$ and a background electrolyte post-plug of $3.4 \mathrm{kPa}(0.5 \mathrm{psi})$ for $5 \mathrm{~s}$. After a run was complete, a $172 \mathrm{kPa}(25$ psi) background electrolyte flush for 5 min was applied in the reverse direction to push out any remaining protein toward the site of injection. 


\subsection{Results and Discussion}

A method to identify the presence of the $\beta(1-3)$-linked galactose residues associated with type-1 LacNAc modifications to glycoproteins was developed using dual stationary zones of $\beta(1-4)$-galactosidase and Erythrina cristagalli lectin. Lectins and enzymes were harnessed differently in capillary electrophoresis. When the galactosidase enzyme matched a terminal residue in a glycan it was cleaved as depicted in Figure 3-1, leading to the appearance of the product at a migration time different from that of the substrate. When the specificity of the Erythrina cristagalli lectin for galactose residues matched the structural features of the glycan, they were bound to the lectin, removing the glycan peak from the electropherogram. The conditions for interaction with lectins were straightforward; however, the $\beta(1-4)$-galactosidase required some optimization.

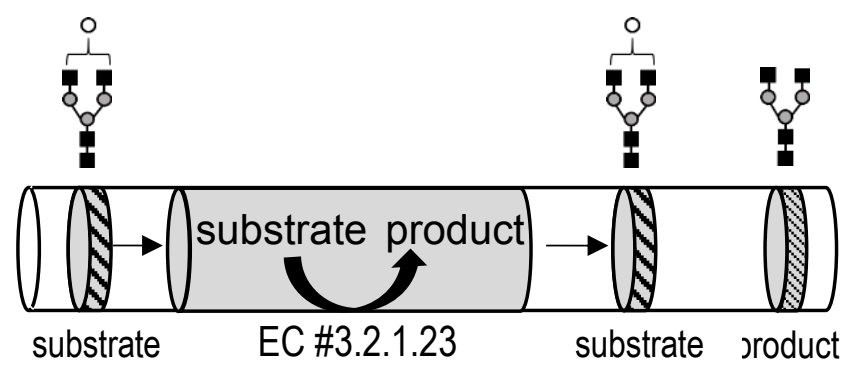

Figure 3.1 Conceptual illustration of electrophoretic migration of substrate in-capillary containing enzyme in a stationary zone. The asialo monogalactosylated biantennary Nglycan was converted to agalactosylated biantennary $\mathrm{N}$-glycan following incubation. Note that the reducing end of the $\mathrm{N}$-glycan was labeled with a fluorophore (e.g. 8-aminopyrene 1,3,6-trisulfonic acid). Figure reproduced from [1]. 


\subsubsection{Creating a stationary enzyme zone in-capillary}

A zone of enzyme was created in the capillary with nanogel as depicted in Figure 3-1. This approach, previously reported with the enzyme neuraminidase,${ }^{25}$ was possible because nanogel is a fluid with a thermally switchable viscosity. ${ }^{29,31}$ The nanogel was introduced into the capillary as a low viscosity fluid at $19{ }^{\circ} \mathrm{C}$ and then held in place by transforming it into a high viscosity material at temperatures ranging from 25 to $35^{\circ} \mathrm{C}$. The surface was passivated with a semi-permanent phospholipid coating, which suppressed the electroosmotic flow. The galactosidase was essentially stationary in the capillary in the absence of electroosmotic flow, in the high viscosity matrix, and as the $\mathrm{pH}$ of the nanogel was close to the predicted isoelectric point of 5.68 (personal communication Prozyme, Inc. Tech Support). Separations were performed using reversed polarity. The negatively-charged substrate was electrokinetically driven into the enzyme zone, where it was converted to product. Following enzyme treatment the product was then separated in the remaining portion of the capillary. In prior reports the capillary was filled with nanogel to improve the separation;22, 25, 26, 32, 33 however, when higher resolution was not required the stationary zone of enzyme functioned equally well when it was introduced into a capillary filled with aqueous background electrolyte instead of nanogel. ${ }^{25}$

\subsubsection{Effect of nanogel on $\beta(1-4)$-galactosidase activity and stability}

Previously, the rate of neuraminidase catalysis was higher and the stability of neuraminidase was longer when the enzyme was reconstituted in nanogel as compared 
to aqueous solution. ${ }^{25}$ There is evidence in the literature that phospholipid monolayers improve the performance of exoglycosidase enzymes. ${ }^{34-37}$ The effect of nanogel on the activity and stability of $\beta(1-4)$-galactosidase was evaluated by monitoring the extent of galactose removal for enzyme reconstituted in aqueous buffer as compared to nanogel. Therefore, the $200 \mu \mathrm{Unit} / \mu \mathrm{L}$ enzyme preparation was composed of sodium phosphate buffered to a pH of 6 or in nanogel that also contained sodium phosphate buffered to a $\mathrm{pH}$ of 6 . The enzyme was mixed outside of the capillary with either buffer or with nanogel, immediately placed in the instrument, and the first run was initiated. The time points were measured from the moment the first programmed run began. A $100 \mu \mathrm{L}$ aliquot of each $200 \mu U$ nit/ $/ \mathrm{L}$ enzyme preparation (aqueous or nanogel) was stored in a separate vial in the sample bay of the instrument, which was maintained at $4{ }^{\circ} \mathrm{C}$. The $200 \mu \mathrm{Unit} / \mu \mathrm{L}$ preparations of $\beta(1-4)$-galactosidase were assessed by quantifying the rate of conversion of monogalactosylated biantennary $\mathrm{N}$-glycan substrate to agalactosylated biantennary $\mathrm{N}$ glycan. For each enzyme preparation, the stationary enzyme zone was introduced at 69 $\mathrm{kPa}(10 \mathrm{psi})$ for $7 \mathrm{~s}$ and then pushed into the thermostated region of the capillary by injection of background electrolyte at $69 \mathrm{kPa}(10 \mathrm{psi})$ for $21 \mathrm{~s}$. As the isoelectric point of galactosidase (5.68) was close to the $\mathrm{pH}$ of both the aqueous and nanogel preparations, the enzyme zones remained stationary in the separation capillary. At the end of each determination the enzyme $(\sim 6 \mathrm{~nL})$ was expelled and the capillary flushed. A new stationary zone was created in the capillary for each determination of enzyme by drawing a fresh sample from the appropriate vial stored in the refrigerated sample bay. 
The results of this study are summarized in Table 3-1. The analyses of enzyme conversion demonstrated the reproducibility of the method when the nanogel-enzyme zone was introduced into the capillary. For the 6 nanogel-enzyme zones analyzed (time points: $1,5,9,13,17,21 \mathrm{~h}$ ), the combined area of the glycan substrate and glycan product peaks had a relative standard deviation of $8 \%(n=6)$. The migration times of the substrate and product were also reproducible for these 6 nanogel-enzyme zones, generating relative standard deviation of $0.3 \%$ for substrate $(n=6)$, as well as product ( $n$ =6). The percent conversion measured for freshly made enzyme preparations was more than 2 times higher in nanogel than aqueous buffer. Within 12 hours the $\beta(1-4)$ galactosidase made in aqueous solution was inactive, but when reconstituted in nanogel it remained active (92 $\pm 4 \%$ turnover, $n=6$ ) during 21 hours of programmed analyses. The prior study revealed that nanogel preparations of neuraminidase remained active for at least 30 days, ${ }^{25}$ suggesting that the $\beta(1-4)$-galactosidase would retain enzyme activity for an extended period as well. 
Table 3.1 Effect of nanogel on enzyme performance ${ }^{1}$

\begin{tabular}{|c|c|c|c|}
\hline \multicolumn{2}{|c|}{ Aqueous Enzyme } & \multicolumn{2}{|c|}{ Nanogel Enzyme } \\
\hline Time point $^{2}$ & $\%$ Turnover $^{3}$ & \multicolumn{2}{|c|}{ Timepoint \%Turnover ${ }^{3}$} \\
\hline $0 \mathrm{~h}$ & 37 & $1 \mathrm{~h}$ & 93 \\
\hline $4 \mathrm{~h}$ & 41 & $5 \mathrm{~h}$ & 100 \\
\hline $8 \mathrm{~h}$ & 10 & $9 \mathrm{~h}$ & 89 \\
\hline $12 \mathrm{~h}$ & 0 & $13 \mathrm{~h}$ & 93 \\
\hline $16 \mathrm{~h}$ & 0 & $17 \mathrm{~h}$ & 91 \\
\hline $20 \mathrm{~h}$ & 0 & $21 \mathrm{~h}$ & 87 \\
\hline \multicolumn{4}{|c|}{$\begin{array}{l}{ }^{1} \text { Enzyme concentration was } 200 \mu \mathrm{Unit} / \mu \mathrm{L} \text {. The } \\
\text { aqueous solution and nanogel }(10 \%) \text { were both } \\
\text { buffered to } \mathrm{pH} 6 \text {. Substrate was } 4 \mu \mathrm{M} \text { mono } \\
\text { galactosylated biantennary N-glycan in } 50 \mathrm{mM} \\
\text { phosphate buffered to pH } 6 \text {. Sample was injected } \\
\text { ( } 2 \mathrm{kV} 6 \mathrm{sec} \text { ) followed by a pre-separation step ( } 3 \mathrm{kV} \\
\text { for } 16 \mathrm{~min} \text { ) to drive substrate through enzyme. } \\
\text { Separations were performed with a background } \\
\text { electrolyte of } 50 \mathrm{mM} \text { sodium phosphate buffered to } \\
\text { pH } 6 \text { in a } 25 \mu \mathrm{m} \text { i.d. capillary with an effective length } \\
\text { of } 50 \mathrm{~cm}, \mathrm{E}=400 \mathrm{~V} / \mathrm{cm} \text { (reverse polarity), and at } 35 \\
{ }^{\circ} \mathrm{C} \text {. }\end{array}$} \\
\hline \multicolumn{4}{|c|}{$\begin{array}{l}{ }^{2} \text { Time point was taken on the same instrument and } \\
\text { separation capillary, alternating the enzyme } \\
\text { preparation leading at } 4 \mathrm{~h} \text { intervals. }\end{array}$} \\
\hline \multicolumn{4}{|c|}{$\begin{array}{l}{ }^{3} \text { Enzyme turnover is calculated by dividing the } \\
\text { product area by the total area of substrate and } \\
\text { product. The RSD in area of total glycan is } 10 \% \text { and } \\
\text { the RSD of migration time is } 1 \% \text { for the substrate } \\
\text { and for the product }\end{array}$} \\
\hline
\end{tabular}

\subsubsection{Effect of the stationary nanogel position on enzyme cleavage}

The temperature control of the separation capillary was enabled through a standard feature of the commercial instrument used in this study. The capillary electrophoresis 
instrument contained a cartridge, which interfaces the separation capillary to the programmable autosampling system. The capillary cartridge was connected to a liquid coolant system to circulate liquid coolant over the outside of the capillary. With this design an approximate length of $3.5 \mathrm{~cm}$ at each end of the capillary was not thermally regulated. Enzyme activity was temperature sensitive, which required that the stationary zone was positioned in the thermostated region of the capillary. Previously, this was accomplished for sialyllactose labeled with a UV-visible active chromophore in a capillary of $30 \mathrm{~cm}$ effective length and $40 \mathrm{~cm}$ total length by moving the stationary zone approximately 15 $\mathrm{cm}$ into the capillary and characterizing the position of the stationary nanogel zone. ${ }^{25} \mathrm{In}$ that prior study moving the enzyme, neuraminidase, to that position in the capillary was feasible because the catalytic rate of the enzyme was fast and because the mobilities of the sialyllactose substrate and lactose product were similar. When the same strategy was applied to $\beta(1-4)$-galactosidase, the position of the stationary enzyme zone in the capillary adversely effected the interpretation of the electropherogram. This was due to the fact that the velocity of the monogalactosylated biantennary $\mathrm{N}$-glycan substrate and agalactosylated biantennary $\mathrm{N}$-glycan product differed. The separations of agalactosylated biantennary $\mathrm{N}$-glycan and monogalactosylated biantennary $\mathrm{N}$-glycan, as shown in Figures 3-2A and 3-2B, were driven through a stationary zone in the separation capillary as in the previous report. ${ }^{25}$ The nanogel-enzyme zone was positioned within the thermostated region of the capillary by pushing the nanogel with a $45 \mathrm{~s}$ injection of aqueous buffer. In $2 \mathrm{~A}$ the zone was composed of nanogel, while in Figure 3-2B the zone was composed of nanogel containing $\beta(1-4)$-galactosidase. Two product peaks were present in trace 3-2B because the agalactosylated biantennary $\mathrm{N}$-glycan standard passed 
through the zone before the monogalactosylated biantennary $\mathrm{N}$-glycan substrate reached the zone and was converted to agalactosylated biantennary $\mathrm{N}$-glycan product.

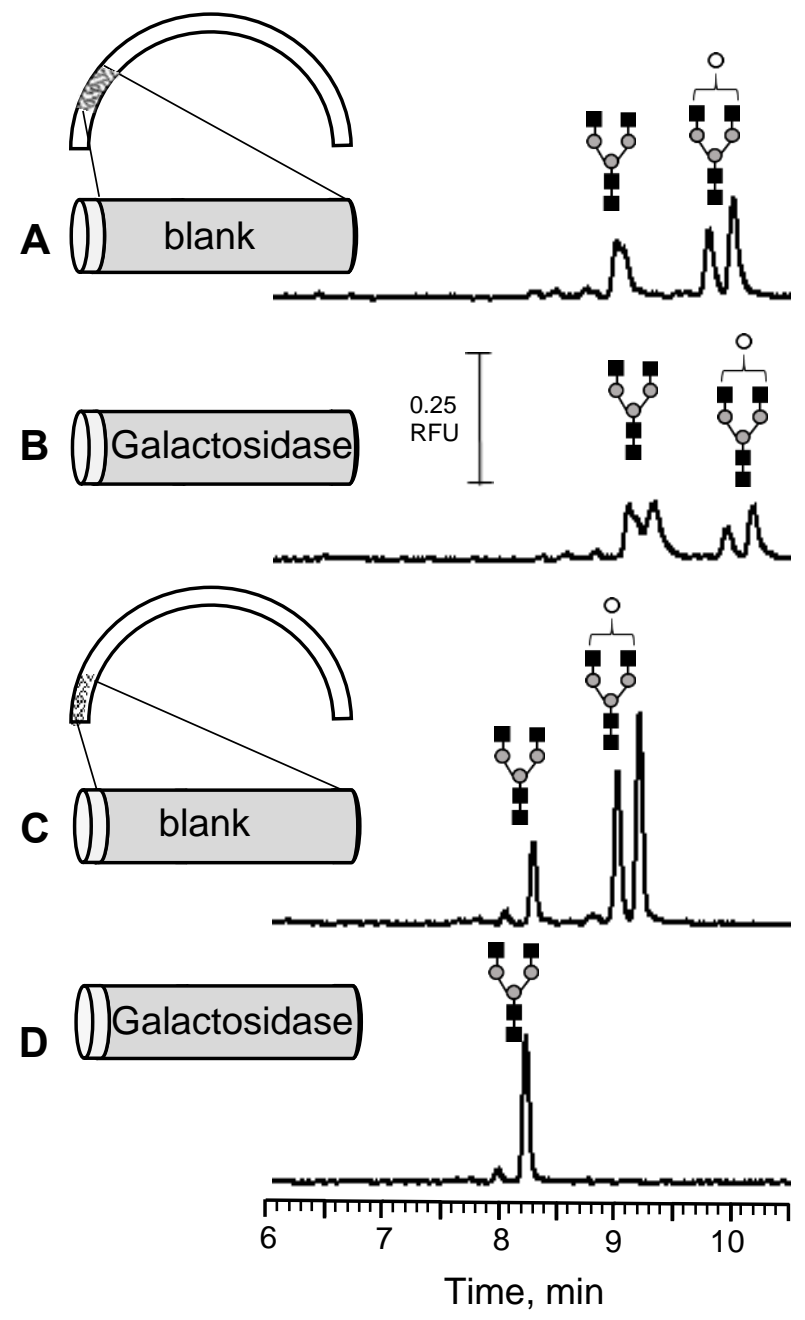

Figure 3.2 Depiction of electrophoretic migration of substrate in-capillary through a stationary zone of nanogel in two different positions. Injected sample was a mix of monogalactosylated biantennary $\mathrm{N}$-glycan (substrate) and agalactosylated biantennary $\mathrm{N}$ glycan (product, and migration time marker). The electropherogram in trace A was obtained in the presence of nanogel pushed into the capillary for $45 \mathrm{~s}$ at $69 \mathrm{kPa}$ (10 psi). The trace in $\mathrm{B}$ was obtained under the same conditions but using a stationary zone of nanogel containing enzyme. The electropherogram in $\mathrm{C}$ was obtained with nanogel thermostated at the end of the capillary using the modified reservoir. The separation in trace $D$ was obtained under the same conditions but using a stationary zone of nanogel containing enzyme. Sample was driven through nanogel using a pre-separation of $3 \mathrm{kV}$. Separations were performed in a $25 \mu \mathrm{m}$ inner diameter capillary, at $35^{\circ} \mathrm{C}$ with an effective length of $50 \mathrm{~cm}$ and $E=400 \mathrm{~V} / \mathrm{cm}$ (reverse polarity). Figure reproduced from [1]. 
This was corrected by using a special reservoir developed and reported earlier ${ }^{38}$ that provided thermal regulation at the inlet end of the separation capillary. Briefly, to thermostat the inlet end of the capillary a P/ACE MDQ large-volume reservoir tray was modified to accept recirculating coolant from a water bath, which allowed for more options for placement of the enzyme nanogel zone. The temperature of the buffer vial was equilibrated to the temperature of the recirculating bath. During enzyme hydrolysis the capillary was maintained to the specified temperature; however, when the incubation was completed the capillary was moved to a vial that was not thermostated. This prevented the accumulation of condensation near the top of the vial, which could potentially lead to electrical arcing. With this modification, the stationary nanogel zone was positioned at the inlet end of the capillary, and was used to obtain the separations shown in Figures 3$2 \mathrm{C}$ and 3-2D. In Figure 3-2C the zone was composed of nanogel, while in Figure 2D the zone was composed of nanogel containing $\beta(1-4)$-galactosidase. A single product peak was obtained in trace 3-2D because the agalactosylated biantennary $\mathrm{N}$-glycan standard and monogalactosylated biantennary $\mathrm{N}$-glycan substrate reached the enzyme zone at the same time. The agalactosylated biantennary $\mathrm{N}$-glycan product formed in the enzyme zone migrated from the same location as the agalactosylated biantennary $\mathrm{N}$-glycan standard added to the sample. 
A. Side view of spool without tubing

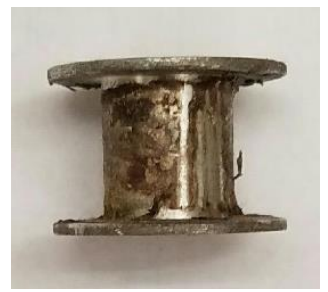

B. Top view of modified reservoir cartridge

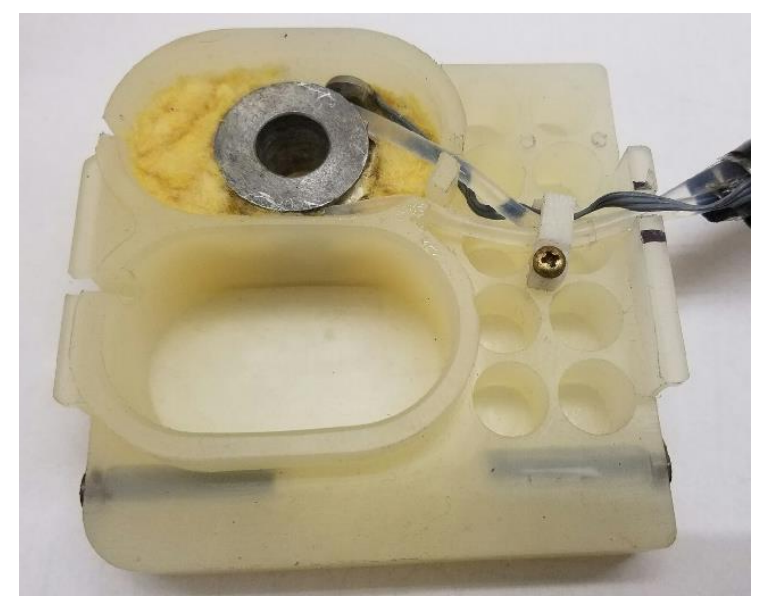

Figure 3.3 Depiction of an aluminum spool that is placed in contact with the glass vial used as either the anode or cathode reservoir. The spool wrapped with tubing is shown in the modified reservoir tray in S-1B. The system is described in a report by $M$. Anderson, L. Holland, T. Pappas, Temperature control of the running buffer: A "homebuilt" modification to the P/ACE ${ }^{\mathrm{TM}}$ MDQ, P/ACE Setter, 9 (2005) 9-11. Figure reproduced from [1].

\subsubsection{Other factors that influence $\beta(1-4)$-galactosidase performance}

The effects of temperature, analyte velocity, and length of the enzyme zone were characterized. The effect of turnover at 3 temperatures $\left(25,30,35^{\circ} \mathrm{C}\right)$ demonstrated only nominal improvement in percent turnover above $25^{\circ} \mathrm{C}$ (see Table 3-2). 
Table 3.2 Effect of Temperature on turnover ${ }^{1}$

\begin{tabular}{lc}
\hline$\frac{\text { Temperature }^{2}}{25^{\circ} \mathrm{C}}$ & $\frac{\text { \% Turnover }}{2}$ \\
$30^{\circ} \mathrm{C}$ & 78 \\
$35^{\circ} \mathrm{C}$ & 87 \\
\hline${ }^{1}$ Enzyme (200 $\mu$ Unit/ $\left.\mu \mathrm{L}\right)$ & reconstituted in 10\% \\
nanogel, sample and separation conditions as \\
described in Table 3-1. \\
${ }^{2} \mathrm{RSD}$ in total glycan area $<8 \%, n=3$, and RSD in \\
rate $<4 \%, n=3$.
\end{tabular}

The velocity of the substrate through the stationary enzyme zone impacted the rate of turnover as well. Slower transit time through the zone resulted in longer periods of incubation. As summarized in Table 3-3, higher turnover was achieved by driving the substrate through the zone at a lower applied voltage. Electrophoretic mixing, achieved by cycling the polarity of the applied electric field, was previously used to control the incubation time. ${ }^{25}$ 
Table 3.4 Effect of plug length on turnover ${ }^{1}$

\begin{tabular}{|c|c|}
\hline Plug Length & $\%$ Turnover $^{2}$ \\
\hline $69 \mathrm{kPa}, 7 \mathrm{~s}$ & 50 \\
\hline $69 \mathrm{kPa}, 10.5 \mathrm{~s}$ & 68 \\
\hline $69 \mathrm{kPa}, 14 \mathrm{~s}$ & 78 \\
\hline \multicolumn{2}{|c|}{$\begin{array}{l}{ }^{1} \text { Enzyme }(50 \mu \mathrm{Unit} / \mu \mathrm{L}) \text { reconstituted ir } \\
10 \% \text { nanogel, sample, separation } \\
\text { conditions as described in Table } 3-1\end{array}$} \\
\hline \multicolumn{2}{|c|}{$\begin{array}{l}{ }^{2} \text { RSD in total glycan area }<6 \%, n=3, \\
\text { RSD in rate }<3 \%, n=3\end{array}$} \\
\hline
\end{tabular}

The results in Table 3-4 demonstrated that different lengths of nanogel-enzyme zone did not affect the reproducibility of the method. The reproducibility of the rate of enzyme conversion was 3,2 , and $5 \%(n=3)$ for lengths estimated to be $2.6,2.0$, and $1.3 \mathrm{~cm}$, respectively. The combined area of the glycan substrate and glycan product peaks had a relative standard deviation of 3,7 , and $9 \%$ for lengths of $2.6,2.0$, and $1.3 \mathrm{~cm}$, respectively. The migration times of the substrate and product were also reproducible for each length of nanogel used. The substrate peak had a relative standard deviation of 1 , 0.2 , and $0.5 \%$ for lengths of $2.6,2.0$, and $1.3 \mathrm{~cm}$, respectively. The product peak had a relative standard deviation of $1,0.3$, and $0.5 \%$ for lengths of $2.6,2.0$, and $1.3 \mathrm{~cm}$, respectively.

\subsubsection{Identification of $\beta(1-3)$-linked galactose using $\beta(1-4)$-galactosidase and Erythrina cristagalli lectin}

With enzyme optimization complete, the enzyme and lectin were combined to demonstrate the presence of any $\beta(1-3)$-linked galactose. Glycans were removed from 
asialofetuin, labeled, and subject to analyses with enzyme and lectin. Agalactosylated biantennary $\mathrm{N}$-glycan was added to the glycan sample to serve as an internal standard because it does not respond to either the $\beta(1-4)$-galactosidase or the Erythrina cristagalli lectin. The trace in Figure 3-4A was obtained with stationary nanogel zones devoid of enzyme and of lectin. The trace in Figure 3-4B was obtained with a stationary nanogel zone of Erythrina cristagalli lectin, which demonstrated the specificity for the presence of terminal galactose residues. The galactosylated biantennary $\mathrm{N}$-glycan and galactosylated triantennary $\mathrm{N}$-glycans were missing from the electropherogram because they were captured by the lectin; whereas, the internal standard, which did not contain galactose residues, migrated through the lectin zone. The trace in Figure $3-4 \mathrm{C}$ was obtained by driving the glycans through the $\beta(1-4)$-galactosidase and mixing with polarity cycling (7-pass) to remove only $\beta(1-4)$-linked galactose residues. This produced an electropherogram with only 3 peaks: the agalactosylated biantennary $\mathrm{N}$-glycan, the agalactosylated triantennary $\mathrm{N}$-glycan, and the $\beta(1-3)$-linked, monogalactosylated triantennary $\mathrm{N}$-glycan known to be present in asialofetuin. The trace in Figure 3-4D was obtained by driving the glycans first through a stationary nanogel zone of $\beta(1-4)$ galactosidase, mixing with polarity cycling (7-pass), and then driving the glycans through a stationary nanogel zone of Erythrina cristagalli lectin. The resulting electropherogram showed that the $\beta(1-3)$-linked monogalactosylated triantennary $\mathrm{N}$-glycan was bound to the lectin and thus retained in the capillary. 


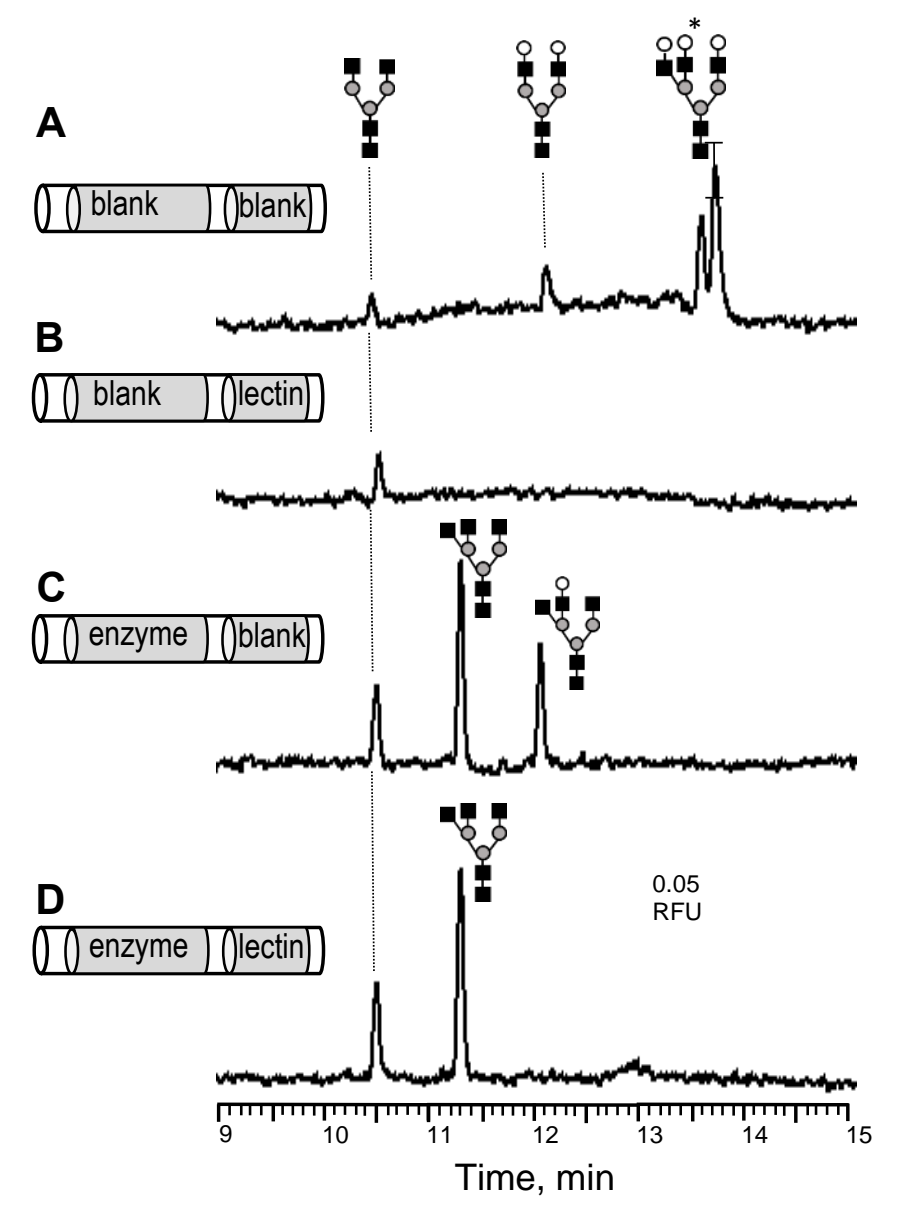

Figure 3.4 Electropherograms of complex $\mathrm{N}$-glycan obtained from asialofetuin incubated in $\beta$ (1-4)-galactosidase and Erythrina cristagalli lectin in different combinations. A stationary zone of nanogel/lectin and then nanogel/enzyme was loaded into the capillary at $69 \mathrm{kPa}$ for $7 \mathrm{~s}$ and $14 \mathrm{~s}$, respectively. Glycan standard agalactosylated biantennary Nglycan was added as a migration time marker. The sample was incubated in the first stationary zone using mixing with polarity cycling for $579 \mathrm{~s}$ at $3 \mathrm{kV}$ for multiple passes as follows: $129 \mathrm{~s}$ forward then three repeats of $75 \mathrm{~s}$ reverse $/ 75 \mathrm{~s}$ forward. The separation in trace $A$ was obtained with no enzyme and no lectin. The asterisk in trace $A$ denotes the position of Gal $\beta(1-3)$ GlcNAc or Gal $\beta(1-4)$ GlcNAc. The trace in $B$ was obtained with a stationary zone of lectin selective for the terminal galactose. The trace in $C$ was obtained with a stationary enzyme zone that was selective for $\beta 1-4$ linkages. The asterisk in trace $\mathrm{C}$ denotes the position of Gal $\beta(1-3)$ GlcNAc. The trace in $D$ was obtained with a stationary enzyme zone and a stationary lectin zone. The data were obtained at $35^{\circ} \mathrm{C}$ with $\beta(1-4)$-galactosidase $(200 \mu \mathrm{Unit} / \mu \mathrm{L})$ and Erythrina cristagalli lectin $(130 \mu \mathrm{M})$ that is suspended in phospholipid nanogel. Separation conditions are the same as described in, the Figure 3-2. Figure reproduced from [1]. 


\subsection{Conclusions and Future Directions}

This report demonstrates the applicability of combining $\beta(1-4)$-galactosidase and Erythrina cristagalli lectin. The linkage specificity could have been determined using combinations of $\beta(1-4)$-galactosidase, $\quad \beta(1-3)$-galactosidase, and/or $\beta(1-3,4)$ galactosidase. However, there are a few advantages to using lectins over multiple enzymes. Galactosidase enzymes have different optimum $\mathrm{pH}$ values and can contain excipients to stabilize them, including lactose, which is an inhibitor of enzyme activity. In addition, some galactosidases also function as a transferase enzyme, conjugating the liberated galactose residues back to a glycan or oligosaccharide terminus. ${ }^{27}$ The optimization of $\beta(1-4)$-galactosidase for the effect of temperature, voltage and plug length on turnover was demonstrated. The results indicate that the nominal increase in enzyme percent turnover above $25^{\circ} \mathrm{C}$ compared to $30^{\circ} \mathrm{C}$ and $35^{\circ} \mathrm{C}$. The velocity of the substrate through stationary enzyme zone impacts the enzyme turnover, as slower transit times through the enzyme zone resulted in longer incubation time and higher turnover is achieved. So, optimizing the conditions required for maximizing enzyme performance are characterized before proceeding to samples.

The temperature responsive nanogel separations provide a rapid, non-covalent method to incorporate enzymes and lectins reconstituted in nanogels directly into the capillary. The in-capillary method of enzyme and lectin processing is practical because the nanogel increases the enzyme lifetime. The use of phospholipids for reconstitution was shown in chapter 2 with exoglycosidases, but this was extended to lectin in chapter 3. Nanoliter volumes of enzyme and lectin are consumed during each run, which decreases the 
overall cost of the enzymes used to facilitate the analyses. Furthermore, the low cost of the nanogel preparations, which are estimated at $\$ 0.09$ for $5 \mu \mathrm{L},{ }^{39,40}$ makes the method more affordable as well.

Also care must be taken for position of the stationary enzyme zone in the capillary, and enzyme presence at two different positions effects the electrophoretic migration of the product, which was shown with a standard. The reason for the difference in electrophoretic mobility of the spiked product different from the product generated from the enzyme reaction, due to the position of the fixed stationary enzyme zone in the capillary. Since the identification of glycan is dependent on migration time, it is crucial that all methods utilize the same separation protocol. On the other hand, lectins avoid confounding results that may be obtained using enzymes with different properties and from different sources. There are various number of exoglycosidases and lectins that are commercially available with different specificity to probe complex solutions of glycans for structure identification. The combined use of enzymes and lectins in capillary electrophoresis is a new strategy to advance rapid and automated analysis of glycans using nanoliter volumes of enzymes and lectins. Using enzymes and lectins in combination for monomer and linkage information in glycans acts as a double conformational tool in glycan structure identification. The applicability of this use of stationary zones of enzyme and lectin in capillary electrophoresis is demonstrated with the identification of $\beta 1-3$ linked galactose in $\mathrm{N}$-glycans obtained from asialofetuin. Future efforts will center on adapting the method to different combinations of enzymes and 
lectins. Ultimately, this approach will be utilized for direct analyses of glycoproteins that contain signatures of type-1 LacNAc moieties, implicated in cancer.

\subsection{Acknowledgements:}

This material is based upon work supported by the NIH Grant No. R01GM114330. CLC acknowledges a National Science Foundation IGERT fellowship, DGE \#1144676 for her work. Srikanth Gattu contributed to the table, figure, and figure caption preparation, experimental design, data collection, data analysis, and data interpretation associated with the following: Figures 3.2, 3.4 as well as Table 3.1, 3.2, 3.3, 3.4. This also includes the APTS labeling reaction. Cassandra Crihfield contributed to the table preparation, experimental design, data collection, data analysis, and data interpretation associated with the following: Table 3.1, 3.2, 3.3, 3.4. This also includes the experimental design of Figure 3.2. Lloyd Bwanali contributed to the figure preparation, experimental design, data collection, data analysis, and data interpretation associated with the following: Figure 3.2, 3.3, 3.4 as well as Table 3.1, 3.2, 3.3, 3.4. This also includes preparation of the phospholipid. Lisa Holland contributed to manuscript preparation, experimental design, data analyses, and data interpretation for all aspects of the work. 


\subsection{References}

1. Holland, L. A.; Gattu, S.; Crihfield, C. L.; Bwanali, L., Capillary electrophoresis with stationary nanogel zones of galactosidase and Erythrina cristagalli lectin for the determination of beta(1,3)-linked galactose in glycans. Journal of Chromatography A 2017, 1523, 90-96.

2. Hajba, L.; Csanky, E.; Guttman, A., Liquid phase separation methods for Nglycosylation analysis of glycoproteins of biomedical and biopharmaceutical interest. A critical review. Anal. Chim. Acta 2016, 943, 8-16.

3. Yamamoto, S.; Kinoshita, M.; Suzuki, S., Current landscape of protein glycosylation analysis and recent progress toward a novel paradigm of glycoscience research. J. Pharm. Biomed. Anal. 2016, 130, 273-300.

4. Kailemia, M. J.; Park, D.; Lebrilla, C. B., Glycans and glycoproteins as specific biomarkers for cancer. Anal. Bioanal. Chem. 2017, 409 (2), 395-410.

5. Planinc, A.; Bones, J.; Dejaegher, B.; Van Antwerpen, P.; Delporte, C., Glycan characterization of biopharmaceuticals: Updates and perspectives. Anal. Chim. Acta 2016, 921, 13-27.

6. Jefferis, R., Glyco-engineering of human IgG-Fc to modulate biologic activities. Curr. Pharm. Biotechnol. 2016.

7. Stanley P, S. H., Taniguchi N., N-Glycans. In Essentials of Glycobiology. 2nd edition, Varki A, C. R., Esko JD, et al., Ed. Cold Spring Harbor Laboratory Press: Cold Spring Harbor (NY), Chapter 8. Available from:

https://www.ncbi.nlm.nih.gov/books/NBK1917/, 2009. 
8. Hasehira, K.; Tateno, H.; Onuma, Y.; Ito, Y.; Asashima, M.; Hirabayashi, J., Structural and Quantitative Evidence for Dynamic Glycome Shift on Production of Induced Pluripotent Stem Cells. Mol. Cell. Proteomics 2012, 11 (12), 1913-1923.

9. Choo Matthew, M., Characterization of $\mathrm{H}$ type 1 and type $1 \mathrm{~N}$-acetyllactosamine glycan epitopes on ovarian cancer specifically recognized by the anti-glycan monoclonal antibody mAb-A4. J. Biol. Chem. 2017, 0.

10. Reatini, B. S.; Ensink, E.; Liau, B.; Sinha, J. Y.; Powers, T. W.; Partyka, K.; Bern, M.; Brand, R. E.; Rudd, P. M.; Kletter, D.; Drake, R.; Haab, B. B., Characterizing Protein Glycosylation through On-Chip Glycan Modification and Probing. Anal. Chem. 2016, 88 (23), 11584-11592.

11. Guttman, A.; Ulfelder, K. W., Exoglycosidase matrix-mediated sequencing of a complex glycan pool by capillary electrophoresis. J. Chromatogr. A 1997, 781 (12), 547-554.

12. Guttman, A., Multistructure sequencing of $\mathrm{N}$-linked fetuin glycans by capillary gel electrophoresis and enzyme matrix digestion. Electrophoresis 1997, 18 (7), 11361141.

13. Feng, H.-t.; Su, M.; Rifai, F. N.; Li, P.; Li, S. F. Y., Parallel analysis and orthogonal identification of $\mathrm{N}$-glycans with different capillary electrophoresis mechanisms. Anal. Chim. Acta 2017, 953, 79-86.

14. Laroy, W.; Contreras, R.; Callewaert, N., Glycome mapping on DNA sequencing equipment. Nat. Protoc. 2006, 1 (1), 397-405.

15. Suzuki, S., Two-dimensional mapping of N-glycosidically linked asialooligosaccharides from glycoproteins as reductively pyridylaminated derivatives 
using dual separation modes of high-performance capillary electrophoresis. Anal. Biochem. 1992, 205 (2), 227.

16. Iourin, O.; Mattu, T. S.; Mian, N.; Keir, G.; Winchester, B.; Dwek, R. A.; Rudd, P. M., The identification of abnormal glycoforms of serum transferrin in carbohydrate deficient glycoprotein syndrome type i by capillary zone electrophoresis. Glycoconj. J. 1996, 13 (6), 1031-1042.

17. Mitra, I.; Snyder, C. M.; Zhou, X.; Campos, M. I.; Alley, W. R.; Novotny, M. V.; Jacobson, S. C., Structural Characterization of Serum N-Glycans by Methylamidation, Fluorescent Labeling, and Analysis by Microchip Electrophoresis. Anal. Chem. 2016.

18. Snyder, C. M.; Alley, W. R.; Campos, M. I.; Svoboda, M.; Goetz, J. A.; Vasseur, J. A.; Jacobson, S. C.; Novotny, M. V., Complementary Glycomic Analyses of Sera Derived from Colorectal Cancer Patients by MALDI-TOF-MS and Microchip Electrophoresis. Anal. Chem. 2016, 88 (19), 9597-9605.

19. Rudd, P. M.; Joao, H. C.; Coghill, E.; Fiten, P.; Saunders, M. R.; Opdenakker, G.; Dwek, R. A., Glycoforms modify the dynamic stability and functional activity of an enzyme. Biochemistry 1994, 33 (1), 17-22.

20. Yamamoto, S.; Shinohara, C.; Fukushima, E.; Kakehi, K.; Hayakawa, T.; Suzuki, S., Partial-filling affinity capillary electrophoresis of glycoprotein oligosaccharides derivatized with 8-aminopyrene-1,3,6-trisulfonic acid. J. Chromatogr. A 2011, 1218 (29), 4772-4778.

21. Yagi, Y.; Yamamoto, S.; Kakehi, K.; Hayakawa, T.; Ohyama, Y.; Suzuki, S., Application of partial-filling capillary electrophoresis using lectins and glycosidases 
for the characterization of oligosaccharides in a therapeutic antibody.

Electrophoresis 2011, 32 (21), 2979-2985.

22. Archer-Hartmann, S. A.; Sargent, L. M.; Lowry, D. T.; Holland, L. A., Microscale exoglycosidase processing and lectin capture of glycans with phospholipid assisted capillary electrophoresis separations. Anal. Chem. 2011, 83 (7), 2740-7.

23. Yamagami, M.; Matsui, Y.; Hayakawa, T.; Yamamoto, S.; Kinoshita, M.; Suzuki, S., Plug-plug kinetic capillary electrophoresis for in-capillary exoglycosidase digestion as a profiling tool for the analysis of glycoprotein glycans. J. Chromatogr. A 2017, 1496, 157-162.

24. Archer-Hartmann, S. A.; Crihfield, C. L.; Holland, L. A., Online enzymatic sequencing of glycans from Trastuzumab by phospholipid-assisted capillary electrophoresis. Electrophoresis 2011, 32 (24), 3491-8.

25. Gattu, S.; Crihfield, C. L.; Holland, L. A., Microscale Measurements of MichaelisMenten Constants of Neuraminidase with Nanogel Capillary Electrophoresis for the Determination of the Sialic Acid Linkage. Anal. Chem. 2017, 89 (1), 929-936.

26. Luo, R.; Archer-Hartmann, S. A.; Holland, L. A., Transformable capillary electrophoresis for oligosaccharide separations using phospholipid additives. Anal. Chem. 2010, 82 (4), 1228-33.

27. Juers, D. H.; Matthews, B. W.; Huber, R. E., LacZ $\beta$-galactosidase: Structure and function of an enzyme of historical and molecular biological importance. Protein Sci. 2012, 21 (12), 1792-1807.

28. Zeleny, R.; Altmann, F.; Praznik, W., A Capillary Electrophoretic Study on the Specificity of $\beta$-Galactosidases from Aspergillus oryzae, Escherichia coli, 
Streptococcus pneumoniae, and Canavalia ensiformis (Jack Bean). Anal. Biochem. 1997, 246 (1), 96-101.

29. Pappas, T.; Holland, L., Fluid steering in a microfluidic chip by means of thermally responsive phospholipids. Sens. Actuators, B, Chem. 2008, 128, 427-434.

30. Prozyme Glyko b(1-4)-Galactosidase [GKX-5014]. https://prozyme.com/products/gkx-5014 (accessed March 30, 2017).

31. Wu, X.; Langan, T. J.; Durney, B. C.; Holland, L. A., Thermally responsive phospholipid preparations for fluid steering and separation in microfluidics. Electrophoresis 2012, 33 (17), 2674-81.

32. Durney, B. C.; Bachert, B. A.; Sloane, H. S.; Lukomski, S.; Landers, J. P.; Holland, L. A., Reversible phospholipid nanogels for deoxyribonucleic acid fragment size determinations up to 1500 base pairs and integrated sample stacking. Anal. Chim. Acta 2015, 880, 136-144.

33. Durney, B. C.; Lounsbury, J. A.; Poe, B. L.; Landers, J. P.; Holland, L. A., A Thermally Responsive Phospholipid Pseudogel: Tunable DNA Sieving with Capillary Electrophoresis. Anal. Chem. 2013, 85 (14), 6617-6625.

34. Sánchez, J. M.; Nolan, V.; Perillo, M. A., $\beta$-Galactosidase at the membranewater interface: A case of an active enzyme with non-native conformation. Colloids Surf., B 2013, 108, 1-7.

35. Sanchez, J. M.; Perillo, M. A., Membrane adsorption or penetration differentially modulates $\beta$-galactosidase activity against soluble substrates. Colloids Surf., $B$ 2002, 24 (1), 21-31. 
36. Sanchez, J. M.; Perillo, M. A., Membrane topology modulates $\beta$-galactosidase activity against soluble substrates. Biophys. Chem. 2002, 99 (3), 281-295.

37. Perillo, M. A.; Yu, R. K.; Maggio, B., Modulation of the activity of Clostridium perfringens neuraminidase by the molecular organization of gangliosides in monolayers. Biochim. Biophys. Acta - Biomembr. 1994, 1193 (1), 155-164.

38. Anderson, M.; Holland, L. A.; Pappas, T. J., Temperature control of running buffer: an integrated modification to the Beckman P/ACE MDQ. P/ACE Setter 2005, $9(1), 9-11$.

39. Avanti Polar Lipids, Product 850305, 1,2-dihexanoyl-sn-glycero-3-phosphocholine $1 \mathrm{~g}$ at $\$ 315$. http://avantilipids.com/product/850305/ (accessed accessed April 02, 2017).

40. Avanti Polar Lipids Product 850345, 1,2-dimyristoyl-sn-glycero-3-phosphocholine $1 \mathrm{~g}$ at $\$ 140$. http://avantilipids.com/product/850345/ (accessed accessed April 02, 2017). 


\section{Chapter 4: Conclusions \& Future Directions:}

\subsection{Conclusions:}

Capillary Electrophoresis continues to meet the challenges faced by the glycan community to separate complex glycans. In summary, the dissertation illustrates how exoglycosidases and lectins can be utilized for glycan structure identification. Chapter 1 provided general information about the significance, fundamentals of glycans and its analysis with capillary electrophoresis using exoglycosidases and lectins. A brief introduction provided a discussion of glycan characterization with other analytical technologies were discussed and how CE improves in glycan structure analysis. The compatibility of $C E$ with various detectors makes it suitable for $\mathrm{K}_{M}$ determinations from nanomoles to millimolar concentrations, and the glycan derivatization for substrate and product detection was also explained. Furthermore, the basic principles of MichaelisMenten determinations are discussed, and the process of translating capillary electropherograms into a Michaelis-Menten curve is explained.

Chapter 2 discusses the Michaelis-Menten constants of enzyme neuraminidase with two different model substrates which ultimately provide a means to quantify sialic acid linkages. The phospholipid nanogel enhanced the stability and performance of the neuraminidase enzyme and was used to create a fixed zone of enzyme within the capillary by working at the isoelectric point of the enzyme. The fixed enzyme zone is inexpensive and easily positioned in the capillary to support electrophoresis mediated microanalysis to analyze sialic acid linkages. The method of polarity cyclic mixing was developed to 
achieve reproducible incubations by overcoming diffusion limited incubation was discussed.

Chapter 3 discusses the use of thermally responsive nanogel to create stationary zones of enzyme and lectin in the separation capillary. Once patterned in the capillary, the analyte is driven through the enzyme zone, where it is converted into specific product when an enzyme is used or captured when lectin is used. Lectins are harnessed to recognize the prevalence of general structural motifs and offer a method to screen glycosylation. However, lectins cannot be used to sequence glycan structure nor can they provide information about linkages that compose the structure. The importance of using stationary nanogel zone is that reaction time can be controlled by length of fixed enzyme zone, applied field strength controlling the analyte mobility and the temperature are characterized, which are the factors for enhancing the enzyme performance. The applicability of this use of stationary zones of $\beta 1-4$ galactosidase and Erythrina Cristagalli lectin is demonstrated for the identification of $\beta(1-3)$ - linked galactose in $N$-glycan, which is a biomarker for ovarian cancer.

\subsection{Ongoing work:}

With the knowledge of rate of hydrolysis for $\alpha 2-3$ and $\alpha 2-6$ sialic acids from previous results demonstrated the \% sialic acid composition in a simple standard. The goal of the ongoing work is to determine sialic acid composition in complex mixtures such as alpha1-acid glycoprotein. The alpha-1-acid glycoprotein is heavily glycosylated and sialylated with a mix of $\alpha 2-3$ and $\alpha 2-6$ sialic acids on di, tri, and tetra sialyation present on bi, tri and 
tetrantennary $\mathrm{N}$-glycans. ${ }^{1,2}$ The impact of glycosylation on protein function is significant, and this makes the characterization of $\mathrm{N}$-glycan structures mandatory for bio-therapeutic development. ${ }^{3}$ The changes in batch to batch variations in sialylation for alpha-1-acid glycoprotein can be studied from vendors to establish if any differences observed in manufacturing. Screening sialylation in this complicated glycan pool will be challenging, and the $\mathrm{N}$-glycan structure can be evaluated by exoglycosidase sequencing.

N-Glycan Sequencing:

The N-glycan structure from this complicated pool can be sequenced by using multiple exoglycosidase enzymes to systematically determine the $\alpha 2-3$ and $\alpha 2-6$ sialylation in a complex sample. The use of $\alpha 2-3$ neuraminidase to completely clip off $\alpha 2-3$ sialic acids as the first fixed enzyme zone. The $\beta$-galactosidase introduced as second fixed enzyme zone would digest the exposed galactose and then $\alpha 2-3,6,8$ neuraminidase can be added as third fixed enzyme zone to remove the $\alpha 2-6$ sialic acids. With this kind of patterning, the overall \%2-3 and 2-6 sialylation should match with the introduction of each enzyme cartridge and would identify the products generated from bi, tri and tetrantennary glycans based on shift in migration time. A potential pitfall of sialic acid composition in complex mixture containing bi, tri and tetrantennary glycans is that the rate of hydrolysis for clipping of a2-3 sialic acid varies with each glycans and optimizing the enzyme concentration to clip off only 2-3 sialic acids is challenging. In addition, the use of enzymes $\alpha 2-3$ neuraminidase, $\beta 1-4$ galactosidase, $\alpha 2-3,6,8$ neuraminidase, fucosidase, and $\mathrm{N}$ acetylglucosaminidase can be used to digest the glycan to its core structure. In patterning 
multiple exoglycosidase enzymes care should be taken in creating fixed enzyme zone by working close to enzymes isoelectric point.

\subsection{Future Direction:}

\subsection{1: Charecterization of $\mathrm{N}$-glycan profiles relevant to clinical samples:}

Plasma N-glycan profiling has emerged as potential candidates for bio-markers identification. The utilization of $\mathrm{N}$-glycan profile as clinical bio-markers for disease diagnosis and prognosis is widely used..$^{1-3}$ The change in glycosylation of $\mathrm{N}$-glycan profile has been identified in various cancers, ${ }^{1,4-6}$ rheumatoid arthritis ${ }^{7}$ and diabetes ${ }^{8}$. The use

of nanogel assisted capillary gel electrophoresis method developed in Hollands lab could be used to evaluate $\mathrm{N}$-glycans obtained from healthy and diseased individuals to compare $\mathrm{N}$-glycan profile changes within and across individuals.

The process involved in collecting the blood sample, N-glycan release, labeling and purification is described. The blood samples should be collected by following standard procedures and guidelines for drawing blood prior to treatment and after treatment. ${ }^{9}$ Blood was drawn into sterile vacutainer blood collection tube and is allowed to clot for $30 \mathrm{~min}$ at ambient temperature. The vacutainer blood collection tubes is a plastic or glass sterile test tube creating a vacuum seal inside the tube and allows to draw blood. After the formation of clot, centrifuge for at least 15 minutes at 2500 RPM within one hour of blood sample collection. When the tube is centrifuged, the materials in the blood sample are 
separated based on density. The blood cells at the bottom of the tube and plasma or serum at the top of the tube. The serum layer should be removed, aliquoted and stored at $-80^{\circ} \mathrm{C}$. The serum samples before $\mathrm{N}$-glycan release needs to be processed in order to remove albumin and other unwanted proteins using multiple affinity removal spin cartridges. ${ }^{10}$ This spin cartridges removes majority of the albumin from serum and the sample can now be treated for $\mathrm{N}$-glycan release.

The N-glycan release from serum samples is reported. ${ }^{11-13}$ The procedure involves $5 \mu \mathrm{L}$ aliquots of processed serum samples diluted to $25 \mu \mathrm{L}$ with glycoprotein denaturation buffer composed of $10 \mathrm{mM}$ sodium phosphate $(\mathrm{pH} 7.5), 0.1 \% \beta$-mercaptoethanol and $0.1 \%$ sodium dodecyl sulfate (SDS). The serum sample was denatured during incubation at $60^{\circ} \mathrm{C}$ for 60 minutes by reduction of the disulfide bonds. The sample was allowed to cool down to room temperature and $2.5 \mu \mathrm{L}$ of $10 \%$ Nonidet P-40 (NP-40) is added. The NP-40 is a nonionic, non-denaturing detergent used to ensure sufficient partitioning of sodium dodecyl sulphate into the micelles to prevent denaturation of peptide $\mathrm{N}$ glycosidase F enzyme (PNGase F). Allow at least five to ten minutes to equilibrate before the addition of enzyme. PNGase $F(5 \mathrm{mU})$ enzyme is added to the sample and the enzyme is used to cleave $\mathrm{N}$-glycans from glycoprotein backbone and the serum samples were incubated at $37^{\circ} \mathrm{C}$ for overnight enzyme reaction. The $\mathrm{N}$-glycans can be separated from protein by using ethanol precipitation. Add ice cold ethanol to the glycan at a three ethanol and one sample volume ratio. The solution is centrifuged at 10,000 RPM for 10 minutes at $4^{\circ} \mathrm{C}$. Remove as much liquid as possible from protein pellet and place it in a vial. Use the spedvac concentrator to evaporate the ethanol from the sample in order to 
prepare the sample for labeling. The 8-aminopyrene-1,3,6-trisulfonic acid (APTS) impart charge needed to induce electrophoretic separation and a fluorescent tag for detection.

The released $\mathrm{N}$-glycans can be labeled using a fluorophore 8-aminopyrene-1,3,6trisulfonic acid, with a protocol developed in Holland lab. The N-glycan labeling can be accomplished using $100 \mathrm{mM}$ 8-aminopyrene-1,3,6-trisulfonic acid in 20\% acetic acid for a reaction of $5 \mathrm{nmol}$ glycan: $250 \mathrm{nmol}$ dye in a total reaction volume of $5 \mu \mathrm{L}$. To the dried $\mathrm{N}$-glycan, $2.5 \mu \mathrm{L}$ of $100 \mathrm{mM}$ APTS and $2.5 \mu \mathrm{L}$ of $1 \mathrm{M}$ sodiumcyanoborohydride were added and allowed to incubate at $37^{\circ} \mathrm{C}$ for two hours for sialylated compounds and overnight for non-sialylated compounds. The labeled $\mathrm{N}$-glycan samples were purified using the discovery DPA-6S solid phase extraction cartridges. Specifically, once the sample was loaded in the extraction cartridge, the APTS dye was eluted using $20-\mathrm{mL}$ of $95 \%$ acetonitrile, $5 \%$ aqueous $1 \mathrm{mM}$ triethylamine and the retained sugars were eluted from the cartridge using 5-mL of aqueous $25 \mathrm{mM}$ triethylamine. Once purified, the samples were dried in a SpeedVac concentrator before reconstituting in water and storing at -20 ${ }^{\circ} \mathrm{C}$ for CE analysis.

\subsection{2: Michaelis Menten Studies of Exoglycosidases:}

Capillary electrophoresis is an enabling tool and will continue to evolve and adapt to meet the challenges of enzyme analysis. The Michaelis Menten studies for some of the exoglycosidases have been previously established. ${ }^{14,15}$ The research in chapter 2 discuss a method of electrophoretically mediated microanalysis for $K_{M}$ and $V_{\max }$ determinations for the enzymes $\alpha 2-3$ neuraminidase and $\alpha 2-3,6,8$ neuraminidase with 
model substrates. This method can be extended to study exoglycosidase enzymes like $\beta$-galactosidase and $\alpha$-fucosidase for $K_{M}$ and $V_{\max }$ determination. The enzyme $\beta$ 1-3,4 galactosidase can be used to evaluate the rate of hydrolysis of different galactose linkages $\beta$ 1-3 and 1-4 using model substrates. The enzyme $\alpha 1-2,3,4,6$ fucosidase can be used to assess the rate of hydrolysis for various fucose linkages. With the knowledge of rates, optimizing the concentration of general enzymes can be used to clip off required linkage instead of using different specific enzymes. The potential challenges would be the compatibility of the enzyme reaction and the separation $\mathrm{pH}$. It is important in creating the fixed enzyme zone by working at its isoelectric point and the optimum conditions for enzyme performance with respect to $\mathrm{pH}$, temperature, and ionic strength need to be optimized. Often high ionic strength buffers support enzyme stability but may not affect the rate of enzyme reaction. For on-line reactions some processing may be required to lower ionic strength that matches that of background electrolyte used for the separation.

\subsubsection{Analysis of O-linked glycans:}

Glycans obtained from glycoproteins are either nitrogen $(\mathrm{N})$ or Oxygen $(\mathrm{O})$ linked. Olinked glycans attach via oxygen to serine or threonine amino acids on the polypeptide chain of the protein and form a wide variety of glycan structures. Change in the glycosylation pattern of O-glycans was reported in breast and ovarian cancer. ${ }^{16-19}$ Therefore O-linked glycan profiling from sera of cancer patients could be a useful biomarker for cancer diagnosis. The O-linked glycans are underexplored, and there is a need to develop procedures for isolating O-linked glycans from the glycoproteins. Olinked glycan structures can be characterized with the use of exoglycosidases or lectins. 
A potential pitfall for O-linked glycans characterization is there are no enzymes comparable to PNGaseF that could clip off O-linked glycans from glycoproteins and chemical release options need to be considered which come with some disadvantages. The disadvantages include the absence of free reducing end for the O-glycan released commonly by reductive $\beta$-elimination ${ }^{20}$ and routinely used labeling derivatization strategies cannot be applicable for O-glycan labeling. Moreover, in contrast to $\mathrm{N}$-linked glycans, O-glycans do not have a common core structure, are more heterogenous, ${ }^{21}$ and are clustered at high density near serine or threonine amino acids on the polypeptide chain. 


\section{References:}

(1) Dube, D. H.; Bertozzi, C. R. Glycans in cancer and inflammation - potential for therapeutics and diagnostics. Nature Reviews Drug Discovery 2005, 4, 477.

(2) Hennig, R.; Cajic, S.; Borowiak, M.; Hoffmann, M.; Kottler, R.; Reichl, U.; Rapp, E. Towards personalized diagnostics via longitudinal study of the human plasma N-glycome. Biochimica Et Biophysica Acta-General Subjects 2016, 1860 (8), 1728.

(3) Adamczyk, B.; Tharmalingam, T.; Rudd, P. M. Glycans as cancer biomarkers. Biochimica Et Biophysica Acta-General Subjects 2012, 1820 (9), 1347.

(4) Miyoshi, E.; Moriwaki, K.; Nakagawa, T. Biological function of fucosylation in cancer biology. Journal of Biochemistry 2008, 143 (6), 725.

(5) Kizuka, Y.; Taniguchi, N. Enzymes for N-Glycan Branching and Their Genetic and Nongenetic Regulation in Cancer. Biomolecules 2016, 6 (2).

(6) Balmana, M.; Gimenez, E.; Puerta, A.; Llop, E.; Figueras, J.; Fort, E.; SanzNebot, V.; de Bolos, C.; Rizzi, A.; Barrabes, S.et al. Increased alpha 1-3 fucosylation of alpha-1-acid glycoprotein (AGP) in pancreatic cancer. Journal of Proteomics 2016, 132, 144.

(7) Huang, C.; Liu, Y.; Wu, H.; Sun, D.; Li, Y. Characterization of IgG glycosylation in rheumatoid arthritis patients by MALDI-TOF-MSn and capillary electrophoresis. Analytical and Bioanalytical Chemistry 2017, 409 (15), 3731.

(8) Testa, R.; Vanhooren, V.; Bonfigli, A. R.; Boemi, M.; Olivieri, F.; Ceriello, A.; Genovese, S.; Spazzafumo, L.; Borelli, V.; Bacalini, M. G.et al. N-Glycomic Changes in Serum Proteins in Type 2 Diabetes Mellitus Correlate with 
Complications and with Metabolic Syndrome Parameters. Plos One 2015, 10 (3), 16.

(9) Lima-Oliveira, G.; Lippi, G.; Salvagno, G. L.; Picheth, G.; Guidi, G. C. Laboratory Diagnostics and Quality of Blood Collection. Journal of medical biochemistry 2015, 34 (3), 288.

(10) Zhou, H.; Froehlich, J. W.; Briscoe, A. C.; Lee, R. S. The GlycoFilter: a simple and comprehensive sample preparation platform for proteomics, N-glycomics and glycosylation site assignment. Molecular \& cellular proteomics : MCP 2013, $12(10), 2981$.

(11) Mitra, I.; Alley, W. R., Jr.; Goetz, J. A.; Vasseur, J. A.; Novotny, M. V.; Jacobson, S. C. Comparative profiling of $\mathrm{N}$-glycans isolated from serum samples of ovarian cancer patients and analyzed by microchip electrophoresis. Journal of proteome research 2013, 12 (10), 4490.

(12) Mitra, I.; Snyder, C. M.; Zhou, X. M.; Campos, M. I.; Alley, W. R.; Novotny, M. V.; Jacobson, S. C. Structural Characterization of Serum N-Glycans by Methylamidation, Fluorescent Labeling, and Analysis by Microchip Electrophoresis. Analytical Chemistry 2016, 88 (18), 8965.

(13) Vanderschaeghe, D.; Szekrényes, Á.; Wenz, C.; Gassmann, M.; Naik, N.; Bynum, M.; Yin, H.; Delanghe, J.; Guttman, A.; Callewaert, N. High-Throughput Profiling of the Serum N-Glycome on Capillary Electrophoresis Microfluidics Systems: Toward Clinical Implementation of GlycoHepatoTest. Analytical Chemistry 2010, 82 (17), 7408. 
(14) Gattu, S.; Crihfield, C. L.; Holland, L. A. Microscale Measurements of MichaelisMenten Constants of Neuraminidase with Nanogel Capillary Electrophoresis for the Determination of the Sialic Acid Linkage. Analytical Chemistry 2017, 89 (1), 929.

(15) Nehme, H.; Nehme, R.; Lafite, P.; Routier, S.; Morin, P. New development in incapillary electrophoresis techniques for kinetic and inhibition study of enzymes. Analytica Chimica Acta 2012, 722, 127.

(16) Kirmiz, C.; Li, B.; An, H. J.; Clowers, B. H.; Chew, H. K.; Lam, K. S.; Ferrige, A.; Alecio, R.; Borowsky, A. D.; Sulaimon, S.et al. A Serum Glycomics Approach to Breast Cancer Biomarkers. Molecular \&amp; Cellular Proteomics 2007, 6 (1), 43.

(17) Mechref, Y.; Hu, Y.; Garcia, A.; Hussein, A. Defining Putative Glycan Cancer Biomarkers by Mass Spectrometry. Bioanalysis 2012, 4 (20), 2457.

(18) An, H. J.; Miyamoto, S.; Lancaster, K. S.; Kirmiz, C.; Li, B.; Lam, K. S.; Leiserowitz, G. S.; Lebrilla, C. B. Profiling of Glycans in Serum for the Discovery of Potential Biomarkers for Ovarian Cancer. Journal of Proteome Research 2006, $5(7), 1626$.

(19) Storr, S. J.; Royle, L.; Chapman, C. J.; Hamid, U. M. A.; Robertson, J. F.; Murray, A.; Dwek, R. A.; Rudd, P. M. The O-linked glycosylation of secretory/shed MUC1 from an advanced breast cancer patient's serum. Glycobiology 2008, 18 (6), 456.

(20) Ruhaak, L. R.; Zauner, G.; Huhn, C.; Bruggink, C.; Deelder, A. M.; Wuhrer, M. Glycan labeling strategies and their use in identification and quantification. Analytical and Bioanalytical Chemistry 2010, 397 (8), 3457. 
(21) Houel, S.; Hilliard, M.; Yu, Y. Q.; McLoughlin, N.; Martin, S. M.; Rudd, P. M.; Williams, J. P.; Chen, W. N- and O-Glycosylation Analysis of Etanercept Using Liquid Chromatography and Quadrupole Time-of-Flight Mass Spectrometry Equipped with Electron-Transfer Dissociation Functionality. Analytical Chemistry 2014, $86(1), 576$. 


\section{Curriculum Vitae}

\section{Srikanth Gattu}

Clark Hall, Department of Chemistry, Morgantown, WV, 26505

srgattu@mix.wvu.edu

srikanthga2@gmail.com

Education:

2012-2018 Ph.D. Candidate in Chemistry

West Virginia University

Morgantown, WV, USA

2009-2011 M.S. in Organic Chemistry

Vellore Institute of Technology

Vellore, TN, INDIA

2006-2009 B.S. in Chemistry, Bio-Chemistry and Microbiology

Osmania University

Hyderabad, TS, INDIA

\section{Fellowship:}

2016 Recipient of C Eugene Bennett Fellowship

2015 Recipient of C Eugene Bennett Fellowship

\section{Professional Experience:}

2013-2018 Graduate Research Assistant, West Virginia University, USA

2012-2013 Graduate Teaching Assistant, West Virginia University, USA

2011-2012 Research Chemist, Chemveda Lifesciences, INDIA

\section{Provisional Patent:}


Gattu, S.; Holland, L. A., Phospholipid Nanogel for Enzyme Stabilization, US Patent Application No: 62467072, United States Patent and Trademark Office (USPTO)

\section{Publications:}

Gattu, S.; Crihfield, C. L.; Lu, G.; Bwanali, L.; Veltri, M.L.; Holland, L. A., Advances in Enzyme Substrate Analysis with Capillary Electrophoresis. Methods 2018, 146, 93-106

Lu, G: Crihfield, C. L.; Gattu, S.; Veltri L.M; Holland, L. A., Capillary Electrophoresis Separations of Glycans. Chemical Reviews. 2018, 118 (17), 7867-7885

Holland, L. A ,; Gattu, S.; Crihfield, C. L.; Bwanali, L., Capillary electrophoresis with stationary nanogel zones of galactosidase and Erythrina cristagalli lectin for the determination of ( $\beta 1-3)$ - linked galactose in glycans. Journal of Chromatography $A$ 2017, $1523,90-96$

Gattu, S.; Crihfield, C. L.; Holland, L. A., Microscale Measurements of Michaelis - Menten Constants of Neuraminidase with Nanogel Capillary Electrophoresis for the Determination of Sialic Acid Linkage. Analytical Chemistry 2017, 89 (1), 929-936

Williams, R. M.; Crihfield, C. L.; Gattu, S.; Holland, L. A.; Sooter, L. J., In Vitro Selection of a Single-Stranded DNA Molecular Recognition Element against Atrazine. International Journal of Molecular Sciences 2014, 15 (8), 14332-14347 